\title{
Assessment of Professional Behavior in Students: Thoughts and Opinions of Occupational Therapy Faculty
}

Diana R. Davis

Follow this and additional works at: https://researchrepository.wvu.edu/etd

\section{Recommended Citation}

Davis, Diana R., "Assessment of Professional Behavior in Students: Thoughts and Opinions of Occupational Therapy Faculty" (2015). Graduate Theses, Dissertations, and Problem Reports. 7074. https://researchrepository.wvu.edu/etd/7074

This Dissertation is protected by copyright and/or related rights. It has been brought to you by the The Research Repository @ WVU with permission from the rights-holder(s). You are free to use this Dissertation in any way that is permitted by the copyright and related rights legislation that applies to your use. For other uses you must obtain permission from the rights-holder(s) directly, unless additional rights are indicated by a Creative Commons license in the record and/ or on the work itself. This Dissertation has been accepted for inclusion in WVU Graduate Theses, Dissertations, and Problem Reports collection by an authorized administrator of The Research Repository @ WVU.

For more information, please contact researchrepository@mail.wvu.edu. 
Assessment of Professional Behavior in Students: Thoughts and Opinions of Occupational Therapy Faculty

\title{
Diana R. Davis
}

\begin{abstract}
Dissertation Submitted to the College of Education and Human Services at West Virginia University
\end{abstract}

In Partial Fulfillment of the requirements for the degree of

\author{
Doctor of Philosophy \\ In Interdisciplinary Education \\ Samuel Stack, Ph.D., Chair \\ Duane S. Davis, Ed.D., PT \\ Reagan Curtis, Ph.D. \\ M Cecil Smith, Ph.D. \\ Lauryl A. Lefebvre, Ph.D.
}

Department of Curriculum \& Instructional/Literacy Studies

Morgantown, West Virginia

2015

Key Words: Assessment, Occupational Therapy, Professional Behaviors, Professionalism Copyright 2015 Diana R. Davis 


\begin{abstract}
Assessment of Professional Behavior in Students: Thoughts and Opinions of Occupational Therapy Faculty

Diana R. Davis
\end{abstract}

Professionalism and professional behavior of students has been a growing concern in the health professions for the past two decades (Aguilar et al., 2013; Davis, 2009; Swick, 2000). As a result multiple professions have identified core values and the professional behaviors that are a reflection of these in practice; and have begun to integrate assessment of student professional behaviors into educational standards. Occupational therapy has a history of publication dating back to 1995 regarding assessment of the professional behaviors of students but no profession wide expectations have been established.

This study attempted to describe the thoughts and opinions of faculty in Master's level entry Occupational Therapy educational programs nationwide regarding assessment of students' professional behaviors. This study also looked for differences in thoughts and opinions between faculty from different types of Carnegie Classification institutions and full- versus part-time faculty. An invitation to complete an online survey was sent to all Occupational Therapy faculty identified through reviews of the websites of all 154 accredited occupational therapy education programs. The survey gathered demographic data $(\mathrm{N}=294)$ and then asked the faculty to indicate their level of agreement with behaviors to be included in professional behavior assessment and asked them to assign value to the various methods used in assessment.

A total of 292 responses (22\%) were included in the final statistical analysis. Participants assigned high importance to all behaviors listed in the survey and identified an additional 52 behaviors for inclusion in professional behavior assessment. Regarding assessment techniques participants preferred the inclusion of direct skilled observations of student behavior in classroom and clinical environments. Participants also indicated a preference for regular assessment intervals.

Statistical analysis of differences in responses of faculty from different Carnegie classification type institutions only revealed significant differences in the value of including observations of students' behavior at conferences and non-institutional sponsored continuing education events with faculty from Baccalaureate institutions assigning less value to these observations. Faculty from Baccalaureate institutions also assigned less importance to compiling assessment results to reflect performance of the group as a whole than faculty from other institution types.

When comparing responses from full-time and part-time faculty some statistically significant results were identified. Full-time faculty assigned more importance to the assessment of initiative and responsibility for own learning. In the area of assessment practices full-time faculty assigned less value to observations of student behaviors in lab sessions while part-time 
faculty assigned less value to the observations of student behavior in group work and assigned less importance to the use of assessment results in program evaluation and to inform professional development opportunities.

Occupational therapy is a broad profession that practices in many settings with a variety of clients with a wide range of disabilities. This diversity of practice expectations is reflected in the importance assigned to all of the behaviors included in the survey as well as the large number of additionally written in behaviors to be included in assessment. The profession of occupational therapy will be strengthened by identifying the essential behaviors that students should develop in academic programs to reflect the professional values of occupational therapy in their professional practice. Occupational therapy faculty express that they value assessment that occurs at regular intervals and includes direct skilled observations and student self-assessment of student's behavior in the classroom, clinic, and professional activities. Further research is needed to identify key behaviors, best assessment practices, and to establish a clear relationship between behavior exhibited in the academic and clinical environment. 


\section{Acknowledgements}

I wish to acknowledge the support of my dedicated committee members at West Virginia University in the College of Education and Human Services. The assistance and willingness of Samuel Stack, Scott Davis, Lauryl Lefebvre, Reagan Curtis, and M Cecil Smith to step up and help me through my often convoluted path through research and dissertation was essential. A special "Thank you" to Scott Davis who provided day-to-day support and teaching that was instrumental to my completion of this project.

I would also like to express my gratitude to my wonderful husband, who put up with plenty and only said "I will be glad when this is over," once and the other times told me I could do this. To my parents who instilled in me a love of exploration and learning. My dad always told me how excited he would be to call me "Dr. Diana." My kids were also a great support system and great at commiserating about the stresses of higher education. This project would have never been completed without the support and harassment of my friends, Donna, Amanda K., Amanda A., Jerry, and Susan. I have been well and truly blessed. 


\section{Table of Contents}

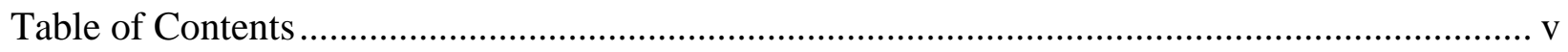

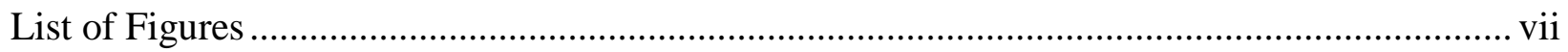

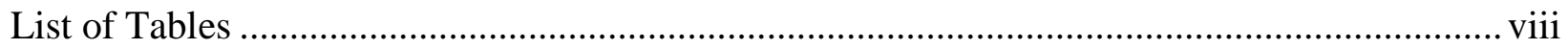

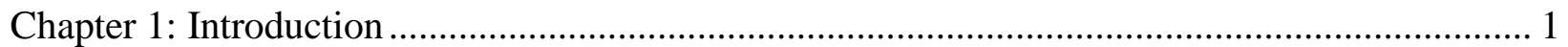

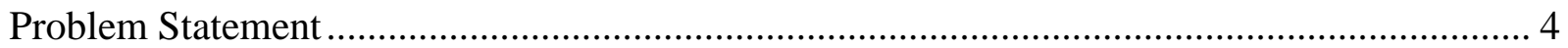

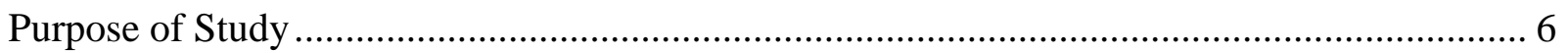

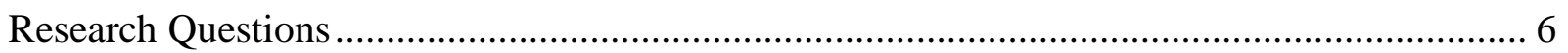

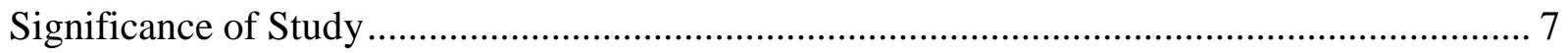

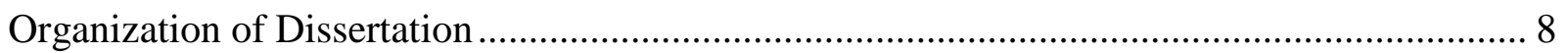

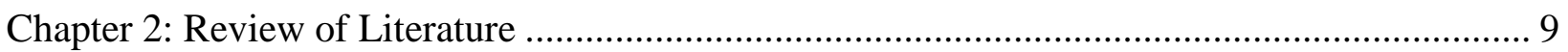

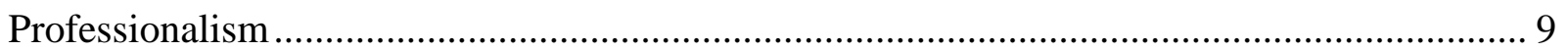

Factors Increasing Focus on Professionalism ..................................................................... 11

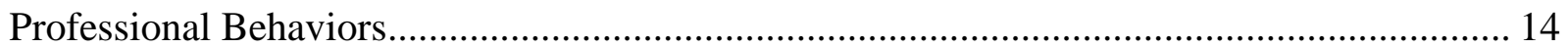

Assessment of Professional Behaviors ............................................................................... 31

Carnegie Classification in Occupational Therapy Education ....................................................... 48

Part-Time Faculty in Occupational Therapy Education .......................................................... 50

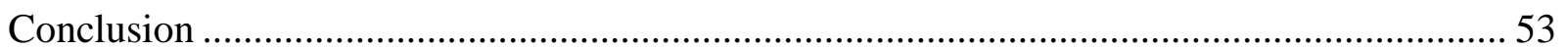

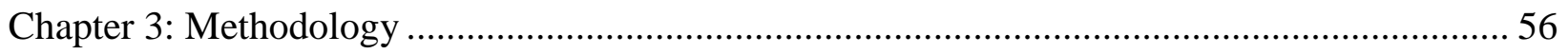

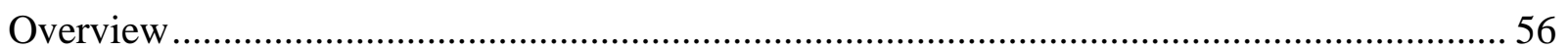

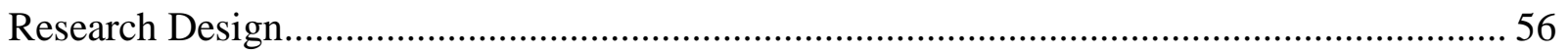

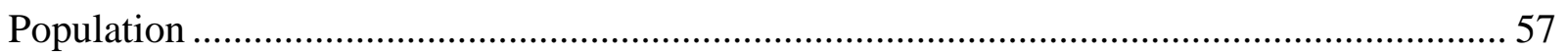

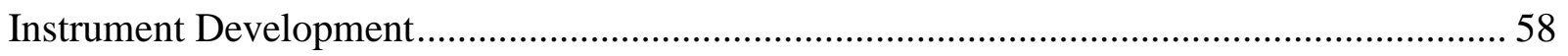

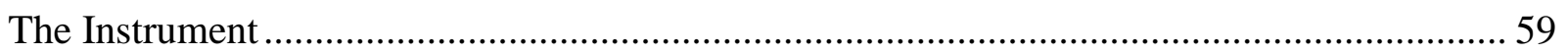

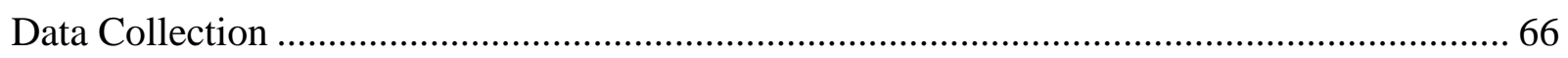

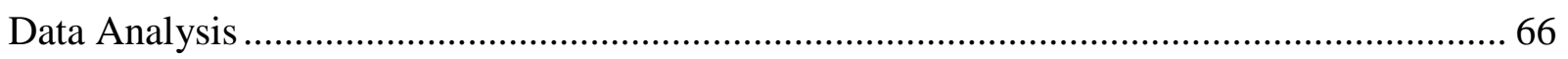

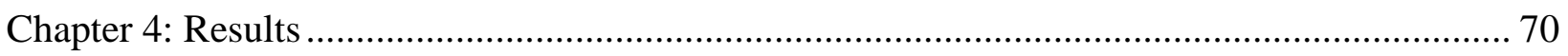

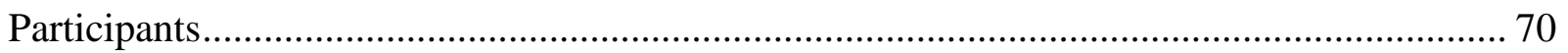

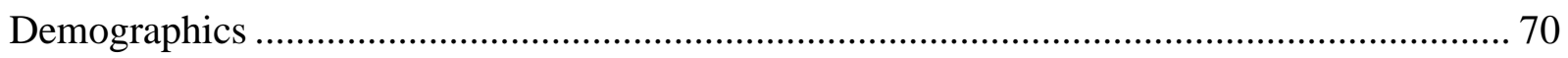

Research Question 1: What professional behaviors do faculty express should be assessed in Occupational Therapy educational programs in the United States? ........................................... 84

Research Question 2: How should professional behaviors be assessed in OT educational programs in the United States as expressed by faculty? 
Research Question 3: Is there a significant difference in the responses of faculty from different institutional (Carnegie Classification) in regards to what professional behaviors should be assessed 102

Research Question 4: Is there a significant difference in responses from faculty from different institutional types (Carnegie Classification) in regards to how professional behaviors should be assessed? 103

Research Question 5: Is There a Significant Difference Between Full-time and Part-time Faculty Responses Regarding What Professional Behaviors Should be Assessed in OT Educational Programs? .....

Research Question 6: Is There a Significant Difference Between Full-time and Part-time faculty Responses how Professional Behaviors Should be Assessed in OT Educational Programs?

Final Thoughts From Participants, Open Comments........................................................ 123

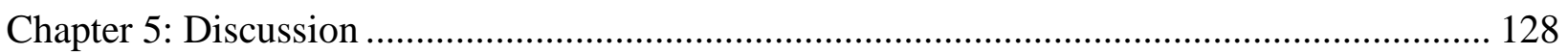

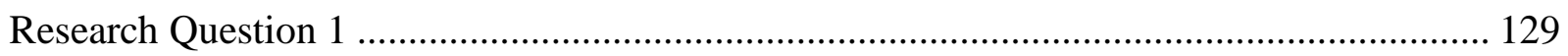

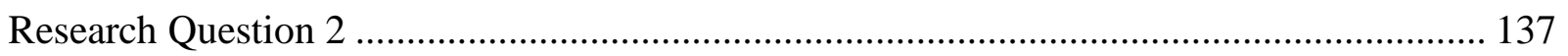

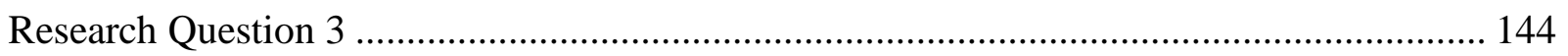

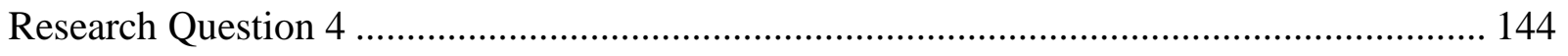

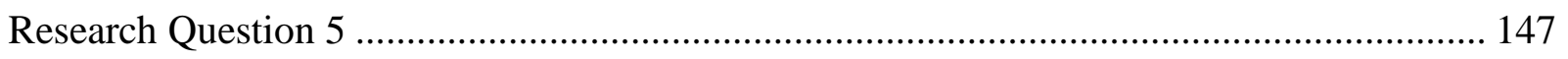

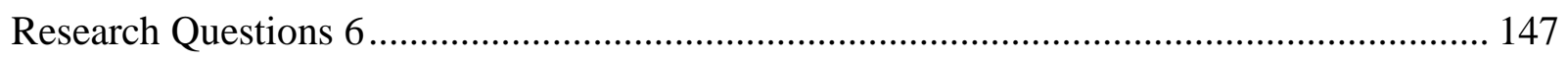

Final Thoughts and Opinions Regarding Assessment .................................................... 150

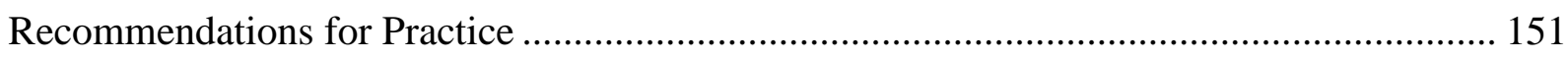

Recommendations for Future Research ................................................................... 151

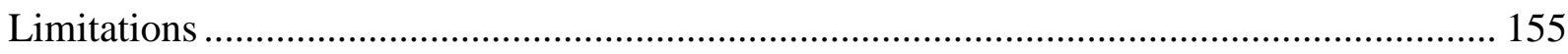

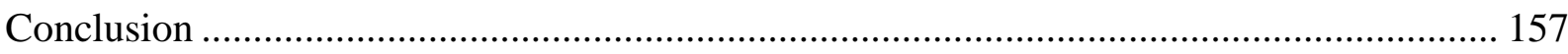

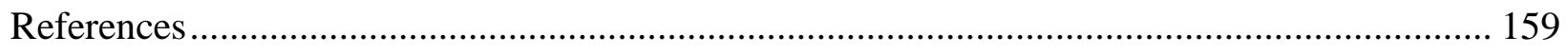

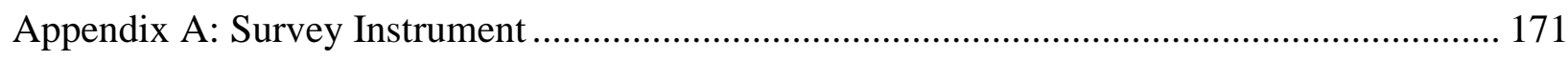

Appendix B: Institutions With Master’s Degree Level Occupational Therapy Educational

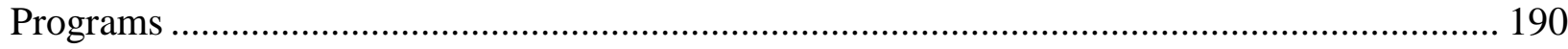

Appendix C: Letter for Pilot Study Participants ............................................................... 197

Appendix D: Pilot Study Phone Interview Questions......................................................... 198

Appendix E: Cover Letter for Participants ........................................................................ 200

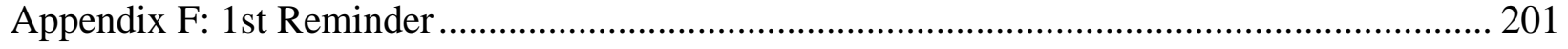

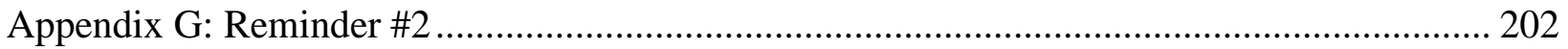




\section{List of Figures}

Figure 2.1 Combined Miller-Rest Model for professionalism assessment............................... 34

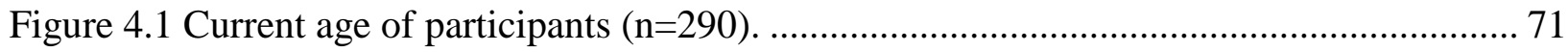

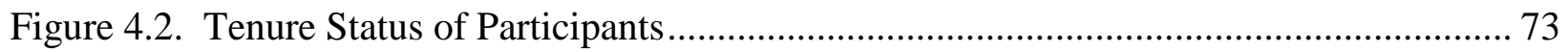

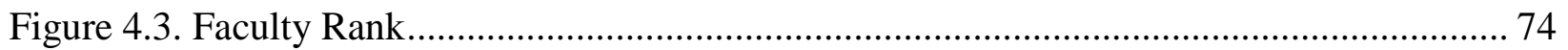

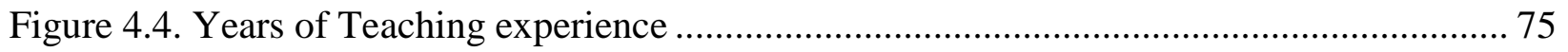

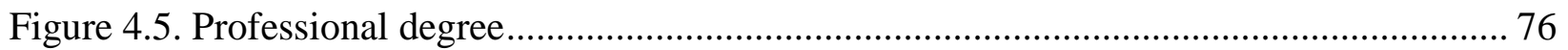

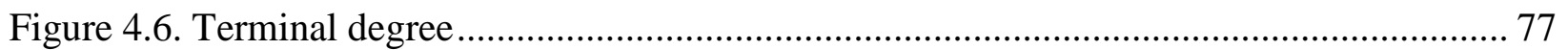

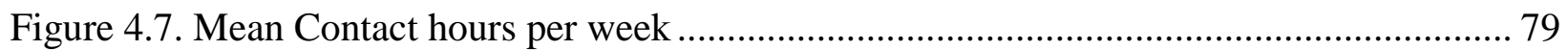

Figure 4.8. Carnegie basic classification of participants' institutions ...................................... 81

Figure 4.9. Regional accreditor of participants’ institutions................................................ 81

Figure 4.10. Behaviors receiving a single mention by participants. ...................................... 87

Figure 4.11. Adequacy of current professional behavior assessment ..................................... 88

Figure 4.12. Frequency of responses expressed in percentages to using assessment result to

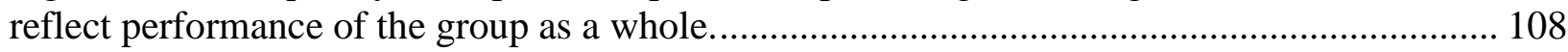

Figure 4.14. Responses to Use of Results in OT program Assessment or Evaluation Plan by

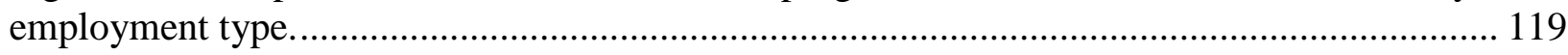

Figure 4.15. Responses to use of results in to inform professional development expressed in

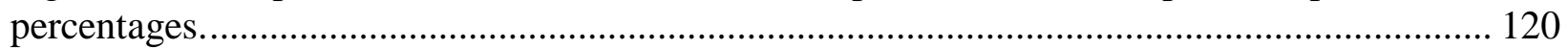




\section{List of Tables}

Table 2.1 Samples of professional behaviors and organization used in assessment in occupational

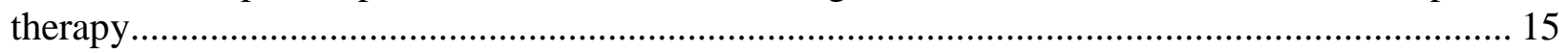

Table 2.2 Affective Domain of Bloom's Taxonomy .......................................................... 32

Table 3.1 Relationship between Survey Items and Research Questions .................................. 60

Table 4.1 Comparison of Gender and Age of Participants to OT Faculty Workforce as a

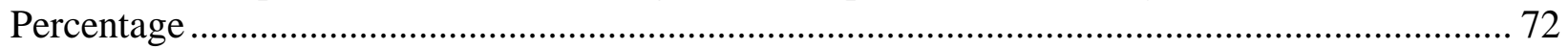

Table 4.2 Initial and Final Descriptive Analysis of Credit Hours of Instruction per Semester .... 78

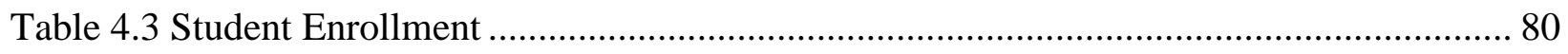

Table 4.4 Comparison of Institutional Type and Regional Accreditor of Participants to ACOTE

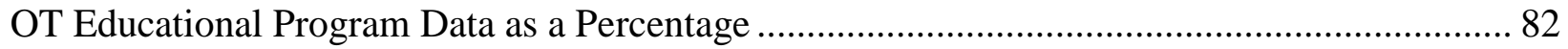

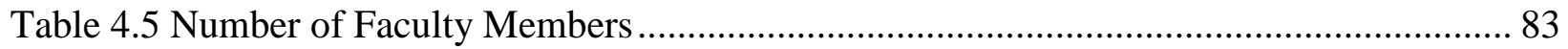

Table 4.6 Age of OT Educational Programs.......................................................................... 84

Table 4.7 Importance of Assessing Behavior ..................................................................... 85

Table 4.8 Behaviors Ranked by Importance .......................................................................... 86

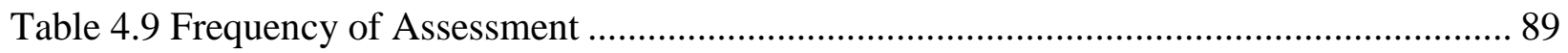

Table 4.10 Assessment Intervals Ranked by Agreement...................................................... 90

Table 4.11 The Value of Specific Tools for the Assessment of Professional Behavior.............. 91

Table 4.12 Assessment Tools Ranked by Value...................................................................... 92

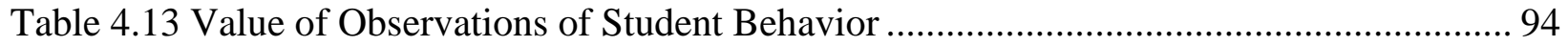

Table 4.14 Observations of Student Behavior Ranked by Value ............................................ 95

Table 4.15 Participants in Professional Behavior Assessment .................................................. 96

Table 4.16 Participants in Assessment Ranked Importance .................................................... 97

Table 4.17 Use of Professional Behavior Assessment Results.................................................. 98

Table 4.18 Uses of Assessment Ranked by Importance .......................................................... 99

Table 4.19 Student Consequences of Poor Professional Behavior ........................................... 100

Table 4.20 General Opinions of Participants Regarding Assessment of Professional Behavior.101

Table 4.21 Chi-Square Analysis of Professional Behaviors by Institution Type ...................... 103

Table 4.22 Chi-Square Analysis of Assessment Timing by Institution Type........................... 104

Table 4.23 Chi-Square Analysis of Assessment Tools by Institution Type ............................ 105

Table 4.24 Observations of Professional Behavior Chi-Square Analysis by Institution Type... 106

Table 4.25 Chi-Square Analysis of Contributors to Assessment by Institution Type ............... 107

Table 4.26 How Assessment Results Should be Used Chi-Square Analysis by Institution Type

Table: 4.27 Consequences of Assessment Chi-Square Analysis by Institution Type ................ 110 
Table 4.28 General Opinions About Professional Behavior Assessment Chi-Square Analysis by

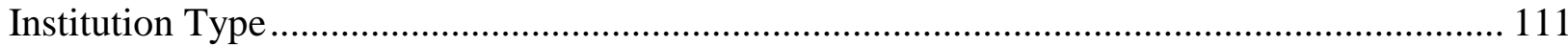

Table 4.29 Importance of Assessing Behaviors Chi-Square Analysis by Faculty Employment Status.

Table 4.30 Opinions Regarding Adequacy of Assessment Chi-Square Analysis by Faculty Employment Type

Table 4.31 Assessment Intervals Chi-Square analysis by Faculty Employment Type.............. 115

Table 4.32 Chi-Square Analysis of Assessment Tools by Faculty Employment Status ............ 115

Table 4.33 Chi-Square analysis of Value of Observations of Student Behavior by Faculty Employment Status

Table 4.34 Chi-Square analysis of Participants in Assessment by Faculty Employment Status)

Table 4.35 Chi-Square Analysis of Uses of Assessment Results by Faculty Employment Status 121

Table 4.36 Chi-Square Analysis of Student Consequences by Faculty Employment Type....... 122

Table 4.37 Chi-Square Analysis of General Thoughts by Faculty Employment Status. 123

Table 5.1 Comparison Between Researchers Provided Behaviors and Participant Written Behaviors. 


\section{Chapter 1: Introduction}

Occupational Therapy is an allied health profession that helps people throughout the lifespan to "participate in the things they want and need to do through the therapeutic use of everyday activities (occupations)” (AOTA, 2012). Occupational Therapy as a profession developed before World War I with the first national meeting of occupational therapists being held in 1917. The occupational therapists of the time were often nurses or social workers with special training. They were always female and worked under the close supervision of a doctor (Quiroga, 1995). During WWI occupational therapists were known as reconstruction aides and specialty certification was obtained through army training programs. Reconstruction Aides worked in field hospitals in France addressing the mental and physical needs of soldiers injured in battle. Once the war ended some reconstruction aides became occupational therapists. The national organization for occupational therapists, The American Occupational Therapy Association (AOTA), developed the first set of educational standards for OT educational programs in 1923 (Quiroga, 1995). As the profession continued to grow and expand its areas of expertise and practice, a bachelor's degree became necessary to enter the profession in the 1940s. As medical care improved, the complexity of services offered by occupational therapists increased. This culminated in a master's degree being required to enter the field in 2007 (ACOTE, 2008; Punwar \& Peloquin, 2000). Today, Occupational Therapists work with a variety of individuals, assisting them in completing life's activities despite the presence of impairments in sensorimotor, cognitive, or emotional functioning.

As described above occupational therapy meets the requirements to be considered a profession set forth by Cullen (1978). Occupational therapists possess a specialized set of skills, 
have specialized training in ethics unique to the profession, and they provide a service to society. The execution of these three concepts by occupational therapists is considered professionalism. Of particular concern of this research project is the specialized training in ethics unique to the profession. Professional behaviors are the observable actions taken by professionals in the execution of their skills to meet a need of society. How occupational therapists apply their skills is guided by the code of ethics and values of the profession.

Students ideally learn the expectations of the profession through formal and informal experiences centered in academic preparation programs. The primary mission of occupational therapy faculty members is to prepare students to enter the profession as competent independent practitioners. Imparting clinical skills involves facilitation of student learning and retention of technical knowledge and skills. However, faculty members are also concerned with students’ development of appropriate professional behaviors needed to succeed in the clinical environment (Fidler, 1996).

The development and assessment of professional behavior has historically been a concern for faculty members who are preparing students to become medical professionals such as physicians, nurses, and therapists (Archer, Elder, Hustedde, Milam \& Joyce, 2008; Foord-May \& May, 2007; Gutman, McCreedy, \& Heisler, 1988). Professional behavior touches all parts of practice for medical professionals: client/patient, staff, and colleague interactions (Swick, 2000). Faculty fear that if professional behavior is not addressed as part of the academic program then the mission to produce competent caring professionals is only half met. College students may possess good technical knowledge and skills. However, these same students may have weak professional behaviors that increase the risk for displeased clients and complaints to employers and licensure boards. The interest of academia in professional behaviors particularly increased 
after the recent publication of a study completed by Papadakis, Therani, Banach et al. (2005) which found that professional behavior problems in medical school were strongly associated with disciplinary actions imposed by medical licensing boards (p. 2673).

Medical and allied health professional undergraduate students regularly participate in both classroom and clinical experiences as part of their degree programs. The basic requirements of education within each profession are determined by individual accrediting bodies. Occupational therapy learning standards are defined by the Accreditation Council for Occupational Therapy Education (ACOTE). These standards include both general requirements, often considered administrative standards, as well as content standards which address knowledge and skills students should learn. The development of professional behavior is included briefly in only two standards. One of these standards addresses working effectively in cooperative relationships between the occupational therapist and the occupational therapy assistant. The second standard addresses verbal and written communication (ACOTE, 2008).

Occupational therapy (OT) student clinical experiences are considered important fieldwork experiences. The accreditation standards for occupational therapy education require that students complete both Level 1 and Level 2 fieldwork experiences. Level 1 fieldwork experiences are short term, and the primary purpose is for the student to observe a clinician at work. Most students typically complete these experiences during their academic work in the first and second years of their professional education. Level 2 experiences are twelve-week full-time experiences in which the student, under the supervision of a clinician, assumes the role of therapist. Students typically complete Level 2 fieldwork experiences at the end of their academic work in the graduate year. In some programs, the Level 2 fieldwork experiences are split with one experience at the beginning of the graduate year and one experience at the end of 
the graduate year. The profession of occupational therapy expects that students who successfully complete their fieldwork experiences to be performing as entry-level therapists at the end of the experience. When students complete the Level 2 fieldwork experience, they are rated on a standardized evaluation form developed by the American Occupational Therapy Association (AOTA) and required by ACOTE, the Fieldwork Performance Evaluation for the Occupational Therapy Student (FWPE). Unlike the ACOTE content standards, the FWPE includes a section to rate professional behavior. This section includes an evaluation of seven professional behaviors that include: supervisory collaboration; responsibility for own learning; integrating feedback; dependability; time management; interpersonal skills and, demonstrating respect for diversity.

Occupational Therapy faculty members are significant contributors to the development of the professionalism of students. However, the experience and views of occupational therapy faculty regarding this area are relatively unknown. Occupational therapy educational programs exist in a wide variety of colleges and universities, from Carnegie Classification Associate/Diverse institution through Doctoral Research Very High institutions (ACOTE, 2013). Part-time faculty also represents a significant portion of the Occupational Therapy faculty at a national level (AOTA, 2010). Research in other fields has suggested that both of these factors have significant effects on the experiences of faculty (Lee, 2007; Levin \& Hernandez, 2014; Milem, Berger, \& Dey, 2000; Pollart et al., 2015). However the effects of institution type and employment status on the views of OT faculty regarding assessment of professional behavior have never been studied.

\section{Problem Statement}

Failure in clinical experiences is highly associated with poor professional behavior (Gutman, McCreedy, \& Heisler, 1998; James \& Musselman, 2005). Although some authors in 
OT have reported that a lack of academic preparation affects performance in fieldwork (James \& Musselman, 2005) they also report that poor clinical knowledge often coexists with poor professional behavior. Academic fieldwork coordinators report that students are usually able to learn clinical skills within the fieldwork experience. However, when students lack professional behaviors they are more likely to fail, as clinical supervisors express that these behaviors are difficult to change (Kessler, personal communication, 2010). Several researchers have also found the correlation between academic success, as measured by grade point average, and fieldwork performance is weak (Best, 1994; Mann \& Banasiak, 1985).

Some published reports of assessments of students’ professional behavior exist within nursing, medical, physical therapy, and occupational therapy programs (Babola \& Peloquin, 1999; Foord-May \& May, 2007; Gutman et al. 1995; Morris \& Faulk, 2007; Sands, 1995). However, a review of the literature leaves many unanswered questions regarding the assessment of professional behavior.

Students’ poor professional behavior and poor academic performance leads to poor performance and possible failure of clinical experiences. Research has also suggested that poor professional behavior exhibited in academic preparation may predict difficulties in future professional clinical practice. In the field of occupational therapy no comprehensive nationally accepted professional behavior assessment taxonomy exists for educational programs. Faculty members in occupational therapy are key stakeholders in the preparation of students for the profession and the views of faculty on issues related to professional behavior assessment in the academic environment are unknown. 


\section{Purpose of Study}

The purpose of this dissertation research study is to provide an in-depth understanding of faculty opinions and thoughts regarding the assessment of the professional behaviors of students enrolled in entry-level masters' degree OT educational programs. This research will describe what assessment practices faculty members in OT programs think are appropriate and should be included in an OT educational program. It will analyze differences in faculty thoughts based on different institutional types (Carnegie classification) and how full-time and part-time faculty differ in their responses about professional behaviors assessment.

\section{Research Questions}

The research questions are:

1) What professional behaviors do faculty express should be assessed in Occupational Therapy educational programs in the United States?

2) How should professional behaviors be assessed in OT educational programs in the United States as expressed by faculty?

3) Is there a significant difference in the responses of faculty from different institutional types (Carnegie Classification) in regards to what professional behaviors should be assessed

4) Is there a significant difference in responses from faculty from different institutional types (Carnegie Classification) in regards to how professional behaviors should be assessed?

5) Is there a significant difference between full-time and part-time faculty responses regarding what professional behaviors should be assessed in OT educational programs? 
6) Is there a significant difference between full-time and part-time faculty responses regarding how professional behaviors should be assessed in OT educational programs?

\section{Significance of Study}

This research may impact OT educators, clinicians, students, and ultimately the general public. The professions of medicine, physical therapy, and nursing require assessment of professional behaviors in their educational standards. Occupational therapy usually follows these professions in developing educational standards. It is reasonable to assume that a future version of the educational standards for occupational therapy education will require explicit assessments of professional behaviors. This research will help OT educators become aware of what professional behaviors and assessment practices faculty think are important. This will help educators in the design, implementation, and improvement of professional behavior assessments. More programs may also implement professional behavior assessments prior to accreditation requirements to meet the demands of their clinical supervisors.

With the changing and increasing demands in healthcare, clinicians have expressed a desire for students who are more prepared to "hit the ground running” on their clinical affiliations. Clinicians also express an increasing unwillingness to deal with students with poor professional behaviors. Clinicians are licensed healthcare practitioners and assume total responsibility for the conduct of their students. In the situation when a student's unprofessional behavior creates a conflict with a client, the clinician bears the legal responsibility. Clinicians have consistently requested better academic preparation of students in the areas of clinical as well as professional skills (Gutman, McCreedy, \& Heisler, 1988). This study will attempt to advance the research regarding the assessment of professional behaviors in occupational therapy 
and ideally increase the formal assessment of professional behaviors in academic programs. This in turn will increase the professionalism of students entering their clinical rotations and increase the professionalism of new graduates entering the profession.

\section{Organization of Dissertation}

In Chapter One, I have introduced the subject of professional behavior assessment. I will review the literature on professional behavior assessment in Chapter Two. In Chapter Three, I discuss the methods and data analysis for this study. I report the results of the study in Chapter Four. In Chapter Five, I discuss the results and what they may mean in the profession and draw conclusions from the results and literature. 


\section{Chapter 2: Review of Literature}

Recent research studies by a variety of scholars addresses professionalism and professional behavior in multiple fields including nursing, physical therapy, occupational therapy, pharmacy, medicine, teaching, law, and business. Due to the similarity of concepts in professionalism and professional behaviors, this review focuses on the literature that can be found in occupational therapy, physical therapy, and medicine.

In the first section of this review of literature, I will review the concept of professionalism, and why there has been an increasing focus on professionalism in health career education. In the second section, I will review a variety of common professional behaviors that are included in professional behavior assessment. Within the literature there is a wide variety of behaviors and definitions included and I will attempt to identify those most often cited in occupational therapy and provide definitions and examples of how particular professional behaviors are integrated into student and professional clinical performance.

In the final section, I will look at common assessment practices discussed in medicine, and occupational therapy literature. This discussion will identify who participates in assessment, how professional behaviors are assessed, and other issues associated with professional behavior assessment.

\section{Professionalism}

Professionalism is considered a key component of successful practice in health related fields such as medicine, nursing, physical therapy, and occupational therapy. Poor professionalism and poor professional behaviors can result in a failure to appropriately care for clients (Roberts \& Stark, 2008). The relationship between practitioner and client is highly 
valuable with both ethical guidelines and federal law outlining the confidential and essential nature of the relationship. However, the relationship can be fragile and easily damaged by the behavior of the practitioner. When the trust between the healthcare provider and client is damaged, the efficacy of care is negatively impacted. The attitudes, values, and behaviors that are valued in healthcare are generally referred to as professionalism (Shah, Anderson, \& Humphrey, 2008).

The term professionalism can be applied in two primary ways. The first application addresses the characteristics of a profession. There is a large body of literature in sociology on the concept of professionalism as it applies to a profession. In this application, professionalism refers to characteristics such as having a common body of knowledge, common beliefs and values, and common procedures (Shah, Anderson, \& Humphrey, 2008). In the second application, professionalism is described as desirable attributes displayed by members of a profession. As reported by Archer, Elder, Hustedde, Milam, and Joyce (2008), there is no widely accepted definition of professionalism in this application of the term. Swick (2000) proposed a normative definition consisting of nine sets of proposed behaviors that comprised medical professionalism based upon the values and nature of work in medicine. Wolfe-Burke (2005) cites May, Straker, and Foord (1997) as defining professionalism in physical therapy as the repertoire of behaviors needed in addition to technical skills to succeed as a professional. Broader definitions of professionalism include attitudes and values of a profession in addition to behavior (Shah et al., 2008).

Typically, the principles of professionalism within the medical fields are aspirational in nature and usually based on the core values of the profession (Archer et al., 2008; Shah et al., 2008). Arnold and Stern (2006) identify professionalism as based upon the principles of 
excellence, humanism, accountability, and altruism. The American Board of Internal Medicine defined the specific elements of professionalism for physicians as altruism, accountability, excellence, honesty, and respect of others (2008). Physical Therapy (PT) also adopted a set of core values as the base for professionalism in 2003 revised in 2010 with the document “Professionalism in Physical Therapy: Core Values” (American Physical Therapy Association, 2010). The seven PT core values include accountability, altruism, compassion and caring, excellence, integrity, professional duty, and social responsibility. These core values also serve as the foundation for the physical therapy document APTA’s Guide for Professional Conduct (Wolff-Burke, Ingram, Lewis, Odom, \& Shoaf, 2007). Occupational Therapy has identified its core values as: altruism, equality, freedom, justice, dignity, truth, and prudence (American Occupational Therapy Association, 2010). While Medicine and Physical Therapy have explicitly linked their values to professionalism expectations, Occupational Therapy has not yet made these types of connections.

\section{Factors Increasing Focus on Professionalism}

Several factors have led to an increased focus on professionalism and professional behaviors in clinical and educational environments including increased autonomy of the health professions, increased legal intervention in healthcare practice, changes in client and client expectations, and changes in students entering the profession (Blue et al., 2009; Little, 2008;

Meruelo, 2008; Peloquin, 2002). In the traditional medical model, care of the client was led and dictated by the physician. The physician served as the gatekeeper, evaluating the client, making the diagnosis, and dictating the care. Nurses, physical therapists, and occupational therapists then offered care prescribed by the physician. This relationship has progressed in the last 
century to a more autonomous approach. Patients can now choose to receive their healthcare from a variety of providers without visiting the physician first.

Occupational therapists, nurses, and physical therapists with advanced training evaluate and treat clients without input from a physician resulting in increased autonomy and responsibility. In some cases, clients have direct access to healthcare because they can obtain care from specialized health professionals without a referral from a physician. In the United States, clients in 34 states or regulated areas have unlimited direct access to occupational therapy, clients have limited direct access in 12 states and regulated areas, and clients have no direct access and must have a physician referral for OT services in only two states (AOTA, 2008).

Clients who see an occupational therapist without the referral of the physician represent greater risk and responsibility for the therapist. The therapist is responsible for assuring that the client does not require medical treatment prior to receiving therapeutic services. This increasing responsibility and autonomy has led to many health professions requiring higher levels of education to enter the field. Occupational therapy has advanced from requiring a certificate to practice in the early 1900s to requiring a Master’s degree to enter the profession in 2007 (ACOTE, 2008). Physical Therapy has progressed from a certificate level of entry in the early 1900s to requiring a clinical doctorate (DPT) by the year 2020. Increasing autonomy and responsibility also present increased legal risks to healthcare professionals.

The second trend that has resulted in an increased emphasis on professionalism in the health professions is the changing legal environment. Several researchers have found that complaints to medical licensure boards and lawsuits for malpractice are associated with poor 
professionalism (Meruelo, 2008; Papadakis, et al., 2005). Meruelo states, “The overwhelming consensus is that patients sue when there is a communication breakdown between themselves and their physicians, when they feel ignored and that their questions and complaints go unanswered, or when physicians fail to express any genuine concern for their welfare” (p. 289). Although malpractice actions in occupational therapy are relatively low when compared to physicians, as occupational therapists assume more autonomy and responsibility more malpractice complaints may occur.

The third trend that has led to increased attention to professionalism among healthcare professionals is the changing expectations of clients and their caregivers. Recently, clients have demanded to become more equal participants in their healthcare rather than passive recipients of care dispensed by a specialist (Peloquin, 1993). Peloquin defined behaviors, that when exhibited by healthcare providers, clients identified as depersonalizing. She identified these as withholding information, misusing power, and/or ignoring patients. Modern clients refuse to tolerate such distancing behaviors from their providers making it essential that healthcare professionals emerge from their education as fully prepared professionals.

The fourth trend that has led to increased emphasis on professionalism in educational programs is changes in students being admitted to health profession educational programs. The current generation of students is more technologically savvy than any prior generation, but may lack many of the interpersonal skills necessary to form good professional relationships. Researchers have also identified differing belief systems held by in current students when compared to previous generations. Blue and colleagues (2009) found that students entering medical school did not know how professional attributes function in practice. Students also demonstrated knowledge of and attitudes toward constructs of professionalism that were 
incongruent with traditional beliefs. Alarmingly, students in this study had different attitudes regarding altruism, believing that subordinating self-interest to the interest of their clients was less valuable.

Professional behaviors are the observable manifestation of professionalism in the individual. A wide variety of important professional behaviors are identified in the medical and health professions. Most definitions of professional behavior include a focus on attitudes, behavior, values, and/or knowledge (Fidler, 1996; Foord-May \& May, 2007; Scheerer, 2003). The attainment of professional behaviors is typically achieved when the student integrates the professional values of the profession (Foord-May \& May). Ledet, Esparza, and Peloquin (2005) defined the process of professional behavior development as requiring, “...integration of knowledge, attitudes, and values that prompt individuals to manifest dependability, initiative, empathy, cooperation, organization, clinical reasoning, responsivity to supervision, effective verbal and written communication and professional presentation” (p. 457).

\section{Professional Behaviors}

Researchers have investigated and/or reported on the assessment of a wide range of professional behaviors. Randolph (2003) discusses one assessment tool used in occupational therapy that assesses 28 distinct behaviors. Different terms may be used to describe the same or similar concepts of behavior, such as ability to self-correct and self-regulated learning. When examining the reports of professional behavior assessment tools or instruments, specific behavioral skills that can be observed and assessed are often organized and categorized within larger behavioral constructs, such as the case of independent learning and seeking feedback being classified under the larger construct of professional responsibility. The classification of professional behavior is not consistent and can be dependent on the perspective of the researcher. 
Fidler (1996) classified professional behaviors under larger self-actualization headings such as positive self-regard or increasing self-awareness. Kasar and Clark (2000) presented classifications of behavior with measureable behaviors listed within the main category such as professional presentation as a category and adherence to dress code is a sub behavior. Ledet, et al. (2005) also presents a similar type of hierarchy.

Some authors simply listed desirable behaviors that are assessed in students (See Table 1). Balboa and Peloquin (1999) presented a simple list of 10 desirable behaviors included in their professional behavior assessment and Koening, Johnson, Morano, and Ducette (2003) presented 12 individual behaviors. These authors used a variety of techniques to name and define important professional behaviors for assessment. Sometimes groups of faculty work together to identify and define the professional behaviors they believe to be important, while in other situations individual faculty member will introduce a framework of professional behaviors for assessment. Some faculty members have initiated focus group meetings with OT clinicians and fieldwork supervisors to identify and define professional behaviors the clinicians' think should be assessed in OT students (See Table 2.1) for examples.

Table 2.1

Samples of professional behaviors and organization used in assessment in occupational therapy

\begin{tabular}{|c|c|c|c|}
\hline Author(s)/Year & $\begin{array}{l}\text { Type of } \\
\text { Classification }\end{array}$ & How developed & Sample of behaviors \\
\hline Fidler (1996) & $\begin{array}{l}\text { Characteristic } \\
\text { Headings }\end{array}$ & Faculty consensus & $\begin{array}{l}\text { III An interpersonal competence as } \\
\text { demonstrated by } \\
\text { A. Being sensitive to the feelings, } \\
\text { values and agendas of others } \\
\text { 1. Acknowledging one's own } \\
\text { feelings and expressing how } \\
\text { they are similar to or }\end{array}$ \\
\hline
\end{tabular}




\begin{tabular}{|c|c|c|c|}
\hline & & & $\begin{array}{l}\text { different from another's } \\
\text { 2. Responding by word, tone } \\
\text { of voice, facial expression, } \\
\text { touch or gestures to the } \\
\text { feeling tone of another } \\
\text { 3. Encouraging another to } \\
\text { clarify or share his or her } \\
\text { values and opinions. } \\
\text { 4. Expressing respect for the } \\
\text { right of another to hold } \\
\text { different values and beliefs } \\
\text { B. Listening to and hearing } \\
\text { others... }\end{array}$ \\
\hline $\begin{array}{l}\text { Balboa \& } \\
\text { Peloquin } \\
\text { (1999) }\end{array}$ & $\begin{array}{l}\text { List of desirable } \\
\text { behaviors }\end{array}$ & Faculty consensus & $\begin{array}{l}\text { 1. Respects others } \\
\text { 2. Assumes responsibility for } \\
\text { own actions } \\
\text { 3. Demonstrates the ability to } \\
\text { problem solve } \\
\text { 4. Demonstrates the ability to be } \\
\text { flexible } \\
\text { 5. Demonstrates the ability to be } \\
\text { a cooperative and } \\
\text { contributing member of the } \\
\text { class and profession } \\
\text { 6. Recognizes and handles } \\
\text { personal and professional } \\
\text { frustration in a non-disruptive } \\
\text { and constructive manner } \\
\text { 7. Demonstrates the ability to } \\
\text { modify behavior in response } \\
\text { to feedback } \\
\text { 8. Demonstrates the ability to } \\
\text { give constructive feedback } \\
\text { 9. Balances personal and } \\
\text { professional obligations. }\end{array}$ \\
\hline $\begin{array}{l}\text { Hubbard, } \\
\text { Beck, Stutz- } \\
\text { Tanenbaum, \& } \\
\text { Battaglia } \\
\text { (2007) }\end{array}$ & $\begin{array}{l}\text { List of specific } \\
\text { behaviors } \\
\text { classified under } \\
\text { three (3) } \\
\text { headings }\end{array}$ & $\begin{array}{l}\text { Focus groups of } \\
\text { fieldwork } \\
\text { supervisors }\end{array}$ & $\begin{array}{l}\text { Organization and Time Management } \\
\text { 34. Well organized; manages time } \\
\text { effectively } \\
\text { 35. Responsible and dependable } \\
\text { in planning and providing treatment } \\
\text { 36. Punctual to work, meetings, } \\
\text { and treatment sessions }\end{array}$ \\
\hline $\begin{array}{l}\text { Kasar \& Clark } \\
(2000)\end{array}$ & $\begin{array}{l}\text { Categorized by } \\
\text { skills with } \\
\text { individual } \\
\text { behaviors }\end{array}$ & Author developed & $\begin{array}{l}\text { Dependability as demonstrated by: } \\
\text { a. Being on time for classes, work, } \\
\text { meetings } \\
\text { b. Handing in assignments, papers, }\end{array}$ \\
\hline
\end{tabular}




\begin{tabular}{|c|c|c|c|}
\hline & & & $\begin{array}{l}\text { reports and notes when due } \\
\text { c. Following through with } \\
\text { commitments and } \\
\text { responsibilities } \\
\text { Professional presentation as } \\
\text { demonstrated by: } \\
\text { a. Presenting oneself in a manner } \\
\text { that is accepted by peers, } \\
\text { clients, and employers. } \\
\text { b. Using body posture and affect } \\
\text { that communicates interest or } \\
\text { engaged attention } \\
\text { c. Displaying a positive attitude } \\
\text { towards becoming a } \\
\text { professional. }\end{array}$ \\
\hline $\begin{array}{l}\text { Randolph, } \\
\text { (2003) }\end{array}$ & $\begin{array}{l}\text { Behaviors } \\
\text { classified under } \\
\text { six fieldwork } \\
\text { and practice } \\
\text { goals }\end{array}$ & $\begin{array}{l}\text { Adaptation of form } \\
\text { followed by } \\
\text { feedback from } \\
\text { faculty, clinical } \\
\text { faculty, and } \\
\text { practitioners. }\end{array}$ & $\begin{array}{l}\text { Goal: Student will exhibit } \\
\text { dependability by displaying } \\
\text { punctuality at fieldwork and practice } \\
\text { sites, safe handling of equipment, } \\
\text { and supplies, and completing all } \\
\text { required tasks in a time period } \\
\text { acceptable by the fieldwork or } \\
\text { practice facility } \\
\text { - Arriving on time to classes, } \\
\text { meetings and fieldwork } \\
\text { assignment } \\
\text { Completing assignments on } \\
\text { time } \\
\text { Making arrangement to } \\
\text { obtain notes and material and } \\
\text { completing missed } \\
\text { assignments according to } \\
\text { instructor guidelines, } \\
\text { Preparing for class by reading } \\
\text { assigned materials }\end{array}$ \\
\hline $\begin{array}{l}\text { Ledet, } \\
\text { Esparza, \& } \\
\text { Peloquin. } \\
\text { (2005) }\end{array}$ & $\begin{array}{l}\text { Hierarchical } \\
\text { Categorization }\end{array}$ & Faculty consensus & $\begin{array}{l}\text { Commitment to Learning/Excellence } \\
\text { Analyses, synthesized, interprets } \\
\text { information } \\
\text { Takes initiative to direct own } \\
\text { learning/competence } \\
\text { Comes prepared for session } \\
\text { Exercises good judgment and } \\
\text { problem solving }\end{array}$ \\
\hline
\end{tabular}


Personal Responsibility

Is dependable and reliable

Acknowledges personal error and

makes adjustments accordingly

Follows through on tasks

The following sections will examine the most frequently cited professional behaviors included in assessments within occupational therapy (Gutman et al., 1998; Hubbard et al., 2007; Kasar \& Clark, 2000; Ledet et al., 2005; Randolph, 2003) organized within categories. When applicable, alternative terms describing similar concepts are also mentioned.

Professional dependability. Professional dependability is the foundation of all other professional behaviors (Petersen, 2000). Dependability is the worthiness of the individual to be trusted. In healthcare, it is essential the client and other team members can trust the professional or student to be dependable and to consistently demonstrate professional behavior and meet obligations (Gutman et al., 1998). Behaviors included in the category of professional dependability are dependability and timeliness.

Dependability. Dependability is characterized by the individual's ability to demonstrate similar behaviors in multiple situations at multiple times especially when under stress. Working in the modern healthcare environment is characterized by time and productivity demands, and emotional stress. It is essential that the healthcare worker or student be dependable in their work and interactions despite the challenges of the environment.

Students and professionals who are not dependable pose a risk in their decision-making when they may be under duress. A lack of dependability can also lead to clients loosing trust in the practitioner (Peterson, 2000). Multiple OT researchers have included dependability in 
professional behavior assessments (Fidler, 1996; Hubbard, Beck, Stutz-Tanenbaum \& Battaglia, 2006; Ledet, Esparza, \& Peloquin, 2005).

Timeliness. Healthcare professionals and students are expected to be timely in their work. Professionals are expected to be on time to client appointments, to complete the treatment and documentation in a timely fashion, to bill accurately and within an acceptable timeframe, and are expected to respond to requests from clients, co-workers, and insurance carriers in prompt fashion. Students face these same expectations while on clinical rotations. Students are also expected to complete client documentation, projects, and assignments by deadlines established by others. Another term frequently seen in the literature for this behavior is time management (Ledet et al., 2005).

Professionals who are not timely in their documentation and billing leave their clients and employer vulnerable to denial of coverage by insurance companies. A denial may result in either the client or employer being responsible to pay or absorb the cost of treatment. Students and professionals who are unable to be prompt to appointments or unable to complete treatment in the time allotted negatively impact their clients and are considered to be communicating a lack of respect for the client's or co-workers' time.

Emotional maturity. Emotional maturity is the largest category of professional behaviors and is the area in which similar concepts are identified by multiple terms. The major behaviors in emotional maturity are the ability to accept and integrate feedback from others, ability to self-correct, and awareness of emotions (Gutman et al., 1998). Other terms referred to in the literature (Punwar, 2000) that address concepts similar to emotional maturity are the constructs of emotional intelligence and psychological insight. Gutman et al. identified lack of 
psychological insight as a common area of behavior difficulty in students who failed a level 2 fieldwork experience.

Awareness of emotions. Awareness of emotions of self and others is a foundational skill that is necessary for professional success. Healthcare professions are fraught with emotional stressors for both the clinician and client. Occupational Therapists are frequently engaged in extended therapeutic relationships with their clients. A typical inpatient rehabilitation therapeutic relationship is characterized by the clinician and client working together in a one on one or small group setting for 90 minutes a day, five days a week for three to six weeks. Occupational therapists working in the school systems may work with the same child weekly from kindergarten through the junior high years. This represents a greater emotional connection between therapist and client than is typically experienced between doctor and patient. To succeed in maintaining an appropriate healthy relationship requires the therapist or therapy student to be aware of and control their own emotions and emotional reactions while simultaneously monitoring and managing the emotions of their client (Punwar, 2000). Failure in this area of professional behavior usually will result in difficulty in other areas of professional behavior such as establishing and maintaining rapport, and therapeutic use of self (Chaffey, Unsworth, \& Fossey, 2012).

Acceptance and integration of feedback. Faculty members or clinical supervisors typically provide feedback to students in the health professions. The onus of responsibility is on the students to accept the feedback and integrate the necessary changes into their behavioral and skill repertoire. This process can often require multiple episodes of feedback focused on the same behavior. However, when the undesired behavior persists despite multiple episodes of feedback and multiple opportunities to demonstrate change, stagnation in professional growth 
and development will occur. This ultimately can lead to incompetent practice and injury to the therapist or client. Clinical supervisors in OT, PT, and Medicine report inability to integrate feedback as one of the most frustrating professional behavior problems they have to address in students (Gutman et al., 1998; James \& Musselman, 2005, Papadakis et al., 2005).

Responsibility. A number of desirable professional behaviors are classified within the category of personal responsibility (Davis, 2009; Ledet et al., 2005) and commitment to learning (Fidler, 1996). Some behaviors that may be classified under responsibility include initiative, independent learning, and responsibility for one’s own performance. Responsibility is identified by PT, OT, and Medicine as a professional behavior that is important in clinical success. Physical therapy faculty members include responsibility as one of seven most important professional behaviors (Davis, 2009), while James and Musselman (2005) found that OT clinical supervisors expressed that students who demonstrated initiative were more likely to pass the Level 2 fieldwork experience. Decreased personal responsibility is associated with failure and poor clinical performance in both OT and Medicine (Gutman et al., 1998; Papadakis et al., 2005).

Initiative. Initiative is an essential skill in today's healthcare environment. Students and clinicians must be able to independently take action to protect and serve their clients. Clinical supervisors often express frustration with the student who waits to be told what to do (Gutman et al., 1998). Initiative is one of the most widely cited professional behavior issues by clinicians (Gutman et al., 1998; Ledet et al., 2005; Wolff-Burke, 2005). Koenig and colleagues defined initiative as the "Ability to demonstrate initiative and flexibility, ability to seek and acquire information from a variety of sources” (2003, p. 88). Petersen (2000) suggests that initiative is an innate characteristic that must be accompanied by motivation to create overt action. Students 
and professionals who exhibit initiative will look up information independently, seek additional learning opportunities, and in general go the extra step to ensure their learning and effectiveness as a clinician.

Students who lack initiative are often perceived as lazy, disengaged, or desiring that professors and clinical supervisor "spoon feed" them what they need to know (Wolff-Burke, 2005). An important part of injury prevention with the therapy population is to actively look for, identify, and remove risks to the client. Students who lack initiation may also place their client in harm's way.

As professionals, clinicians who lack initiative may not follow up on issues clients present with in treatment, believing instead that others will address the problem. Some of these issues can have a significant impact of the health and well-being of the client. For example, a clinician who lacks initiative may choose to ignore the subtle signs of abuse and neglect in their elderly clients instead adhering to a belief that it is the nurses' or social workers responsibility to deal with the issue. Initiative is closely tied to the professional behavior of independent learning.

Taking responsibility for one's own learning. Taking responsibility for one’s own learning is an essential skill in the rapidly changing healthcare environment. Another term used by researchers in professional behaviors is self-directed learning which Koenig et al. (2003) defined as the “Ability to take responsibility for own learning, demonstration of motivation” (p. 88). Students who take responsibility for their own learning are observed to seek resources beyond those required in a class, to use multiple sources to investigate a question, and actively attend learning opportunities both in and out of the classroom. Students with strong skills in this area will often seek feedback regarding their performance from professors and clinical 
supervisors. Professionals who demonstrate a responsibility for their own learning seek learning opportunities that will enhance their job performance. They make an effort to stay up-to-date with the latest information in their field or specialty area of practice. In a study of essential OT professional behaviors in Australia, continually striving to improve knowledge, skills, and competence was identified as the most important professional behavior (Agulier, et.al, 2014).

Students who do not look up information and instead expect the clinical supervisor to tell them the information are often perceived as having a decreased commitment to their own learning (Fidler, 1996). Other troublesome behaviors include the expectation of the student that the professor or clinical supervisor is responsible for telling them everything they could ever need to know. Students who think a decreased responsibility for their own learning will often rely on easy to access but less accurate, and/or more superficial sources of information such as unreliable Internet sites or quick handbooks. Clinical supervisors in PT expect students on clinical rotations to accept responsibility for their own learning (Wolff-Burke, 2005).

Professionals who fail to take responsibility for their own learning will often only complete the minimum work when it comes to their own continuing education completing the minimum number of hours required by state licensure. They will also often seek free, quick, and easy opportunities without considering whether the topic will enhance their knowledge and/or clinical performance. For example, a clinician who primarily works with children may attempt to meet his/her yearly continuing education requirement by attending a low cost, local workshop that addresses caring for clients with Alzheimer's disease.

Responsibility for one's own actions. Another skill that is closely related to initiative is assuming responsibility for one’s own actions (Babola \& Peloquin, 1999). Students in a health 
profession education program make mistakes. Professors and clinical supervisors are concerned with how students react to their errors and the feedback process. Students who accept responsibility for their own actions will acknowledge that they have made the error, accept the consequences, and plan how to avoid the error in the future. Professionals who are responsible for their actions will appropriately self-identify when they have erred, take steps to remediate the error, be honest in their account of the error, and express regret.

Students who have difficulty accepting responsibility for their own actions often blame others for their difficulties in the classroom and clinic (Gutman et al., 1998). Common complaints from students struggling in the clinical environment are that their academic program did not prepare them or that their clinical supervisor does not like them. Students who are unable to accept responsibility for their own actions will also struggle with integrating feedback from clinical supervisors and changing their behavior in response to the environmental demands as discussed earlier. Professionals and students who do not accept responsibility for their own behaviors may commit fraudulent or unethical behavior such as incomplete or incorrect documentation, dishonesty when relating the events in question, or blame other staff or the client for an incident.

Professional communication. Professional communication is a collection of essential behaviors that affect how the student or professional is perceived by those around them. In professional behavior assessment, this category of behaviors might also be known as professionalism or interpersonal competence (Fidler, 1996). The skills commonly included in professional communication are communication skills, enthusiasm, and appearance. These skills are critical in establishing rapport, working in a team, and therapeutic use of self. Therapeutic use of self is a concept in occupational therapy that refers to the therapist ability to use 
themselves and his/her talents while interacting with the client to help the client during the therapeutic process (Peloquin, 2002).

Professional communication skills are a common area of difficulty for students and an area of particular concern for clinical supervisors and faculty. In medicine, researchers have identified that written and verbal communication, and ability to work on a team affected performance on clinical rotations (Morris \& Faulk, 2007). In her survey of clinical educators, Wolff-Burke (2005) discovered that Physical Therapists expect students to communicate well and identified lack of interest as an inappropriate behavior. PT faculty members have also identified oral communication as an important professional behavior (Davis, 2009).

Communication skills. Communication skills and behaviors are an extensive area of professional behaviors and in many professional behavior assessments are contained in their own category (Kasar \& Clark, 2000; Ledet et al., 2005). Judgment of student and professionals’ competence by clients is often heavily based on their communication skills. Verbal communication abilities are critical in establishing rapport with clients and maintaining professional relationships with supervisors, peers, and other members of the healthcare team. In occupational therapy verbal communication abilities that are assessed include expressing conflict appropriately, communicating at a level appropriate to the audience, and assertiveness (Fidler, 1996; Koening et al., 2003). Students and professionals with good verbal communication skills are able to transition between conversations with clients using every-day terminology to conversations with other healthcare professionals utilizing medical terminology and expressing complex concepts with ease. The ability to talk to the client and their family at their level of understanding is critical in being able to establish a beneficial therapeutic relationship. The ability to discuss the care of others in a professional and educated manner is essential in 
garnering the respect of peers on the healthcare team. An essential function for many

occupational therapy students and professionals is advocating for their client. This might occur when trying to establish the best treatment plan, recommend discharge destination, or to obtain the correct assistive technology to facilitate function. Students and professionals have to demonstrate assertiveness in their communications with clients, family, and healthcare team members.

Students and professionals with poor verbal communication skills often struggle to be successful in a clinical environment. When occupational therapists talk at a level above the understanding of the client they silently communicate that they believe they are better than the client or that obtaining the client's understanding is not important (Peloquin, 1993). OT professionals who are unable to communicate professionally with other members of the healthcare team are perceived as less competent and less worthy of trust. Students and professionals who are not appropriately assertive are either perceived as passive or aggressive.

In the healthcare arena written communication skills are essential in documenting what has occurred and serves as the basis for payment for services. Therapists document their work in written records that summarize the interventions of the therapist and the client response to the treatment. This written record is often examined in malpractices cases (Muscari, 2000).

Students and clinicians who have good written communication skills are able to concisely and accurately describe a client's impairments, function, and participation. Well-written documentation serves as an accurate record of the services provided and the client's response to those services. The unique documentation demands of healthcare professions includes ability to document initial and follow-up evaluation results, treatment plan, goals that are appropriate to 
the client and setting, daily or weekly treatment notes, discharge notes, letters of medical necessity, incident reports, and requests for insurance coverage. Occupational therapists typically document their work with clients for other medical professionals, insurance companies, case managers, and in some cases the client and/or family. The ability to accurately communicate client status is as important as is the ability to attend to the basic mechanics of writing such as spelling and grammar. A student and/or clinician with good written communication skills is able to quickly and accurately provide the necessary information that relays the necessity of ongoing treatment and the progress experienced in treatment.

Students often struggle with accurately writing what they have observed the client doing in a professional manner using appropriate terminology. When this occurs, notes are often too long, difficult to understand and/or indecipherable. The consequences of a poorly written note can be great including the denial of future services and payment. For example, a student who documents that the client is independent in self-care with close supervision, risks the insurance company perceiving that the client is independent in these skills and ready to go home. The student should have written that the client required close supervision in self-care tasks due to a lack of safety awareness. When written this way, it is clear that the client is not ready to return home.

Appearance. Another key component of professional practice is appearance (WolffBurke, 2005). In the past occupational therapists often wore uniforms very similar to nurses. In these situations, the choice of what to wear was simple. Employers could also be assured in these situations that the therapist would appear professional when they came to work. As part of the emerging independence of the professions as well as a change in the medical culture that deemphasizes the wearing of special uniforms, therapists have more freedom to choose what they 
want to wear to work. Healthcare professionals now try to strike a balance of wearing clothes that project their professionalism, allow them to complete the physical tasks of their job, and not offend other people's sensibilities. This choice in conjunction with a change in fashion that emphasizes showing more skin has led to professional appearance concerns becoming prevalent in occupational therapy. Most healthcare environments are considered more conservative than the general environment. The clientele tends to be older than the therapists, with different sensibilities (Larkey, 2000). Occupational therapists should be able to complete their job, which involves significant physical activity and movement while keeping, a modest neckline, their back and trunk fully covered, a modest hemline, and their clothes appropriately loose (Larkey, 2000). Working in a healthcare environment also raises some unique issues regarding cleanliness and minimization of the transmission of germs. For these reasons multiple facial piercings, unkempt facial hair, and open-toed shoes are often forbidden. Even therapists who work in non-healthcare settings such as in an elementary school are expected to keep their appearance modest, although they may be allowed to appear more casual in dress.

Students transitioning from a college environment that encourages casual dressing and the revealing of skin may struggle with these new expectations. This can lead to several consequences. The supervisor of the clinical site may choose to send the student home until he or she are able to dress appropriately. Casual dressing decreases the positive regard that supervisors have of students. Clothing choices that reveal skin or highlight physical features of students' bodies can also lead to inappropriate comments from clients with brain injuries or developmental delays who are not able to adhere to sexually appropriate social norms. Students who appear overly casual may not inspire confidence in their abilities from their clients which can inhibit the therapeutic relationship (Larkey, 2000). 
Enthusiasm. The final aspect of professional communication noted in some of the literature is enthusiasm (Fidler, 1996). Enthusiasm can be defined as projecting a positive attitude that indicates the student is happy working in his/her profession, enjoys his/her work, and is confident in his/her abilities (Kasar \& Clark, 2000). Students who enter the clinical arena for the first time often feel unsure of their abilities, and in extreme circumstances they can experience fear, or intimidation. Although these feelings are normal, it is important to project an attitude of enthusiasm and appropriate confidence to gain the trust of the client. Students who fault on either side of this attitude can damage the therapeutic rapport with their clients. Students who appear unsure, scared, or lacking confidence will cause the client to question their clinical competence and often times request treatment from a "real" therapist. Students who project an overly confident attitude often inspire fear or distrust in their clients. For example, Wolff-Burke (2005) described the problems that may arise from a physical therapy student projecting an overly confident attitude with his/her clinical supervisor in front of clients. This type of behavior angered the clinical supervisor and created distrust in the client.

Clinical reasoning skills. Clinical reasoning is defined by Punwar and Peloquin as “The process by which a health professional analyzes the available client data and then decides on the treatment strategies to be employed” (2000, p. 278). However, research in the field of occupational therapy has identified clinical reasoning as a complex process that differs from the clinical reasoning employed by physicians (Fleming, 1991). Work by multiple researchers in the early 1990s identified that clinical reasoning in occupational therapy is less focused on the diagnosis of the client and more focused on the meaning of the diagnosis to the client, and the impact of the diagnosis on his/her function, and in predicting a path forward for the client given the multiple factors that can affect the client’s future (Schell \& Cervero, 1993). 
In her explanation of the concept of clinical reasoning Mattingly (1991) identified five domains of knowledge that may be combined in clinical reasoning, understanding of the client's inner world, assessment of the environment in which the client functions, knowledge of the client's physical, cognitive, and emotional impairments and how to intervene with those impairments, understanding of the nature of the therapeutic relationship between the therapist and client, and the goals for the client in both the short and long term (p. 983). Integration of these domains of knowledge requires the ability to mix both cognitive and affective abilities. Ideally, clinical reasoning is the integration of cognitive knowledge with the affective skills associated with professional behavior.

Students and therapists with good clinical reasoning skills are able to quickly and efficiently integrate their scientific knowledge of the diagnosis or disability with their affective knowledge of clients and their situation. They are able to accurately predict future function, project appropriate discharge destination, and select the most appropriate treatment methods (Fleming, 1991). Excellent clinical reasoning skills allow the therapist or student to provide the most effective treatment and can lead to better outcomes.

Students and therapists who struggle with clinical reasoning have difficulty integrating their cognitive and affective knowledge. They have difficulty identifying common patterns and deviations from norms in their clients. They often rely on a limited set of interventions and desire right and wrong answers. Gutman et al. (1998), state that clinical reasoning requires the tolerance of ambiguity. In their study of students who failed a Level 2 fieldwork experience, they found that $98 \%$ of failing students had difficulty accepting the ambiguity of the clinical reasoning. James and Musselman (2005) found that poor clinical reasoning was the second most important item in behaviors identified by supervisors as being associated with failure of level 2 
fieldwork. Clinical reasoning also appeared as one of the seven most important professional behaviors identified by Physical Therapy Faculty (Davis, 2009).

\section{Assessment of Professional Behaviors}

In this section, I will discuss the processes and principles of assessment and review the assessment practices discussed by researchers in the literature. Assessment scholars articulate the ideal assessment process that faculty and staff should follow. I then apply this discussion to the occupational therapy and medical education literature.

Effective assessment is achieved through a thoughtful and deliberate process (Palomba \& Banta, 1999). Suskie (2009) defines assessment as a four-step process of establishing measurable learning outcomes, ensuring that students have learning opportunities to meet the outcomes, gathering and analyzing evidence of student learning and achievement of the outcomes, and using assessment findings to improve student learning (p. 4). These steps can be summarized into a three-phase process of assessment planning, implementation, and reporting and effective use of results.

\section{Planning Assessment.}

Learning outcomes. Planning for assessment requires identification of the desired learning outcomes for students. Suskie (2009) and Palomba and Banta (1999) identify that Blooms’ Taxonomy often serves as an organizational structure for creating these learning outcomes although other learning taxonomies may be used. Bloom's taxonomy presents three domains of learning: cognitive; affective; and, psychomotor. Gaining and demonstrating professional behaviors requires learning primarily in the affective domain. Table 2.2 below 
presents the different levels of the affective domain, highlights verbs that are used in each level, and provides an example learning objective in professional behavior.

Table 2.2

Affective Domain of Bloom’s Taxonomy

\begin{tabular}{|c|c|c|}
\hline Category & Illustrative verbs & $\begin{array}{l}\text { Sample Objective in } \\
\text { Professional Behavior }\end{array}$ \\
\hline $\begin{array}{l}\text { 1) Receiving: } \\
\text { Awareness, } \\
\text { Willingness to hear. } \\
\text { Attending to }\end{array}$ & $\begin{array}{l}\text { Asks, chooses, describes, } \\
\text { follows, gives, holds, } \\
\text { identifies, locates, names, } \\
\text { points to, selects, replies, uses }\end{array}$ & $\begin{array}{l}\text { Student will actively listen to } \\
\text { all members of group in class } \\
\text { activities. }\end{array}$ \\
\hline $\begin{array}{l}\text { 2) Responding: Active } \\
\text { participation in } \\
\text { learning. }\end{array}$ & $\begin{array}{l}\text { Answers, assists, aids } \\
\text { complies, conforms, discusses, } \\
\text { greets, helps, labels, performs, } \\
\text { practices, presents, reads, } \\
\text { recites, reports selects, tells, } \\
\text { writes }\end{array}$ & $\begin{array}{l}\text { Student will conform to } \\
\text { specific appearance policy and } \\
\text { dress code required in the } \\
\text { fieldwork site. }\end{array}$ \\
\hline $\begin{array}{l}\text { Valuing: The worth of value a } \\
\text { person attaches to a particular } \\
\text { phenomenon or behavior. }\end{array}$ & $\begin{array}{l}\text { Completes, demonstrates, } \\
\text { differentiates, explains, } \\
\text { follows, forms, initiates, } \\
\text { invites, joins justifies, } \\
\text { proposes, reads reports, selects } \\
\text { studies, works }\end{array}$ & $\begin{array}{l}\text { When assigned a client, } \\
\text { students initiate reviews of } \\
\text { appropriate charts and } \\
\text { research on client diagnosis. }\end{array}$ \\
\hline
\end{tabular}




\begin{tabular}{|c|c|c|}
\hline Organization: Organizes & Adheres, alters, arranges, & Students appropriately alter \\
\hline values into priorities, resolves & combines, compares, & behavior in response to \\
\hline \multirow[t]{5}{*}{ conflicts between values. } & completes, defends, explains, & feedback from faculty, clinical \\
\hline & formulates, generalizes, & supervisors, or peers. \\
\hline & identifies, integrates, modifies, & \\
\hline & orders, organizes, prepares, & \\
\hline & relates, synthesizes & \\
\hline Characterization: Has a value & Acts, discriminates, displays, & Students are able to modify \\
\hline system that controls behavior, & influences, listens, modifies, & treatment plans easily in \\
\hline \multirow[t]{3}{*}{ The behavior is consistent, } & performs, practices, proposes, & response to new information \\
\hline & qualifies, questions, revises, & they receive from their clients. \\
\hline & serves, solves, verifies & \\
\hline
\end{tabular}

Adapted from: http://thecenter.spps.org/uploads/BloomAffect_Taxonomy.pdf

Arnold (2002) notes that medical education programs must first determine what professional behaviors are important to clinical and academic success. In 2006, Arnold and Stern introduce the Combined Miller-Rest model for articulating stage specific professionalism expectations for medical students (see Figure 2.1). Within this model, students should be aware of the professional behavior expectations set by physicians. At the next level of development, medical students should be able to express how to demonstrate professional behavior. At the third stage, students should be able to show how to behave professionally in structured clinical experiences or supervised clinical experiences. In the final stage, medical students or residents are professional in all situations. 


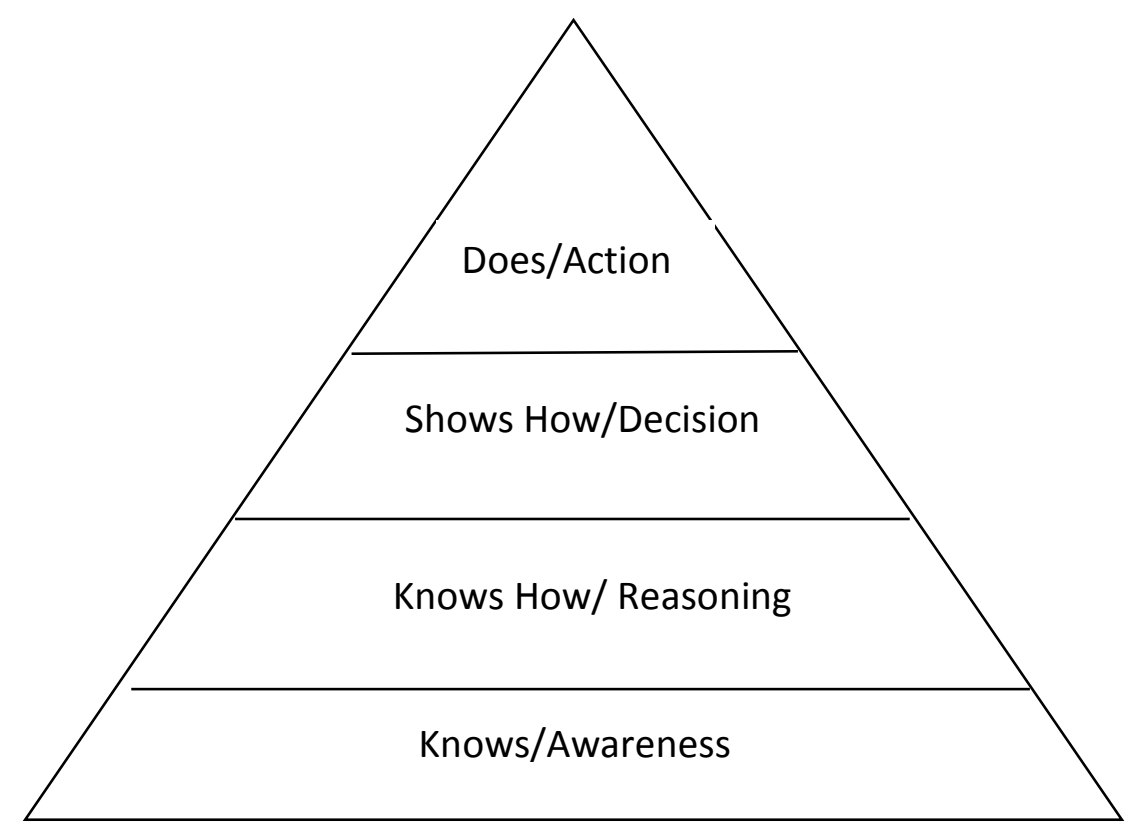

Figure 2.1 Combined Miller-Rest Model for professionalism assessment (Arnold \& Stern, 2006, p. 29)

Implementing assessment. Successful implementation of the assessment plan requires the cooperation and participation of both faculty and students. Professional development for faculty and student education is necessary to ensure that they understand the purposes and goals of assessment and participate fully and ethically (Suskie, 2009). Students entering education programs in the health fields have limited experience with assessment and have not typically been involved in professional behavior assessment. They require orientation to the professional behavior assessment to understand the purpose and process. Scheerer (2003) reports that students compare professional behavior assessment to therapy. Faculty members also require education to understand the assessment process, what their role in the process is, and receive training on how to use the tools involved (Palomba \& Banta, 1999). 
Assessment tools. Once faculty members have clearly defined learning objectives, the next step is to determine the most effective and efficient way to access student progress toward achieving those objectives (Arnold, 2002). Assessment tools can be classified as direct or indirect. Direct evidence of learning is observable, tangible, and self-evident (Suskie, 2009). Tools in professional behavior assessment that provide direct evidence are rubrics or rating forms, specific scored items on practical exams, peer evaluations, fieldwork evaluations, or critical incident reports. Indirect evidence of learning, “consists of proxy signs that students are probably learning” (Suskie, p. 20). Common indirect measures of learning include student reflection or self-assessment, passing rates on clinical experiences, results of employer surveys, or course grades. Robust assessment efforts utilize a variety of tools that solicit both direct and indirect evidence.

Academic programs must also choose to use either locally developed and/or commercially available assessment tools. Locally developed tools are designed and developed by the faculty and have the advantage of being designed specifically for the academic program. They usually are low cost in terms of using the tools to assess students but it takes time to develop high quality tools. Concerns may also arise around the reliability and validity of the tool. Commercially developed instruments usually have addressed issues of reliability and validity through research. However, they may not be a perfect fit for an academic program and may be more expensive but might represent a savings of faculty time in development.

Reliability and validity of assessment tools. Within the Occupational Therapy education field most professional behavior instruments are locally developed. A primary concern with the use locally developed rating forms or rubrics are reliability and validity. Reliability is the tool's 
ability to consistently measure what it is designed to measure while, validity is the extent to which an assessment tool measures what it is supposed to measure (Gay \& Ariasian, 2003).

Researchers in medical education have identified rater errors as the biggest threat to reliability. The primary raters of professional assessment are faculty members (Arnold \& Stern, 2006), research has also examined the potential errors of peers as assessors (Kovach, Resch, \& Verhulst, 2009). The primary threats to reliability are stringency or leniency errors (vanMook et al., 2009). Stringency errors occur when raters assess students differently dependent upon their other skills. Researchers have found that raters tend to assign higher ratings to students who demonstrate other strong abilities, such as intelligence or likability. The opposite tendency occurs when faculty members and peers assign lower scores in professional behaviors to students who have a particularly noticeable weakness in academic performance. Leniency errors occur when generous ratings are given despite actual performance that is poorer than the rating assigned. Both Arnold and vanMook identify training of faculty and peers on how to use the assessment tool and rate professional behaviors as the most important step to increase reliability.

When researchers examined the results of peer assessment, scores of professional behavior were found to be consistently lower than the scores issued by faculty members during medical clerkships. This result suggested that students have a more intimate knowledge of their peers’ behaviors that many faculty raters may not be aware of (Kovach, Resch, \& Verhulst, 2009). The researchers also surveyed students and faculty regarding their perceptions of the peer feedback process and both groups identified the peer assessments as valuable, accurate or more accurate than faculty ratings, and expressed that peer assessment should continue as part of the professional behavior assessment. 


\section{Tools used to gather Information.}

Rubric or rating scale. A rubric is a scoring guide that defines the criteria that will be used to grade or assess a particular assignment or behavior. Rubrics are helpful because they often clarify expectations for both students and the raters (Suskie, 2009). Rubrics, also referred to as rating scales, are the primary tool used to gather information on student professional behaviors (Ledet et al., 2005; Randolph, 2003; vanMook et al., 2009). Faculty use the rubric to indicate the behaviors deemed important and assessable by the specific program and can provide direct evidence of student learning.

The rubrics presented in the literature use a variety of rating scales that reflect differing philosophies of professional behavior development. The first philosophy values the developmental approach to educating students. The developmental philosophy assumes that students at different points in their education will demonstrate different levels of professional behavior becoming more proficient as they progress. In this approach, the raters are comparing behavior exhibited against a belief of what is expected at that level of professional development. The behavioral expectation of students enrolled in the first year of a professional program will be lower than what is expected of a student enrolled in the final year of the professional education program. Arnold and Stern (2006) identify this as the preferred approach in medical education.

The second philosophy values the faculty as experts who set the standards for professional behavior based on their beliefs of the expectations of practicing clinicians. This standardized type of rating scale is based on standards of performance that are static throughout the educational program. 
Within both of these approaches, different types of descriptors are used. Some rating scales provide behavioral descriptors of the ideal behavior and the behavior in differing levels of development and the rater chooses the best descriptor. Other ratings used a Likert scale of consistency of demonstration of performance. A third type of scale described in the literature looks at the degree of development on a three or four step scale. In this type of scale rating such as “poorly developed” to “fully developed” may be used (Kasar \& Clark, 2000; Koenig, Johnson, Moran, \& Ducette, 2003; Randolph, 2003).

In occupational therapy, three groups of researchers have examined the reliability and validity of professional behavior rating forms (Hubbard et al., 2007; Kasar, 2000; Koenig et al., 2003). Only the professional behavior assessment developed by Kasar was intended to be used in the academic environment. The assessment tool developed by Hubbard et al. is intended for use at the completion of the Level 2 fieldwork experience and the assessment developed by Koenig et al. is intended to be used at the end of the Level 1 fieldwork experience.

The Occupational Therapy Attribute Scale (OTAS) was developed and tested by Hubbard et al. To establish content validity the researchers conducted a series of focus groups of fieldwork supervisors and clinicians to identify and define important professional behaviors. From these focus groups a 43-item professional behavior scale was developed. The researchers then field tested the instrument and collected data to determine reliability and validity. Based on their findings a second version of the OTAS was developed. Research on the second version of the OTAS indicated that the assessment had strong reliability, test-retest reliability, and good sensitivity (Hubbard et al., 2007). 
Koenig et al. (2003) developed the Philadelphia Region Fieldwork Consortium (PRFC)

Level 1 Fieldwork Student Evaluation. They also used focus groups to identify expected professional behaviors to increase content validity. The researchers also trained raters on how to use the form and rate students to increase reliability of the instrument. The researchers were able to collect 317 rating forms. Statistical analysis revealed high internal consistency reliability, and adequate intra-rater reliability. Based on their results the authors identified the PRFC Level 1 Fieldwork Student evaluation as a reliable assessment of professional behavior of students completing level 1 fieldwork experiences. This assessment originally developed by the researchers at Jefferson University is now used by multiple universities to rate student professional behavior at the conclusion of Level 1 fieldwork.

Kasar (2000) tested the Professional Development Assessment, an instrument used by academic programs to rate student professional behavior. In his book on the development of professional behaviors, he reports that the rating form has good internal and inter-rater reliability.

Portfolios. Portfolios are an increasingly popular assessment tool. Palomba and Banta (1999) define portfolios as “... a type of performance assess in which students work in systematically collected and carefully reviewed for evidence of learning and development” (p. 131). Portfolios are a particularly effective assessment tool in programs when the primary goal is to develop thinking skills or metacognition (Suskie, 2009, p. 204). The evidence of learning contained in a portfolio can be both direct and indirect. When deciding what the content of the portfolio will be it is important to be clear on the purpose of the portfolio (Meeus, VanPetegem, \& Engels, 2009; Palomba \& Banta, 1999). For example, portfolios meant to demonstrate learning require both evidence of poor and improved work. Portfolios intended to demonstrate competency require evidence of good work. 
The use of portfolios to assess professional behaviors is discussed by professional behavior experts. In their review of professional behavior assessment techniques used by medical programs in Europe, vanMook et al. (2009), identify portfolios as an effective assessment of professionalism. According to Fryer-Edwards, Pinsky, and Robins (2006) portfolios are well suited to assessing complex constructs such as professionalism (p. 215). Fryer-Edwards et al. suggest nine possible artifacts for inclusion in a medical student portfolio including, professionalism goals, a learning plan, standardized and real patient evaluations, videotaped segments, self-evaluation forms, peer feedback, reflective exercises, faculty feedback from mentoring and faculty evaluation forms (p. 216). Students are asked to review and reflect on the materials included in the portfolio. Self-reflection is critical to development of professionalism and professional behavior (vanMook et al.). Arnold (2002) also mentions the strength of portfolios in encouraging reflection by medical students.

In the occupational therapy research, Bossers et al. (1999) describe the use of a Professional Practice Portfolio by students to assess professionalism of which professional behaviors are considered a component part. Students are responsible for collecting evidence of professional development and participation and then reflecting on their development. Some of the artifacts that may be included in the portfolio include reports, placement evaluations, case studies, and material or feedback from others. Students may also include evidence of involvement in the profession, e.g, record of attendance at professional meetings, and personal statements and reflection of their professional development.

Critical incident recording. The use of critical incident recording to assess professional behavior in academic programs is discussed in the medical education literature (Arnold, 2002; Papadakis et al., 2005; vanMook et al., 2009). Critical incidents may be observed by faculty and 
clinical instructors in the classroom, standardized clinical experiences or in supervised clinical practice. Critical incident reporting focuses on identifying students who demonstrate outstanding or deficient professional behavior and provides direct evidence of learning. When an incident occurs in which the student demonstrates either exemplary or poor professional behavior the incident is written up by the observing faculty member and included in the student file. Critical incident recording may be used to determine awards or to establish the need for corrective action.

The use of critical incident reporting presents a challenge to the academic program. Establishing a threshold of behavior when a critical incident report should be submitted can be difficult. Faculty members often have difficulty determining when a behavior is poor enough or outstanding enough that it should be submitted to the student's record. Arnold (2002) reports that one-way threshold issues can be addressed by using a severity scale along with the qualitative report of the incident in situations when negative behavior is being reported. This way faculty can report the behavior and indicate what they perceive the level of severity of the behavior to be.

Who participates in assessment? There are many individuals who participate in professional behavior assessment including faculty, clinical supervisors, peers, and the student themselves (Balboa \& Peloquin, 1999; Fidler, 1996; Ledet et al., 2005; Schonrock-Adema, Heinje-Penninga, vanDuijn, Geertsma, \& Cohen-Schotanus, 2007; vanMook et al., 2009).

Faculty. All of the reports of professional behavior assessments include faculty feedback. Within the medical education literature, Norcini (2006) identifies that faculty may provide feedback based on their perception of the students routine performance or based on one interaction/observation such as observing a standardized clinical experience. Rating professional 
behavior based on routine performance is most common in both medical and occupational therapy education.

In occupational therapy, faculty contributes information regarding students’ professional behaviors in two ways, group discussion, and individual reporting. Gutman et al. (1998) and Randolph (2003), report on group discussion of professional behavior performance that occurs at regular intervals and involve the entire faculty. In this processes all faculty members are asked to provide information about the students' professional behavior and the feedback in compiled into one form.

When providing feedback individually faculty members might be asked to contribute information by entering information on an electronic form housed on a central server (Randolph, 2003). The second method of obtaining individual faculty feedback highlights particular classes in the curriculum that emphasize concepts of professionalism and having the faculty of those courses complete professional behavior assessments as part of the grading process (Ledet, Esparza, \& Peloquin, 2005). This approach places most of the burden of assessment on a few faculty members and can lead to students believing that the assessment only reflects the views of a few faculty members.

Fieldwork or clinical supervisors. In occupational therapy education, students complete two types of clinical experiences; they are called Level 1 and Level 2 fieldwork. Level 1 fieldwork experiences are typically integrated as part of the curriculum and occur while the students are simultaneously engaged in classroom instruction. The level 1 experience is primarily observational in nature. In these experiences, students are typically supervised by full time clinicians. Level 2 fieldwork experiences are 12-week full time experiences that the student 
usually completes at the end of the educational experience. Students on level 2 fieldwork experiences are supervised by full time occupational therapists with at least one year of experience. Although students expressed a desire for feedback from level 1 fieldwork supervisors to be included in professional behavior assessment, (Scheerer, 2003) none of the academic professional programs described by researchers included feedback from Level 1 supervisors. Two of the professional behavior rating scales examined by researchers were intended for use at the end of the fieldwork experience and are completed by the fieldwork supervisor (Randolph, 2003; Hubbard et al. 2007).

Peers. Within the occupational therapy literature peer assessment is only mentioned in one article by Fidler (1996) reporting on the development and implementation of a professional behavior assessment plan. In the field of medical education, peers typically provide feedback by the use of a rubric or rating form (Arnold, 2006).

When looking at the effect of peer assessment on professional behavior it appears that performance is enhanced, especially later in the medical school curriculum. Schonrock-Adema et al. (2007) compared two groups of students in an undergraduate medical education program to judge the effect of peer ratings. The students in the test group received peer feedback regarding professional behavior at the end of each trimester. There was no difference in professional behavior scores given by peers or tutors at the end of the first trimester. At the end of the second trimester students in the peer assessment condition received increased professional behaviors scores from tutors and peers. The authors of this study propose that the transition to medical education is significant and cognitive overload may have limited the learning in a noncognitive domain such as professional behaviors in the first trimester. 
When examining peer assessment Arnold, Shue, Kritt, Ginsburg, and Stern (2006) identified several general contextual concerns expressed by students. Students are concerned with the stakes associated with their ratings, and the anonymity of their ratings.

Self-assessment. Self-assessment of professional behavior provides indirect evidence of development of professional behaviors. Self-assessment is used in medical, occupational, and physical therapy education. Development of professional behavior requires the student to gain an awareness of his or her own strengths and weaknesses and opportunities for improvement (Kasar, 2000). Self-assessment encourages such awareness.

Self-assessment may be completed by having the student fill out the professional behavior assessment form (Kasar, 2000; Randolph, 2003). Students may also include a reflection of their professional development and performance in a portfolio (Bossers et al., 1999; Santasier \& Plack, 2007). In their research on assessing professional behaviors using qualitative data, Santasier and Plack describe the use of self-reflection essays and student developed graphic representations of their professional development as self-assessment tools.

An area of concern with self-assessment in medical education is the accuracy of student rankings. Students who have poorer professional performance tend to overestimate their performance and student who are consistently high performers tend to underestimate their performance. Some researchers have also found that females tend to underestimate performance while men tended to overestimate performance (Rees \& Shepherd, 2005). Another issue that may arise in self-assessment in the medical and health professions is the competiveness of the educational program. This may lead to students feeling that they have to give themselves a higher ranking to continue to be equal to or ahead of their peers (vanMook et al., 2009). Most 
researchers have found only weak correlation between medical students' self-ratings and the ratings of faculty members (Arnold, 2002).

Several of the published case reports of assessment in occupational therapy include selfassessment as a key component (Balboa \& Peloquin, 1999; Bossers et al., 1999; Fidler, 1996; Ledet et al., 2005; Randolph, 2003). However, to date researchers in occupational therapy education have not examined the validity of self-assessment or the relationship between selfassessment ratings and ratings provided by faculty.

Reporting and using assessment results. The critical and often overlooked last phase of the assessment process is reporting the assessment results and utilizing results to improve the educational and/or assessment process. If assessment is to improve student learning, the academic program faculty need to compile, review and act on assessment results (Suskie, 2009)

Assessment results should be reported to a variety of internal and external audiences. In occupational therapy, the primary internal audience is the faculty and students of the program. Another possible internal audience is higher administration in the institution. Possible external audiences interested in the results of professional behavior assessments include the Accreditation Council for Occupational Therapy Education (ACOTE), the community advisory board for the OT program, fieldwork sites, employers, and the regional accrediting agency of the institution (Banta, Jones, \& Black, 2009).

After the results have been compiled and reported, they must be acted upon. When assessment results reveal that students are not meeting the established learning objectives then faculty may consider changes in the curriculum, course content, or teaching methods. 
Assessment results can be used to establish the need for further faculty development, additional student learning experiences, or a shifting in the use of resources (Palomba \& Banta, 1999).

It is also necessary to evaluate the assessment plan and implementation. This evaluation may lead to changes including improving assessment tools to increase their reliability or altering assessment activities to decrease time demands. Ledet et al. (2003) provide an excellent example of this. In their article, the authors outline a 12-year process of altering a professional behavior assessment process in response to student and faculty feedback. The authors clearly express the struggle between offering a comprehensive assessment and the time demands placed on faculty (p. 460).

Sharing assessment results with students. Students should receive feedback on their professional behaviors (Kasar, 2000). All of the case examples in occupational therapy detail a process of feedback typified by faculty meeting with students to discuss the results of the assessment. In some models, the meeting is driven by the student's self- assessment. The faculty advisor reviews the self- assessment and contributes feedback or additional comments as he/she sees necessary (Balboa \& Peloquin, 1999; Fidler, 1996; Ledet et al., 2005). Students are asked to support their rankings by providing examples; this model of feedback encourages reflection by the student by asking students to provide examples to support their ratings (Arnold, 2002).

In the second model of professional behavior feedback, the faculty member leads the discussion and focuses on the feedback generated by faculty. The "expert role" of the faculty member emphasized and self-reflection by the student is de-emphasized.

Scheerer (2003) found that students valued the professional behavior assessment meeting as an opportunity to learn what they were doing well and what they could improve on. Students 
emphasized that the face-to-face meeting was important and better than only receiving a satisfactory check in a box on a form. Students expressed concerns about faculty assessing students in a consistent manner with similar criteria. The students also felt that input from Level 1 fieldwork supervisors should be included in the professional assessment completed by faculty members.

Closing the loop: Actions for individual students. In a great majority of professional behavior assessment, students are meeting the expectations of faculty. Typically, students will identify areas for development while meeting with their advisor and then continue in the professional education program without interruption (Gutman et al., 1998; Norcini, 2006).

Students who demonstrate poor professional behavior may be referred to the dean or other academic administrator (Arnold, 2002). Dependent upon the policies of the medical or professional education program the dean may choose further action including probation, suspension, inclusion of professional behavior concern in the Medical Student Performance Evaluation (Dean’s Letter) or removal (Teherani, Hodgson, Banach, \& Papadakis, 2005).

Gutman et al. (1999) discusses the use of professional development plans to address poor professional behavior in students. The professional development plans included additional meetings and advising by faculty and fieldwork supervisors, encouragement of self-reflection and development of professional behavior goals. Randolph (2003) reports possible consequences as professional behavior advisement, remediation plan, probation, or dismissal.

Closing the loop: Actions for the program. Scholars in assessment emphasize that assessment results should be used by educational programs to improve their curriculum and success with students (Suskie, 2009). Banta, Jones, and Black 2009) identify making changes to 
the curriculum, revising individual courses, or adding new services as possible improvements resulting from assessment results (p. 21). Assessment results may also inform changes in the assessment program specifically changes may occur in rubrics, assignment guidelines, test items, and diversifying the tools they utilize (Banta et al., 2009, p 27). In the reports of professional behavior assessment included in this review of the literature no mention was made of how professional behavior assessment results were used to improve or alter educational practices. It seems unlikely that health education programs are unresponsive to assessment results; it is more likely that how the results are used has not been studied extensively.

\section{Carnegie Classification in Occupational Therapy Education}

The Carnegie Classifications of Institutions of Higher Education began in 1970 as a way to describe different institution types for the purpose of research and policy analysis (Carnegie, 2015). The Carnegie classification groups institutions using six categories including: undergraduate instructional program, graduate instructional program, enrollment profile, undergraduate profile, size and setting, and basic classifications.

Within the basic classification, Associates and Baccalaureate institutions focus on undergraduate education. Ninety percent of the degrees awarded at Associated Institutions are at the Associate level. At Baccalaureate institutions fewer than 50 Masters Degrees or 20 doctoral degrees are awarded per year.

At Master’s Colleges and Universities at least 50 Masters Degrees are awarded per year with fewer than 20 doctoral degrees. Masters Colleges and Universities are further divided by size into small, medium, and large. Special Focus institutions award baccalaureate or higher level degrees in a single or set of related fields. The final type of institution type is Doctorate- 
granting universities. Doctoral granting institutions award at least 20 research doctorates per year. Doctoral granting universities are further divided by amount of research activity.

Master's degree level occupational therapy education programs exist at all of the types of institutions listed above. However there is no understanding of how the Carnegie Classification type of the home institution affects the occupational therapy educational program. Studies completed in occupational therapy that examined research productivity (Paul, Liu, \& Ottenbacher, 2002), mentoring in research productivity (Paul, Stein, Ottenbacher, \& Liu, 2002) and scholarship and research in OT education (Gupta \& Bilics, 2014) did not control for or look at the effects of the Carnegie Classification of the institution their participants worked in.

Although the stated purpose of the Classification system is to describe and group similar institutions; as time has passed and competition has increased, the classification system has become viewed as a hierarchy of institutions with the highest rankings of institutions being considered the most desirable (McCormick \& Zhao, 2005; Williams-June, 2015). When the classification was first developed it was intended to group institutions of similar function and characteristics of faculty and students. This classification allowed for researchers to compare and contrast the experiences of students and faculty at different types of institutions. However, as the classification has become a measure of prestige some researchers have discussed a concept of 'mission creep' where time and money spent in activities such as research have become viewed as more prestigious and/or valued so that these type of activities are rewarded at a variety of institutions. Fairweather (1993) found that research and publication were rewarded consistently across institutional types. 
Although research leads to reward in all institution types, faculty workload does appear to differ between institutional types. In describing his research, Levin (2012) reports that there was a difference in the workload between faculty at Research institutions, Masters universities, and Associate colleges. Gutman (1997) and Lee (2007) also found that Carnegie Classification of the institution had significant effect on scholarly activity.

Lusher (2010) surveyed accounting education programs at a variety of Carnegie institution types to look for similarities and differences in various parts of the assessment process by institution type, region, and size. Although she concluded that size of institution appeared to have the greatest effect on assessment of learning practices she did discover some significant differences in the use of graduate follow up studies and retention records in assessment by Carnegie Classification. She also found significant differences by Carnegie Classification in the use of assessment data for resource allocation.

The effects of Carnegie Classification on faculty workload and rewards appear to be understood. The effects of Carnegie Classification on assessment are less understood. Although the effect of institution classification on the work of Occupational Therapy faculty has not been explored it is possible that the workload and reward characteristics at different institutions could affect how faculty members feel about assessment of professional behavior.

\section{Part-Time Faculty in Occupational Therapy Education}

A significant portion of occupational therapy curricula are being taught by part-time faculty. According to the 2013-2014 Academic Program Annual Data Report published by the American Occupational Therapy Association (AOTA, 2014), 42\% of faculty positions in Masters level-entry occupational therapy programs are held by part-time or adjunct faculty 
members. Very little has been published to describe the characteristics or experiences of parttime faculty in occupational therapy education.

Published research in education regarding part-time faculty proposes three profiles of the part-time faculty member. One profile reveals a younger scholar trying to break into academia who might be working part-time at several institutions teaching low-level classes considered less desirable by full-time faculty. This part-time faculty member is often underpaid, poorly supported and not involved fully engaged in the academic department or institution. (Leslie \& Gappa, 2002; Liu \& Zhang, 2007).

The second profile of part-time faculty includes a part-time academic who is employed in industry and teaches to contribute to their profession. This part-time faculty member is often teaching at only one institution and often times is working in an adjunct role only, teaching one class at a time. Involvement in the academic department and institution is decreased due to the multiple demands posed by their 'regular' employment (Hudd, Apgar, Bronson, \& Lee, 2009; Pollart et al., 2015).

The third profile of part-time faculty involved academicians who choose to work parttime as their primary employment. In the literature these part-time faculty are described as mothers seeking flexibility while raising their children or experienced faculty members progressing toward retirement. These part-time faculty members are more engaged in the academic department and institution as their primary employment site (Pollart et al., 2015).

When analyzing the environment of occupational therapy education it is most likely that part-time faculty in OT fall into the last two categories described above. There are only 154 accredited Masters level occupational therapy programs in the United States. Only a few 
metropolitan areas host multiple occupational therapy programs: New York City; Boston; Chicago; and, Los Angeles. Thusly working for more than one occupational therapy program at a time would be the exception. The occupational therapy faculty workforce is primarily female with males representing only $10 \%$ of the workforce according to the 2010 Faculty Workforce survey (AOTA, 2010). The employment market for Occupational therapists is also strong with the Department of Labor projecting faster than average growth of 29\% by 2022 (Department of Labor 2015). These factors when viewed together lend one to believe that part-time faculty in occupational therapy education programs are most likely employed in occupational therapy and serving as adjunct faculty or are parents seeking flexible employment while raising their children. However, it is impossible to confirm these assumptions with the currently available published research.

Educational research on part-time faculty suggests many ways in which they are similar and some ways in which they are different from full-time faculty. Overall researchers have found part-time faculty to be committed motivated teachers (Leslie \& Gappa, 2002). However part-time faculty are more likely to use traditional instructional techniques and less likely to receive awards for teaching (Kozeracki, 2002; Leslie \& Grappa, 2002). Part-time faculty are also less likely to be aware of assessment of learning techniques and often have to be targeted with specific techniques to encourage and enlist their participation in assessment (Suskie, 2009; Zubrow, 2012).

Of particular interested to this research project is the differences between full-time and part-time faculty when it comes to their role and perception in student integrity. Student integrity and professional behavior are both based in ethics. In a published article Hudd, Apgar, Bronson, and Lee (2009) describe the results of their study describing the differences between the views of 
full-time and part-time faculty on issues of cheating, student integrity and faculty role in maintaining integrity. The researchers found that part-time faculty tended to take a slightly more lenient view of the severity of cheating. Part-time faculty members were less likely to address integrity issues in their classroom discussion or syllabi and were more likely to have a slightly more positive view of students and integrity issues on campus than full-time faculty. Assuming there are similarities between the part-time faculty described in educational research and in occupational therapy it is possible that full-time and part-time faculty may differ on their views of the assessment of the professional behavior of students.

\section{Conclusion}

There is an increasing focus on professionalism and professional behavior education and assessment in most health education disciplines. There is a large body of current research, both American and European, addressing the multiple issues associated with the assessment of professional behavior.

Researchers and experts in professionalism in medicine and occupational therapy have described desirable professional behaviors in students and professionals. Within the Physical Therapy literature researchers have examined both the behaviors desired by faculty and the behavior desired by clinical supervisors. These behaviors include consistency, responsibility, communication, professional presence, timeliness, and emotional maturity.

Very few researchers have looked at the reliability and validity of the variety of professional behavior assessment scales and rubrics used in health career educational programs. Studies by Koening et al. (2003) and Hubbard et al. (2007) examined the validity of a professional behavior rating form used at the end of Level 1 and Level 2 fieldwork in 
occupational therapy. Only one study by Kasar (2000) examined the psychometric properties of an assessment form used in the academic portion of the curriculum.

Another question that remains unanswered by researchers in the literature is whether the professional behavior displayed by students in the academic environment is consistent with the behavior observed in the clinical environment. In the field of medical education, Papadakis et al. (2005) have demonstrated that it most likely is. However, there is no similar research in occupational or physical therapy.

The effects of the Carnegie Classification of the institutions that offer occupational therapy education on both the faculty member and the curricula have not been studied to date. Research in other fields has indicated the effects on faculty vary but Carnegie classification may affect some assessment practices.

Although occupational therapy educational program faculty consist of almost 50\% parttime faculty no previous research as looked at how part-time faculty may differ from full-time in their views of students, education, professional behavior, and assessment. Given that many parttime faculty are still working in the clinical environment and are not well integrated into the academic department it is reasonable to expect that they may hold different thoughts and opinions regarding OT education issues.

Occupational Therapy has yet to adopt educational standards that require the assessment of student professional behaviors as part of the academic educational program. Current educational standards only require students to demonstrate knowledge of concepts of professionalism (ACOTE, 2008). Both Medicine and Physical Therapy have increased professionalism expectations in both knowledge and performance. As professionalism is a 
growing concern and as practice of occupational therapy becomes more independent it is reasonable to expect Occupational Therapy to adopt increased professional behavior standards in education in the future. Further research is needed to understand the reliability, validity, and effectiveness of the various types of professional behavior assessment. Additional research is also needed to determine what professional behavior assessment practices OT faculty members think are appropriate and desirable. This research study will survey OT faculty members regarding their opinions and thoughts regarding specific professional behavior assessment practices including, specific behaviors that should be assessed, specific tools that should be used, and how assessment results should be used. The results of this research can serve as the basis of future research and development of professionalism and professional behavior assessment in the profession of OT and will also start to build an understanding of how Carnegie classification and employment status affect the views of faculty members. 


\section{Chapter 3: Methodology}

\section{Overview}

This study used quantitative methods to describe the opinions and thoughts of current OT faculty members in the United States regarding assessment of OT students’ professional behaviors. Participants were sent an e-mail invitation to complete an online survey hosted by Qualtrics to collect information regarding program and faculty demographics, opinions about what professional behaviors should be assessed, and thoughts regarding appropriate professional behaviors assessment practices. Surveys are often used in descriptive studies and, are often concerned with identifying attitudes and preferences (Gay \& Ariason, 2003).

\section{Research Design}

Through the process of the literature review, useful and important practices of professional behavior assessment were discovered. The review identified the wide variety of behaviors that are important for success in the clinic. However, it is unclear what methods faculty members think should be used by occupational therapy programs to assess professional behaviors. It is also unclear what effect if any, institutional type and faculty employment status have on faculty preferences for professional behaviors assessment.

This study was designed to gather descriptive information about the respondents, OT programs, and faculty opinions and thoughts regarding assessment of the professional behaviors of students. Descriptive research is intended to “...document conditions, attitudes, or characteristics...” (Portney \& Watkins, 2000, p. 265). The first research question sought to describe which professional behaviors of students should be assessed. The second research question sought to identify how OT faculty think assessment of professional behaviors should be 
completed. The third research question attempted to determine if there was a difference between the OT faculty members opinions relative to importance of professional behaviors (dependent variable) and faculty members’ Carnegie Classification (independent variable). The fourth research question looked for differences between the dependent variable of faculty members' preferred professional behavior assessment practices based on the same independent variable of Carnegie classification type. Research questions five and six used the independent variable of full or part time employment status as the bases of comparison. The fifth question examined the difference in responses to professional behaviors that should be assessed. The sixth research question utilized preferred assessment practices as the dependent variable.

\section{Population}

This study surveyed the census (1359) of occupational therapy faculty working in OT educational programs in the United States. At the time of this survey there were 154 accredited Masters’ Degree awarding OT educational programs in the United States. Each OT faculty member was invited to complete the survey to increase the number of responses received, to increase probability of receiving a response from each OT program, and to increase validity of the results (Sapsford, 2007).

E-mail addresses for the faculty members were gathered from each occupational therapy educational program website. When compiling the list of e-mail addresses four institutions did not provide e-mail addresses for their faculty through their websites. In this case a request for information was completed via the program website to request e-mail addresses. None of the four programs responded to the request for information. An alternative approach would have been to obtain a central mailing list from the American Occupational Therapy Association (AOTA), but this approach was rejected for two reasons. First, the association only sells mailing 
lists with physical United States Post Service (USPS) addresses and, secondly AOTA is a voluntary membership association, and the percentage of faculty who are members cannot be predicted.

\section{Instrument Development}

The initial survey was developed by the primary researcher. After the initial tool was developed it was reviewed and approved by the prospectus committee. The survey was then validated further by being reviewed by three Ph.D. prepared researchers in educational leadership and physical therapy who were familiar with the development and use of surveys. The survey was then piloted among four occupational therapy faculty familiar with the issues surrounding assessment of student professional behaviors.

Validation of the Instrument. The survey was provided to a Ph.D. prepared assistant professor in Educational Leadership and two Ph.D. prepared professors of physical therapy. All three reviewers had experience in survey research. Feedback from the reviewers was then integrated into the originally proposed survey instrument. Alterations varied from simple grammatical or spelling errors on the online survey to more complex concerns regarding the use of descriptors on the Likert style questions. The concern of greatest note involved a question soliciting the participants’ opinions regarding appropriate consequences of poor professional behavior assessment to the student. The reviewer commented that all of the suggested consequences could be appropriate depending on the severity of the professional behavior problem or issue. This led the researcher to develop a new scale and question, asking the participant to indicate at which level of severity of a professional behavior infraction a particular consequence would be appropriate. 
Piloting of the survey. Acknowledgement of the pilot study of the survey was sought and received from the Institutional Review Board from West Virginia University Office of Research Integrity and Compliance at West Virginia University before completion of the pilot study. Once approval was received an invitation to participate in the pilot study was sent to five occupational therapy faculty members known to the researcher. Of the five invitations four faculty members accepted and completed the online survey and brief phone interview afterwards. See appendix D for the interview questions. All four participants expressed concerns with the faculty workload questions and felt that the researcher would not get the information necessary with the current questions. The questions on the original survey only sought information regarding credit hour responsibility per semester in three types of teaching activities, lecture, lab, and clinical instruction. The pilot study participants expressed that a more accurate indication of workload would be to add questions seeking contact hour commitments per week for lecture and lab instruction. Two pilot study participants also indicated that it would be necessary to seek commitment to online instructional time. Those changes were integrated into the final version of the survey instrument.

All four participants indicated the survey flowed well and that they were able to complete it in 10 minutes or less.

\section{The Instrument}

A quantitative research design consisting of a survey was used to describe the opinions and preferences of occupational therapy faculty members regarding professional behaviors assessment in OT educational programs. This section provides a description of the survey. The survey (see Appendix A) was divided into four sections and consisted of open response and Likert scale items. The answers to the questions in Section A, Program Demographics, provided 
information regarding the Carnegie designation (Carnegie Foundation for the Advancement of Teaching), regional location, age, and size of the education program. Information gained from answers to questions in Section B, Faculty Instructional Workload, were used to describe the respondents and determine the relative workload they experience. The answers from the items in Section C, Assessment of Professional Behaviors, and the answers to the questions in Section D, Using Assessment Results, were used to describe faculty members’ preferences and/or thoughts about appropriate assessment of students’ professional behaviors. The relationship between the survey items and the research questions is shown in Table 3.1

Table 3.1

Relationship between Survey Items and Research Questions

\begin{tabular}{ll}
\hline Research Question & Survey Items \\
\hline OT Program Demographics & $1-6$ \\
OT Faculty Demographics & $7-22$ \\
RQ1 & 24 \\
RQ2 & Items 23, 25-31 \\
RQ3 & Items 1 and 24 \\
RQ4 & Items 1 and 24, 25-31 \\
RQ5 & Items 7 and 24 \\
RQ6 & Items 7 and 24, 25-31 \\
\hline
\end{tabular}

Section A: Program demographics. The first section of the survey solicited information regarding the institution's occupational therapy program. The first question was an open response question asking the respondent to identify their institution. This information was used to assign a Carnegie designation to the survey, and to place the OT program in regional accreditation categories. Carnegie classifications are used to describe institutions of higher learning in the United States (Carnegie Foundation for the Advancement of Teaching, 2012). Occupational therapy programs exist in a variety of institutions (AOTA, 2012) from Research 
Universities/ Very High research activity to Associates Primarily, 4 year. An open response was chosen to address the concern that respondents may not know their basic Carnegie designation or regional category as established by the Associations of Schools and Colleges. The information regarding Carnegie Classification and regional location was used to compare the characteristics of respondents to the known characteristics of the population being surveyed to ensure representativeness of respondents. The information gathered from this question also served as the independent variable for research questions three and four.

Questions two and three were open response and provided information regarding the overall age of the OT educational program, as well as the age of the Master's level program. Participants were asked to indicate the year of their OT educational program establishment and the year of initiation of the Master's level program. The program assessment efforts described in the OT literature associated the development of professional behavior assessment with new, (Fidler, 1996; Bossers et al., 1999) and established OT educational programs (Babola \& Peloquin, 1999; Gutman, McCreedy, \& Heisler, 1998; Ledet, Esparza, \& Peloquin, 2005).

The information from questions four through six helped to identify demographic features of the program that may affect faculty workload. Many authors in occupational therapy have identified professional behavior assessment as a time consuming process (Randolph, 2003; Ledet et al., 2005) and have reported that increasing enrollment has led to changes in professional behavior assessment practices (Randolph, 2003). Question four asked for the number of students enrolled in the degree program. Questions five and six sought information regarding the number of full-time (question 5) and part-time/adjunct faculty (question 6) employed in the program. 
Section B: Faculty and instructional workload characteristics. The second section of the survey solicited information that helped to describe the individual respondents and determine the workload experienced by faculty employed in OT educational programs through a series of open response questions. Survey questions 7, 8, and 9 sought information regarding the faculty status of the respondents, specifically if they were full or part time, faculty rank, and tenure status. Questions 10 through 14 asked respondents for further demographic information including years of experience teaching OT (question 10), age of the faculty member (question 11), gender identity (question 12), OT degree (question 13) and terminal degree (question 14). Question 15 asked for the number of credit hours of lecture-based instruction the faculty member completes per semester and question 16 asked for the number of contact hours per week spent in lecture instruction. Question 17 sought information regarding the number of credit hours of labbased instruction the faculty member completes per semester and question 18 asked for the number of contact hours per week spent in lab instruction. Question 19 asked the participant to identify how many contact hours per week were spent in online instruction. Question 20 asked the respondent to indicate the number of students enrolled in the typical lecture course per semester. Question 21 inquired about the number of students enrolled into a typical lab course section per semester. Finally, in question 22, respondents were asked to indicate how many students they supervise in clinical experiences per semester.

Section C: Professional behavior assessment practices. This section consisted of five questions and helped answer research questions one through six regarding professional behaviors and assessment practices.

Item 23 asked the respondents to indicate their level of agreement with five statements regarding frequency of professional behavior assessment. This item utilized a Likert scale 
(strongly agree, agree, neutral, disagree, and strongly disagree). The respondents were provided statements that suggested professional behavior assessment intervals of each semester, each year, at the end of Level 1 fieldwork, at the end of Level 2 fieldwork, and only if a problem arises. The intervals presented to respondent represented the common intervals discussed by researchers of professional behavior assessment in occupational therapy (Balboa \& Peloquin, 1999; Bossers et al. 1999; Gutman et al., 1998; Hubbard et al., 2007; Koening et al., 2003; Ledet et al., 2005).

Question 24 asked the respondents to indicate how important they thought it was to assess specific student professional behaviors. The participant was presented with a list of behaviors and definitions. They were asked to indicate importance of assessing the behavior on a Likert scale (very unimportant, unimportant, neither important or unimportant, important, and very important). The list of behaviors presented to the respondent was derived from the extensive literature review described in chapter two. Due to the large variety of professional behaviors described by researchers in various articles, the respondents were also provided with four choices of "other” and asked to indicate any additional behaviors they thought should be included in the assessment of students' professional behaviors.

Question 25 asked respondents to indicate the value of specific tools used in professional behaviors assessment. Respondents were presented with a brief list of tools including, rating forms, rubrics, critical incident reports, portfolios, specific items on practical exams, specific items on written quizzes or exams, and other (please indicate). The respondents answered this question by using a Likert scale (very valueless, valueless, neither valueless or valuable, valuable, very valuable). Because some of the terms presented may have been unfamiliar, definitions were provided. The choices of tools presented to the respondents were gathered from 
the research reports of assessment activity in occupational therapy, physical therapy, and medicine, (Arnold, 2002, Bossers et al., 1999; Gutman et al., 1998; Santasier \& Plack; 2007).

Item 26 sought to identify the value of sources of observations that can be included in professional behavior assessment. Using the same Likert scale discussed above, the respondents were presented with the following situations: classroom behavior, laboratory behavior, clinical behavior, performance in group work and activities, performance on practical exams, performance on specific items on written quizzes or exam, social interactions with peers, OT related on-campus extra-curricular activities, attendance at professional conferences, and attendance at professional educational events not hosted by institution. The selected behavior locations included in this question were based on information gleaned from research reports, (Arnold, 2002; Scheerer, 2003) and the primary researcher’s knowledge of OT education.

Item 27 asked respondents how important it was for certain individuals to participate in professional behavior assessment. Respondents were presented with a list of possible participants and are asked to use the same Likert scale used in item 25. The list of possible participants includes full-time faculty, part-time or adjunct faculty, the student (self-assessment), peers, Level 1 fieldwork instructors, Level 2 fieldwork instructors, lab instructors/TAs, program professional or administrative staff, and other.

\section{Section D: Impact of professional behavior assessment on students and OT}

program. The questions in this section focused on how an OT educational program could use assessment results. Specifically it examined how respondents believed the information should be shared, and how the assessment results should be used to improve the programs' efforts. 
Item 28 sought information regarding how faculty members thought information gained from professional behavior assessment should be used in the educational program. Participants were presented with a list of possible statements that represented possible actions regarding the results of professional behavior assessment. The list (see Appendix A) was developed based on the literature review. The faculty members completing the survey were asked to indicate how important they think the actions are using a Likert scale of, very important, important, neither important or unimportant, unimportant, very unimportant.

In item 29, the faculty members are asked to indicate the level of severity of professional behavior infraction that specific consequences would have been appropriate. The respondents were presented with a list of consequences derived from the literature review. The respondents are provided with a Likert style scale of mild, mild to moderate, moderate, moderate to severe, severe, and never appropriate.

Item 30 sought information regarding the respondents’ general opinions regarding the assessment of the professional behaviors of students. Participants were presented with five general statements (See Appendix A) regarding assessment and asked to indicate their agreement with the statements on a Likert scale.

Item 31 was a yes/no item that asked participants to indicate if their Master’s entry-level educational program had a formal process in place to assess the professional behaviors of students.

The final question in the survey was an open comment box that asked the respondent to share any additional comments they had regarding the assessment of professional behaviors in OT students. Because the concepts of professional behavior assessment are not well developed 
in occupational therapy education, the open comment box allowed for capturing additional information not included in the survey.

\section{Data Collection}

This investigation used a survey to gather information about the thoughts and opinions of Occupational therapy faculty members regarding the assessment of OT students’ professional behaviors. The use of the survey allowed for collection of data from a larger sample, in a time and resource efficient manner (Sapsford, 2007, p. 109). The survey was completed electronically and potential participants received an informational letter via e-mail (see Appendix E) with a link to the survey. Using a web-based survey allowed for easy access to the population being surveyed, increased speed of responses, higher response quality, and reduced error in data entry (Hoonakker \& Carayon, 2009). Solicitation for participation was sent to the faculty members' institutional e-mail address to decrease non-deliverability of the message. The subject line read “OT Students' professional behaviors" to increase saliency and to decrease the likelihood of spontaneous deletion of the e-mail without reading the message (Hoonakker \& Carayon, 2009).

Follow - up Procedure. Ten days after the initial e-mail, a reminder e-mail was sent. The follow up e-mail thanked those who have already completed the survey and provide a link to the survey for those who have not completed the survey. After 10 more days, a final second follow-up was e-mailed.

\section{Data Analysis}

Demographics. The first section of the survey was intended to collect demographic information regarding the respondents' institution as well as about the respondents. The 
variables in this section were Carnegie type, age of program, age of master's program, number of students, number of full-time faculty, and number of part-time faculty. The data for these variables were reported using frequencies, and percentages.

The second section of the survey provided demographic information regarding the respondents and their workload. The variables in this section were, employment status, faculty rank, tenure status, number of credit hours spent in lecture, number of contact hours spent in lecture, number of credit hours of lab instruction, number of contact hours spent in lab instruction, number of contact hours spent in online instruction, number of students enrolled in lecture sections, number of students enrolled in lab sections, and number of students supervised in the clinic. The data for these variables were reported using frequencies and descriptive statistics.

1) Research Question 1: What professional behaviors do faculty express should be assessed in Occupational Therapy educational programs in the United States? This question was answered using frequencies, percentages, and medians describing the responses to question 24 .

Research Question 2: How should professional behaviors be assessed in OT educational programs in the United States as expressed by faculty? This question will be answered with descriptive statistics from items regarding assessment practices (questions 23, and 25 through 30). Responses will be reported utilizing frequencies and percentages.

Research Question 3: Is there a significant difference in the responses of faculty from different institutional (Carnegie Classification) in regards to what professional behaviors should be assessed The Carnegie Classification of the respondents' institution was the independent 
variable and the respondents' responses to question 24, importance of specific professional behaviors, was the dependent variables. A Chi-Square was used to look for significant differences. Due to the number of comparisons being completed and the potential for lower sample sizes in some comparison groups there was a risk for Type 1 error; to offset this risk a significance level of .01 was used for all Chi-square tests.

Research Question 4: Is there a significant difference in responses from faculty from different institutional types (Carnegie Classification) in regards to how professional behaviors should be assessed? In this analysis, the Carnegie Classification of the respondents' institutions was the independent variable. A Chi Square was used to compare the respondents' answers to questions regarding assessment practices (Questions 23, and 25 through 30). An alpha level of .01 was used to identify significant differences.

Research Question 5: Is there a significant difference between full-time and parttime faculty responses regarding what professional behaviors should be assessed in OT educational programs? The respondents' employment status with their institution was the independent variable. The dependent variable was the level of importance for professional behaviors the respondents indicated in question 24. A Chi-Square with a significance level of .01 was used to look for a significant difference in responses between full-time and part-time faculty members.

Research Question 6: Is there a significant difference between full-time and parttime faculty responses regarding how professional behaviors should be assessed in OT educational programs? A Chi-Square was used to look for significant differences in responses 
to questions regarding assessment practices (questions 23, and 25 through 30) between full and part-time faculty. The significance level was set at .01 for this comparison also.

Analysis of Question 32. Question 32 was an open-ended response question where respondents provided additional information regarding the assessment of professional behaviors. Information was read by the primary investigator, coded, and organized into categories. The categories are described in the final analysis (Chapter 4). 


\section{Chapter 4: Results}

\section{Participants}

Invitations to participate in the survey were sent to 1,359 Occupational Therapy faculty members utilizing the e-mail list developed by the researcher as described in the methods section. Twenty-nine e-mails were returned as undeliverable from the initial mailing, resulting in a final mailing of 1,330. The primary researcher received six e-mails through the datagathering period from individuals who reported that they had retired or were no longer working in academia. The survey administration software reported that 749 of the original e-mails were opened and of those 552 surveys were initiated. From the opened surveys, 345 participants proceeded beyond the first informational page and completed some or all demographic information. Two hundred ninety-four (294) participants completed the demographic and some or all of professional behavior portions of the survey and were included in the final analysis. This resulted in a response rate of 22\% (294 from 1330 invitations). This response rate is similar to other studies that surveyed the population of occupational therapy faculty (Gupta \& Bilics, 2014; Fazarano \& Zipp, 2012).

\section{Demographics}

\section{Participant characteristics.}

Gender and age. Participants were predominately female with 257 identifying as female and 33 identifying as male; four participants did not identify a gender. The greatest percentage of participants (38.3\%) reported their age in the range of 50 to 59 years of age. The second most reported age range was 40 to 49 years of age (28.3\%). Four participants did not report an age. See Figure 4.1 for further details. When compared to the latest AOTA OT Faculty Workforce 
Survey (2010) participants in this survey closely represent OT educational program faculty in the United States in gender. Participants in this survey were younger than the faculty profile reported in the Workforce Survey. See Table 4.1 for detailed comparison.

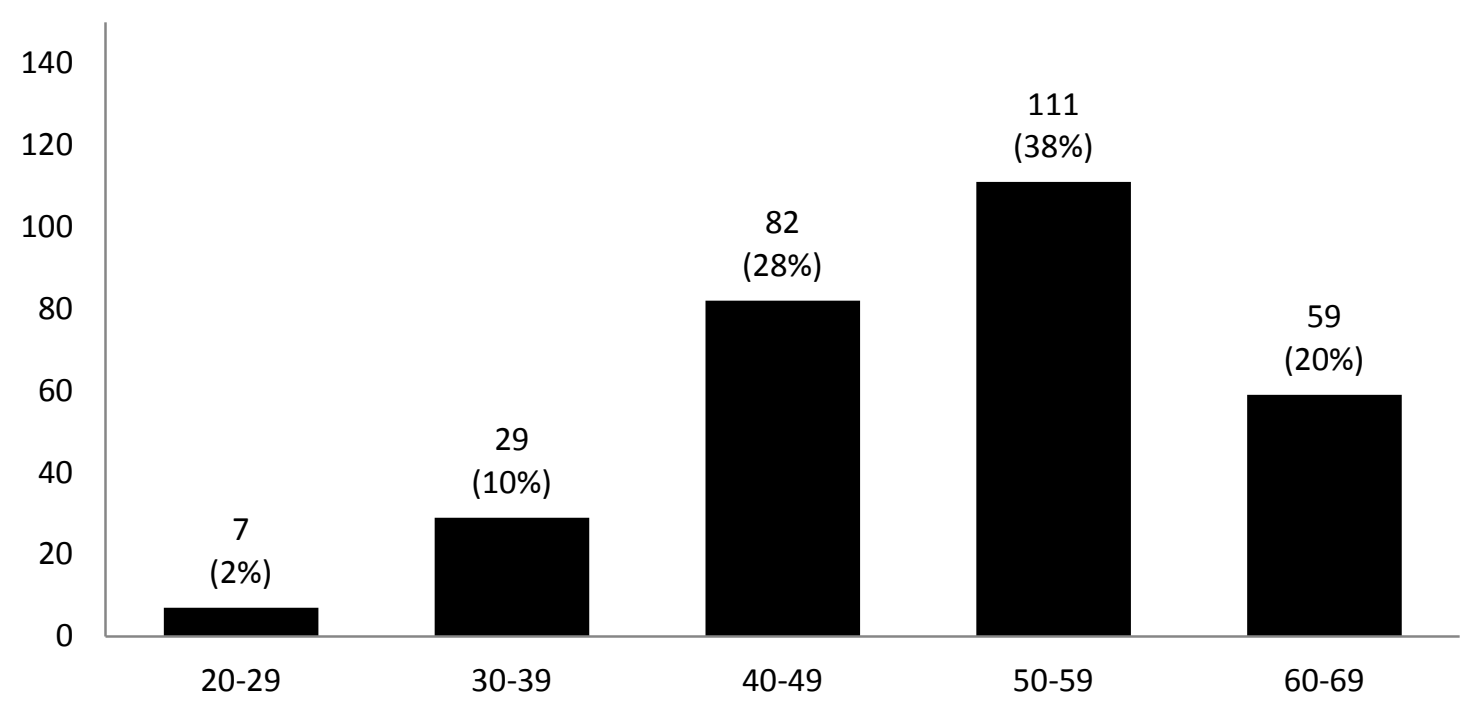

Figure 4.1 Current age of participants $(\mathrm{n}=290)$. 
Table 4.1

Comparison of Gender and Age of Participants to OT Faculty Workforce as a Percentage

$(\mathrm{N}=294)$

\begin{tabular}{lcc}
\hline & Participants in this Survey & AOTA 2010 Faculty Workforce Survey \\
Gender & 87 & 87 \\
Female & 11 & 13 \\
Male & 2 & \\
Did not Identify & & \\
Age in Years & 2 & 0 \\
$20-29$ & 10 & 7 \\
$30-39$ & 28 & 23 \\
$40-49$ & 38 & 55 \\
$50-59$ & 20 & 16 \\
$60-69$ & & \\
\hline
\end{tabular}

Faculty employment status. Most participants (272) were full-time faculty (93.8\%) and 18 (6.1\%) indicated that they were part-time or adjunct faculty. According to the 2013-2014 annual report from the Accreditation council for OT Education (ACOTE) faculty for Masters level OT degree programs are composed of 58\% full-time and 42\% part-time or adjunct faculty (ACOTE, 2014). When compared to this full-time faculty members are over represented in this study. This is most likely due to the method used to create the initial invitation list. Some institutions only list full-time faculty on their websites and part-time and adjunct faculty may be under-reported. It is also possible that part-time faculty might not be inclined to participate in research. Four participants did not indicate their employment status.

Faculty rank and tenure status. Participants were predominately non-tenured, with 29.9 percent reporting they had earned tenure. The other participants reported they were either non- 
tenured, clinical track, or worked at an institution with no tenure availability. Three participants did not report a tenure status. See Figure 4.2 for details.

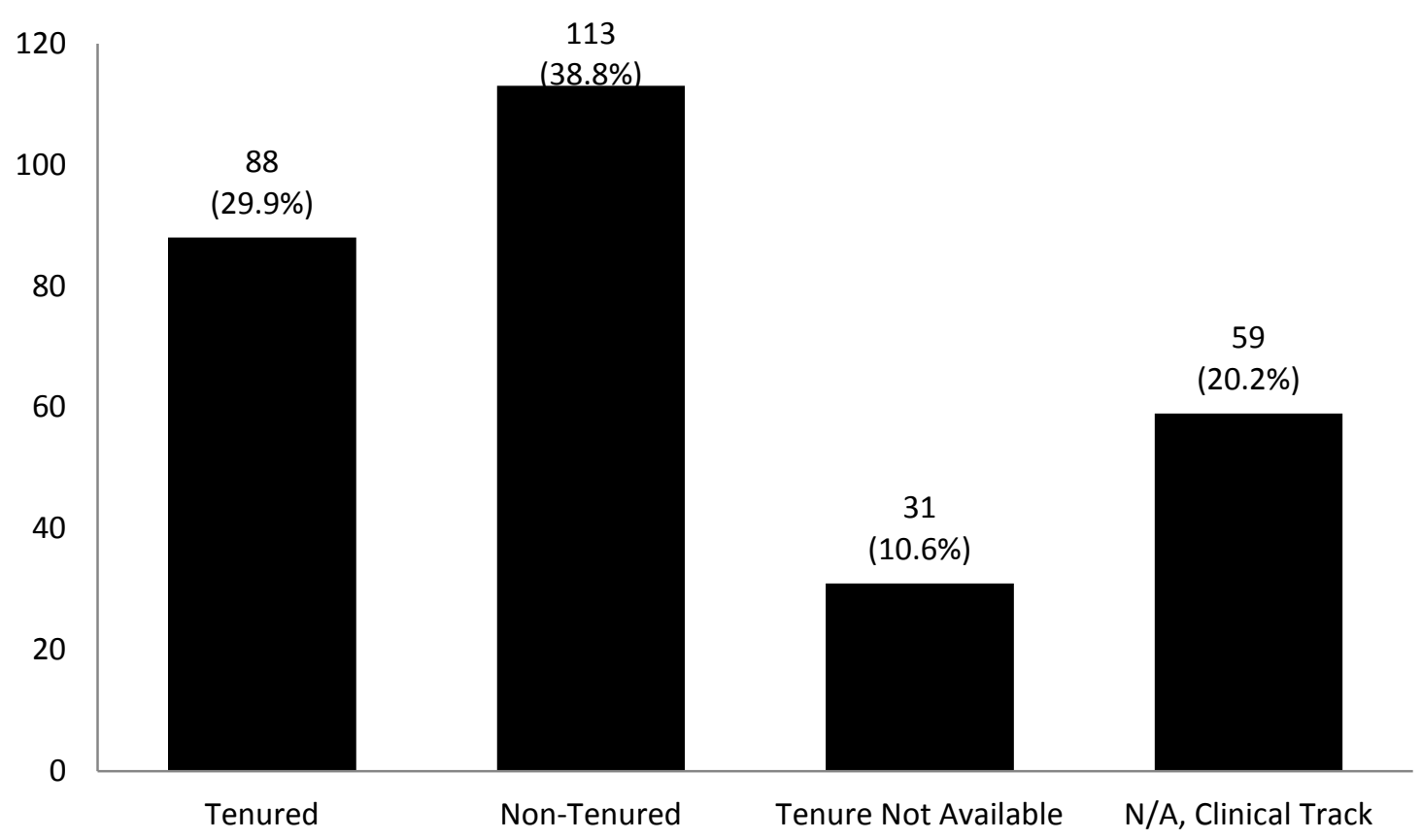

Figure 4.2. Tenure Status of Participants $(\mathrm{n}=291)$.

Faculty rank. The greatest percentage of participants reported a faculty rank of assistant professor (47.8\%) followed by Associate Professor (23.9\%), Full Professor (13.3\%), Instructor (7.8\%), and other (7.2\%). One participant did not report his/her faculty rank. The responses reported in the other category included, Lecturer (6), Adjunct Professor (2), Clinical Associate (2), Clinical Assistant Professor (2), Clinical Associate Professor (1), Clinical Instructor (2), Full Professor and Director (1), Director of Clinical Ed. (1), Master Faculty specialist (1), Professional staff (1), and Academic Fieldwork Coordinator (1). 


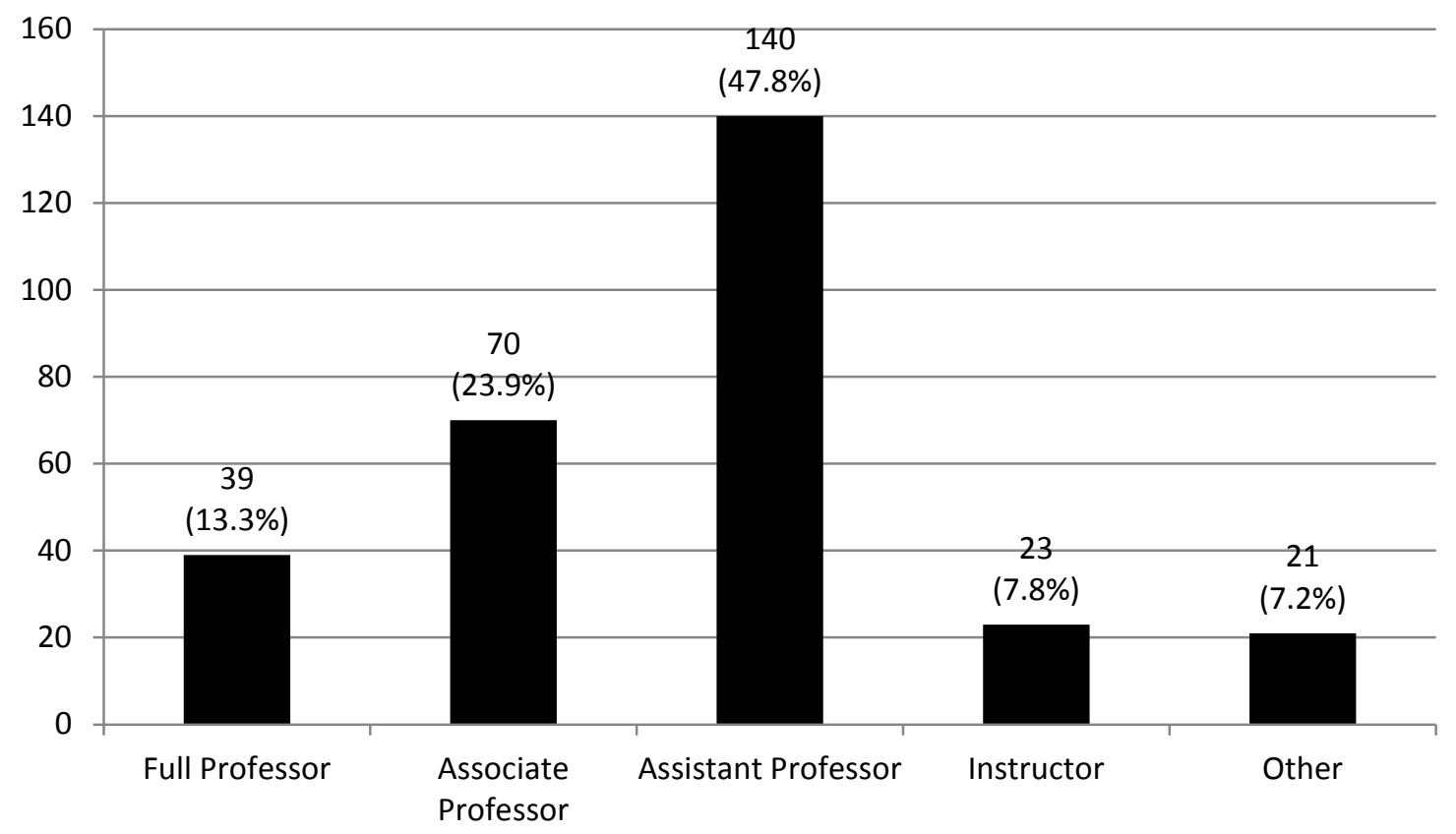

Figure 4.3. Faculty Rank (n=293).

OT teaching experience. The greatest percentage of participants had ten years or less experience teaching in Occupational Therapy (42.3\%). See Figure 4.4 for more detail. 


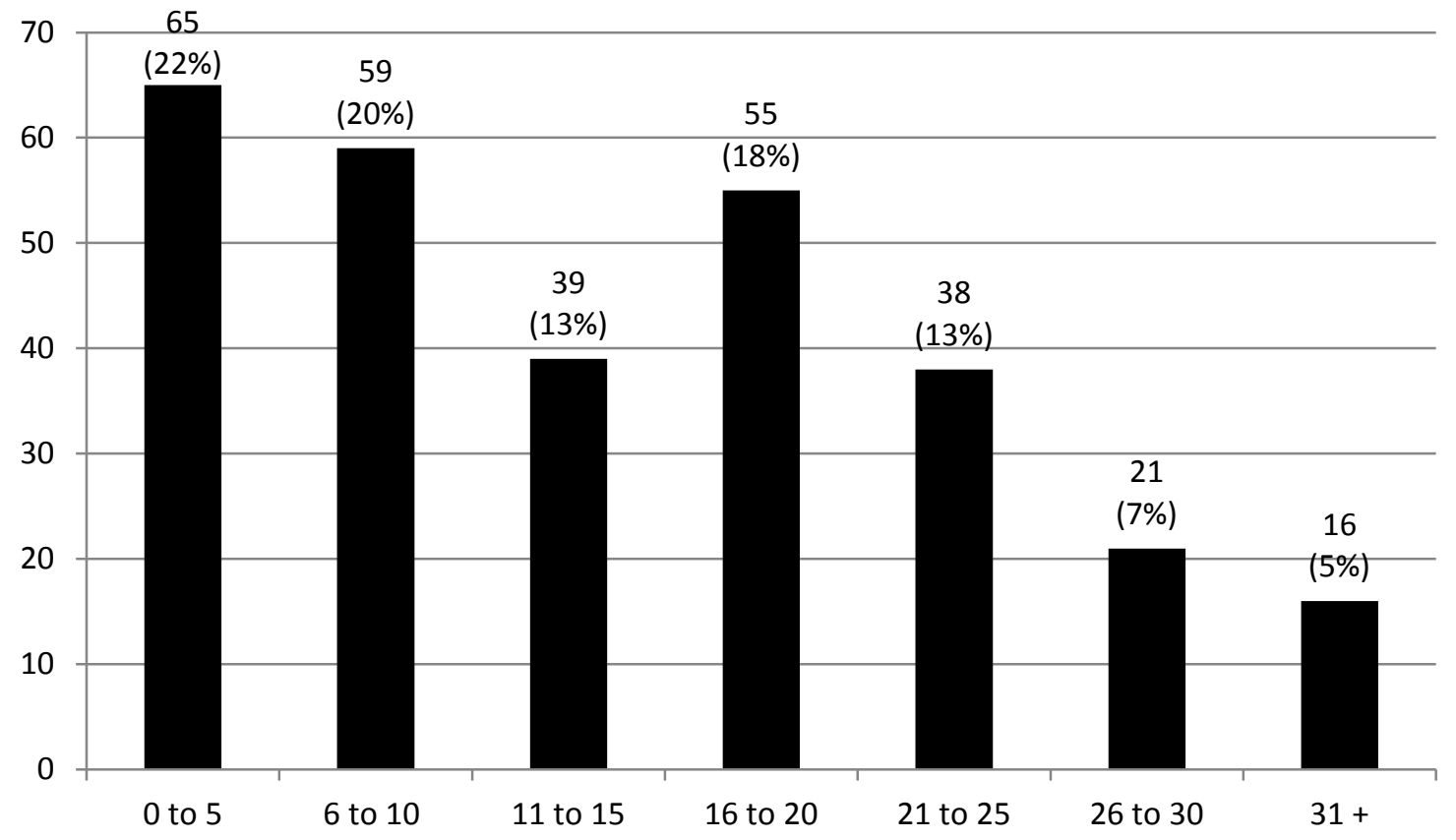

Figure 4.4. Years of Teaching experience $(n=293)$.

Professional OT degree. Most participants reported that they had a Doctoral OT degree (35.9\%) followed by Master’s degree (33.2\%) and Bachelor’s degree (28.3\%). See Figure 4.5 for specific numbers. 


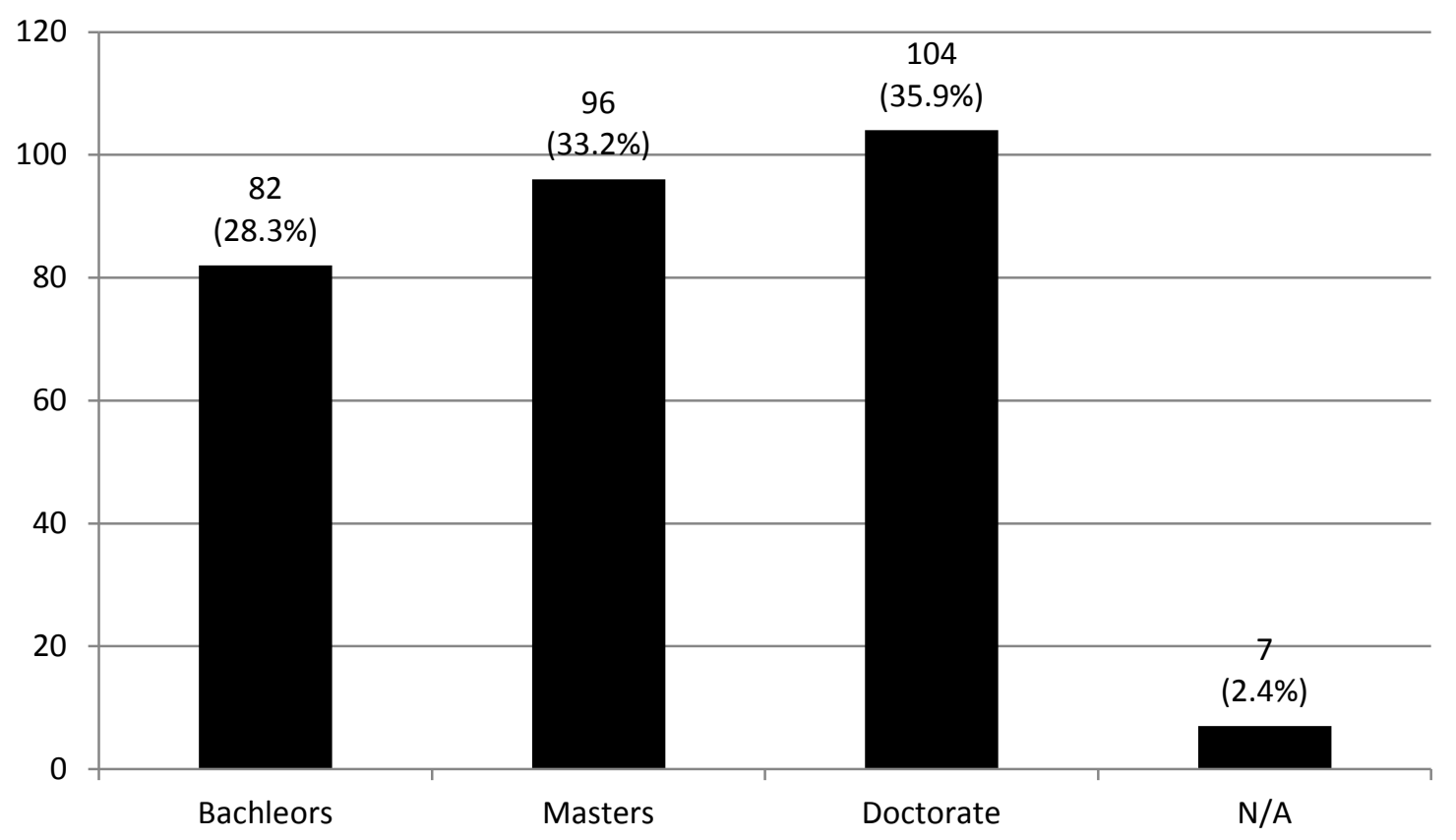

Figure 4.5. Professional degree (n=289).

Terminal degree. Participants in the survey were primarily doctoral degree prepared with 65.9 percent reporting that they held a Ph.D., Ed.D, OTD, or SCD. Thirty-four participants indicated "other” when asked their terminal degree. A review of the degrees reported for the other category revealed four participants in the process of obtaining a Ph.D., two who were “All But Dissertation” (ABD), three with DrOT, two with a MED, and two with a MPH. One participant each indicated they had the following terminal degrees: BS, DHEd, DHS, DHSc, DPT, DSW, JD, MBA, MGA, MHS, MPA, MSOT, and MSW. Four participants did not enter a terminal degree. See Figure 4.6 for a complete breakdown of responses. 


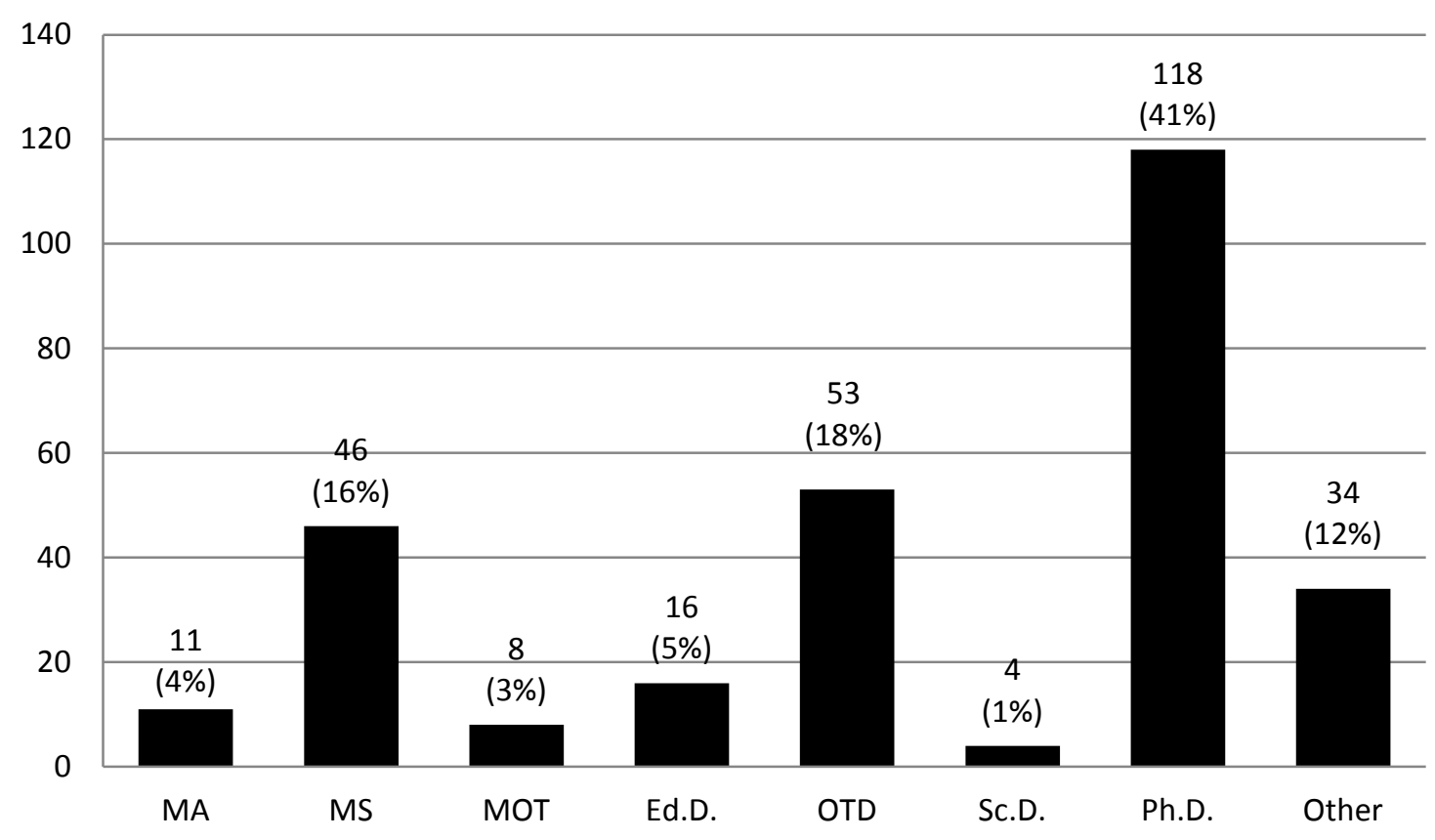

Figure 4.6. Terminal degree $(\mathrm{n}=290)$.

Faculty workload. Participants were asked to report how many credit hours of lecture and lab instruction they were responsible for per semester or term. Some faculty members reported their typical credit hour responsibilities in ranges. This resulted in only 224 valid responses to the question for the initial statistical analysis. Following completion of the initial statistical analysis the researcher examined the data and calculated the median point for entries that included ranges and entered those into the statistical analysis database and ran the descriptive statistics again. Finally an examination of the data revealed one response to the credit hour question that was an outlier. One participant indicated that they were responsible for 128 credit hours of lecture instruction and was removed from the final descriptive analysis. Table 4.2 below reflects the results of the initial and final analysis.

Overall, faculty reported greater lecture credit hour responsibility (mean 6.39 hours) versus lab instruction (mean 3.98 hours). 
Table 4.2

Initial and Final Descriptive Analysis of Credit Hours of Instruction per Semester (N=294)

\begin{tabular}{lcccccc}
\hline \multicolumn{1}{c}{ Variable } & $\mathrm{n}$ & $\mathrm{M}$ & Median & $\mathrm{SD}$ & Min & Max \\
\hline $\begin{array}{l}\text { Lecture Credit Hours } \\
\quad \text { Initial }\end{array}$ & 224 & 6.0 & 5.0 & 9.7 & 0 & 128 \\
$\quad$ Final & 276 & 6.4 & 6.0 & 3.7 & 0 & 21 \\
Lab Credit Hours & & & & & & \\
$\quad$ Initial & 233 & 2.9 & 2.0 & 7.4 & 0 & 64 \\
$\quad$ Final & 261 & 3.4 & 2.0 & 7.3 & 0 & 64 \\
\hline
\end{tabular}

Participants were also asked to report the typical number of contact hours they spent per week in lecture, lab, and online instruction per week. Some participants indicated their normal contact hours in ranges resulting in a decreased number of responses being included in the initial descriptive analysis. After the initial analysis, the researcher adjusted entered data ranges to the median for each range increasing the number of cases included in the final descriptive analysis. Participants reported more of their time being spent in lecture instruction (mean 6.7 hours/week), than in lab instruction (mean= 3.4 hours/week) or in online instruction (mean= 1.8 hours/week). See Figure 4.7 for further detail. 


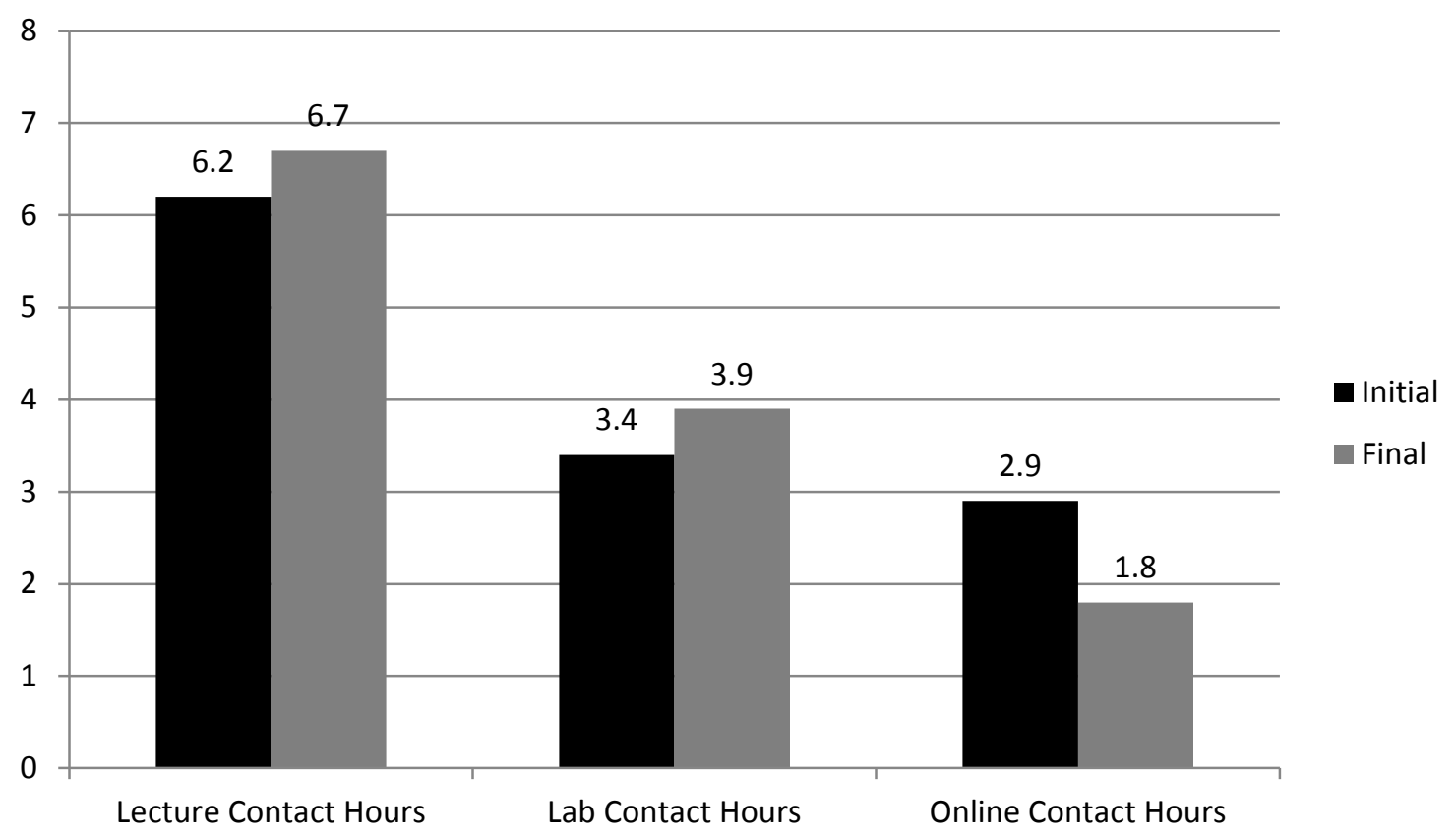

Figure 4.7. Mean Contact hours per week.

Class enrollment. Participants reported the typical enrollment in their lecture and lab sections and how many students they supervised in clinical experiences per term or semester. In the initial descriptive analysis 23 responses in each category of enrollment were invalid or missing because the participant had entered a range. For the final analysis the researcher adjusted the ranges to the median point of the range reported. Overall, participants reported a mean enrollment of 37.2 students in lecture sections, 23.9 students in lab sections, and 13.2 students in clinical supervision. See Table 4.3 below for a detailed results of both the initial and final descriptive analysis. 
Table 4.3

Student Enrollment $(\mathrm{N}=294)$

\begin{tabular}{lcccccc}
\hline & $\mathrm{n}$ & $\mathrm{M}$ & Median & SD & Min & Max \\
\hline $\begin{array}{l}\text { Lecture Enrollment } \\
\text { Initial }\end{array}$ & 249 & 34.4 & 34 & 20.4 & 0 & 180 \\
$\quad$ Final & 272 & 37.2 & 35 & 17.2 & 0 & 180 \\
Lab Enrollment & & & & & & \\
$\quad$ Initial & 231 & 22.1 & 20. & 17.7 & 0 & 120 \\
$\quad$ Final & 253 & 23.9 & 20 & 16.3 & 0 & 120 \\
Clinical Supervision & & & & & & \\
$\quad$ Initial & 235 & 11.0 & .00 & 23.0 & 0 & 135 \\
$\quad$ Final & 258 & 13.2 & 1. & 23.5 & 0 & 135 \\
\hline
\end{tabular}

\section{Program demographics.}

Carnegie classification and regional accreditor. Participants in the survey represented a wide variety of institutional types and regional locations. In Figure 4.8 below the frequency and percentage of institution type is reported. Figure 4.9 demonstrates the regional distribution of participants. When compared to the Carnegie Institution type of OT educational programs listed by AOTA (2010), Bac/Assoc. colleges and Research Universities/high research are over represented while Master’s Medium, Master’s Large, Specialty/Health, and Doctoral institutions are slightly underrepresented. Regionally when compared to data from the 2011-2012 Academic Year Report of the Accreditation Council for Occupational Therapy Education the southern region is over represented this sample while the Middle states, Northwest, and Western regions are under-represented. Please see Table 4.4 for a detailed comparison. 


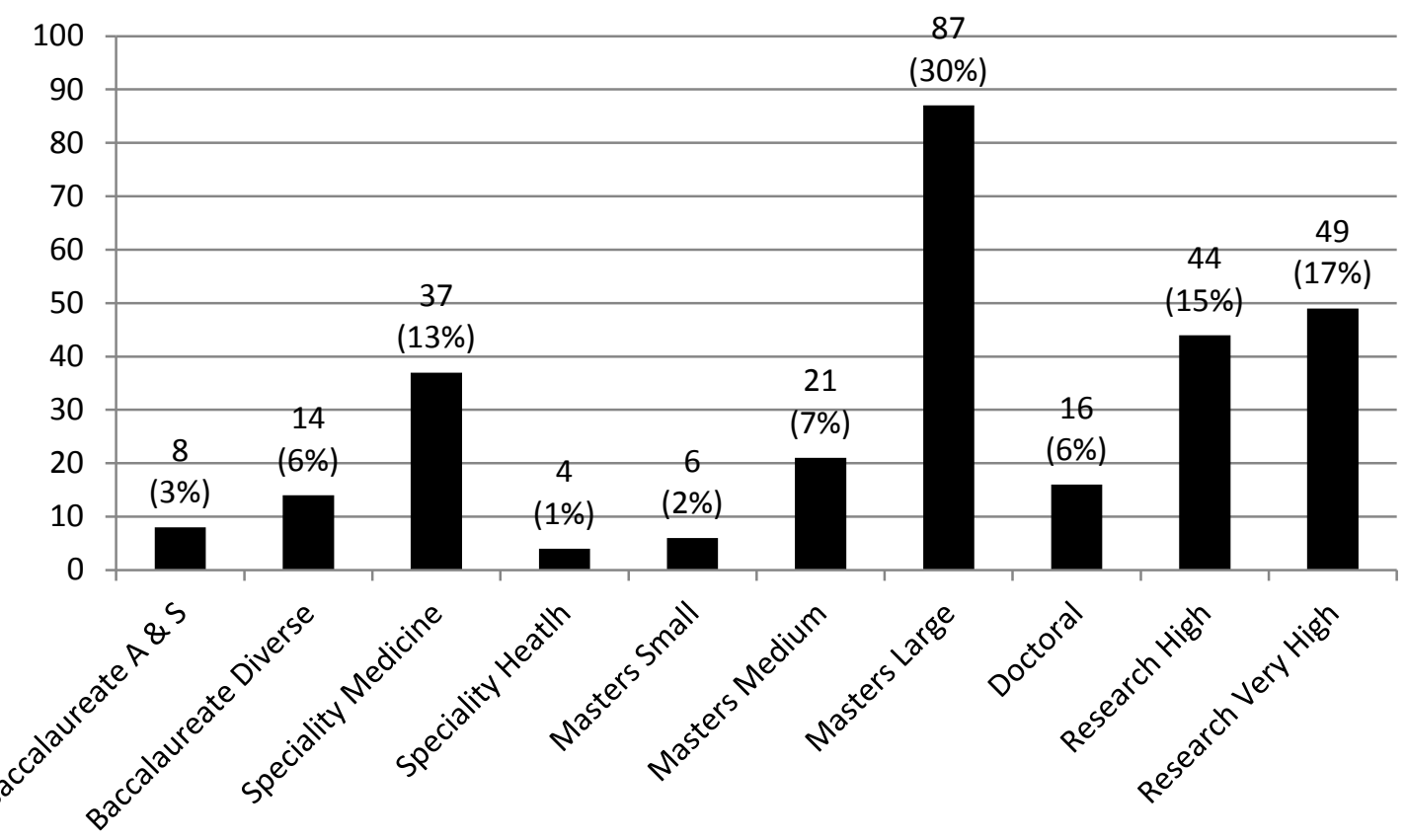

Figure 4.8. Carnegie basic classification of participants' institutions ( $\mathrm{n}=286)$.

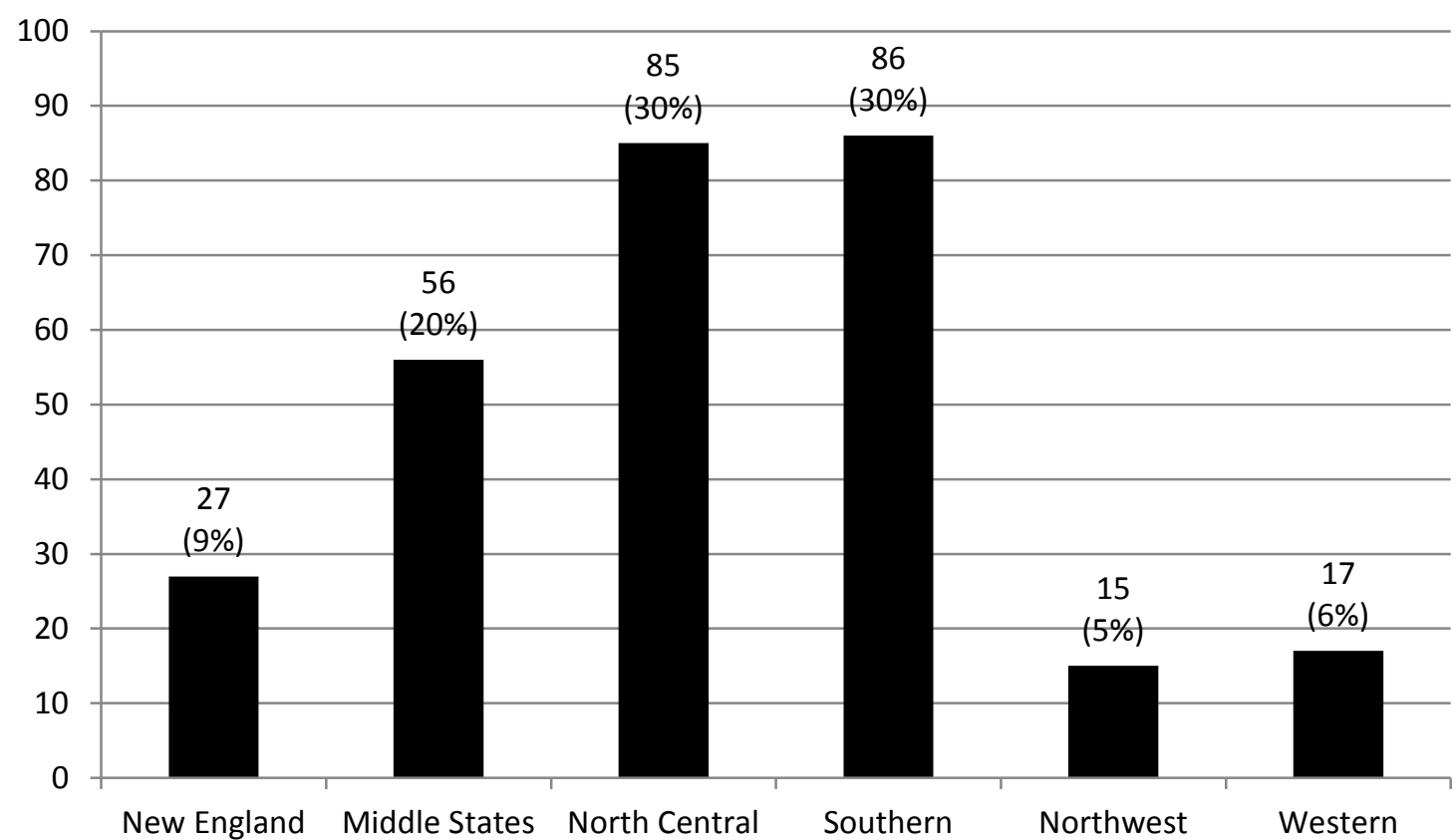

Figure 4.9. Regional accreditor of participants' institutions (n=286). 
Table 4.4

Comparison of Institutional Type and Regional Accreditor of Participants to ACOTE OT Educational Program Data as a Percentage

\begin{tabular}{|c|c|c|}
\hline & Participants in this survey & ACOTE 2010 Data \\
\hline \multicolumn{3}{|l|}{ Institution Type } \\
\hline Bac/Diverse & 6 & 7 \\
\hline Bac/Assoc & 3 & .5 \\
\hline Specialty/Medicine & 13 & 12 \\
\hline Specialty/Health & 1 & 3 \\
\hline Master Small & 2 & 2 \\
\hline Masters Medium & 7 & 9 \\
\hline Masters Large & 30 & 32 \\
\hline Doctoral & 6 & 10 \\
\hline Research High & 15 & 9 \\
\hline Research Very High & 17 & 16 \\
\hline Regional Accreditor & & ACOTE 2011 - 2012 Data \\
\hline New England & 9 & 9 \\
\hline Middle States & 20 & 24 \\
\hline North Central & 30 & 30 \\
\hline Southern & 30 & 25 \\
\hline Northwest & 5 & 4 \\
\hline Western & 6 & 4 \\
\hline
\end{tabular}

Number of students enrolled. Participants reported a range of enrollment in the Masters OT program between zero and four hundred. The mean was 113.9 students with a standard deviation of 65.5 . 
Number of faculty members. Participants reported both full-time and part-time faculty employed in the OT program. The average number of full-time faculty was 9.2 and the average number of part-time faculty was five. See Table 4.5 for further descriptive analysis.

Table 4.5

Number of Faculty Members (N=294)

\begin{tabular}{lllllc}
\hline Variable & $\mathrm{n}$ & $\mathrm{M}$ & $\mathrm{SD}$ & Min & Max \\
\hline Full-Time & 280 & 9.2 & 5.6 & 2 & 70 \\
Part-Time & 267 & 5 & 4.7 & 0 & 35 \\
\hline
\end{tabular}

Age of OT education program and of Masters Education program. Two hundred thirty-one (231) participants provided the year the OT program was established and 226 participants provided the first year their program offered the Master's degree. The age of the program was then calculated by subtracting the founding year from 2014. The mean age of the participants’ programs of was 37 years. The average age of the OT Master’s degree program was 15.8 years. See Table 4.6 for further detail. 
Table 4.6

Age of OT Educational Programs and Master’s Program Age in Years (N=294)

\begin{tabular}{lcccccc}
\hline \multicolumn{1}{c}{ Variable } & $\mathrm{N}$ & $\mathrm{M}$ & Median & SD & Min & Max \\
\hline Program Age & 231 & 37 & 30 & 22.2 & 5 & 109 \\
Master’s Program Age & 226 & 15.8 & 13.5 & 11.1 & 2 & 67 \\
\hline
\end{tabular}

Research Question 1: What professional behaviors do faculty express should be assessed in Occupational Therapy educational programs in the United States?

Participants were asked to indicate how important it is to assess twelve professional behaviors on a five-point scale. Overall most participants identified all of the behaviors as “Important” or “Very Important.” Acceptance and integration of feedback, responsibility for own actions, and clinical reasoning were identified most frequently as "Very important." Enthusiasm, professional appearance, and written communication were identified by participants least frequently as “Very important.” See Table 4.7 for complete ratings. A ranked list of importance was created by adding the number of responses of "Very important" and "Important" to each item. This ranked list is presented in Table 4.8. 
Table 4.7

Importance of Assessing Behavior $(\mathrm{N}=294)$

\begin{tabular}{|c|c|c|c|c|c|}
\hline & $\begin{array}{c}\text { Very } \\
\text { unimportant }\end{array}$ & Unimportant & $\begin{array}{c}\text { Neither } \\
\text { important or } \\
\text { unimportant }\end{array}$ & Important & $\begin{array}{c}\text { Very } \\
\text { important }\end{array}$ \\
\hline $\begin{array}{l}\text { Dependability } \\
(\mathrm{n}=291)\end{array}$ & $3(1 \%)$ & $0(0 \%)$ & $2(1 \%)$ & 85 (29\%) & 201 (69\%) \\
\hline $\begin{array}{l}\text { Timeliness } \\
(\mathrm{n}=290)\end{array}$ & $3(1 \%)$ & $1(.3 \%)$ & $2(.6 \%)$ & 83 (29\%) & 201 (69\%) \\
\hline $\begin{array}{l}\text { Awareness of } \\
\text { Emotions } \\
(n=290)\end{array}$ & $3(1 \%)$ & $0(0 \%)$ & $4(1 \%)$ & 90 (31\%) & 193 (67\%) \\
\hline $\begin{array}{l}\text { Acceptance and } \\
\text { Integration of } \\
\text { Feedback } \\
(n=290)\end{array}$ & $3(1 \%)$ & $0(0 \%)$ & $0(0 \%)$ & 48 (17\%) & 239 (82\%) \\
\hline $\begin{array}{l}\text { Initiative } \\
(n=291)\end{array}$ & $3(1 \%)$ & $0(0 \%)$ & $3(1 \%)$ & $102(35 \%)$ & $183(63 \%)$ \\
\hline $\begin{array}{l}\text { Responsibility } \\
\text { for own } \\
\text { learning } \\
(n=290)\end{array}$ & $3(1 \%)$ & $0(0 \%)$ & $1(.3 \%)$ & 79 (27\%) & 207 (71\%) \\
\hline $\begin{array}{l}\text { Responsibility } \\
\text { for own actions } \\
(n=291)\end{array}$ & $3(1 \%)$ & $0(0 \%)$ & $0(0 \%)$ & 40 (14\%) & 248 (85\%) \\
\hline $\begin{array}{l}\text { Verbal } \\
\text { Communication } \\
(n=291)\end{array}$ & $3(1 \%)$ & $0(0 \%)$ & $0(0 \%)$ & 97 (33\%) & $191(65 \%)$ \\
\hline $\begin{array}{l}\text { Written } \\
\text { Communication } \\
(n=290)\end{array}$ & $3(1 \%)$ & $0(0 \%)$ & $2(1 \%)$ & 120 (41\%) & 165 (57\%) \\
\hline $\begin{array}{l}\text { Professional } \\
\text { Appearance } \\
(n=291)\end{array}$ & $4(1 \%)$ & $0(0 \%)$ & $8(3 \%)$ & 120 (41\%) & 159 (55\%) \\
\hline
\end{tabular}




\begin{tabular}{|c|c|c|c|c|c|}
\hline $\begin{array}{l}\text { Enthusiasm } \\
(n=291)\end{array}$ & $3(1 \%)$ & $0(0 \%)$ & $10(3 \%)$ & 137 (47\%) & $141(48 \%)$ \\
\hline $\begin{array}{l}\text { Clinical } \\
\text { Reasoning } \\
(\mathrm{n}=289)\end{array}$ & $3(1 \%)$ & $0(0) \%$ & 3 (1\%) & 55 (19\%) & 228 (79\%) \\
\hline
\end{tabular}

Table 4.8

Behaviors Ranked by Importance

\begin{tabular}{ll}
\hline Behavior & $\begin{array}{l}\text { No. and (\%) of participants who replied } \\
\text { "Very Important” or "Important" }\end{array}$ \\
\hline Responsibility for own actions & $288(99)$ \\
Verbal Communication & $288(99)$ \\
Acceptance and Integration of & $287(99)$ \\
Feedback & \\
Dependability & $286(98)$ \\
Responsibility for own learning & $286(98)$ \\
Initiative & $285(98)$ \\
Written Communication & $285(98)$ \\
Timeliness & $284(98)$ \\
Clinical reasoning & $283(98)$ \\
Awareness of emotions & $283(98)$ \\
Professional Appearance & $279(96)$ \\
Enthusiasm & $278(95)$ \\
\hline
\end{tabular}

Additional behaviors were identified through an open text box “other” option. The most frequently reported additional behaviors were teamwork (12), ethical behavior (9), respect for others (8), cultural competence (6), leadership (5), and self-awareness (4). 
The following behaviors were mentioned three times: body language, engagement, flexibility, manage technology, organization, professional involvement, therapeutic use of self, and use of social media. Eight behaviors were reported twice: client-centered communication, commitment to learning, confidence, conflict resolution, interdisciplinary collaboration, problem solving, safety, and stress management. Twenty nine behaviors received a single mention and are reported in Figure 4.10 below

\begin{tabular}{|c|c|c|}
\hline $\begin{array}{l}\text { Ability to articulate, } \\
\text { embrace and live the } \\
\text { department mission }\end{array}$ & - Empathy & - Rational judgment \\
\hline $\begin{array}{l}\text { - Ability to communicate } \\
\text { role of OT }\end{array}$ & - Follow procedure & - Reflective listening \\
\hline $\begin{array}{l}\text { - Ability to identify and } \\
\text { utilize problem focused } \\
\text { strategies }\end{array}$ & $\begin{array}{l}\text { - Give constructive } \\
\text { feedback }\end{array}$ & $\begin{array}{l}\text { - Represents OT and } \\
\text { university }\end{array}$ \\
\hline - Advocate & - Goes to research & - Self-monitor \\
\hline - Body awareness & - Intellectual curiosity & - Sense of humor \\
\hline - Classroom discussion & - Managing personal affairs & $\begin{array}{l}\text { - Synthesis and application } \\
\text { of knowledge }\end{array}$ \\
\hline - Cover tattoos & - No gossiping & - Teach others \\
\hline - Critical thinking & - Observation skills & $\begin{array}{l}\text { - Understanding health care } \\
\text { systems }\end{array}$ \\
\hline - Diverse clientele & - Occupational based & $\begin{array}{l}\text { Use wisdom of the mind to } \\
\text { wisely face stress, pain, } \\
\text { and illness }\end{array}$ \\
\hline $\begin{array}{l}\text { - Effectiveness of } \\
\text { relationship }\end{array}$ & $\begin{array}{l}\text { - Personal and professional } \\
\text { boundaries }\end{array}$ & \\
\hline
\end{tabular}

Figure 4.10. Behaviors receiving a single mention by participants.

Research Question 2: How should professional behaviors be assessed in OT educational programs in the United States as expressed by faculty?

\section{Adequacy of professional behavior assessment by OT educational programs.}

Results indicate that faculty members are split on this question. Eighty-one (27.6\%) faculty 
members indicated that they disagreed or strongly disagreed that professional behaviors were being adequately assessed, while sixty-seven (22.9\%) were neutral, and one hundred fifty-five (52.9\%) either agreed or strongly agreed. See Figure 4.11 for specific results.

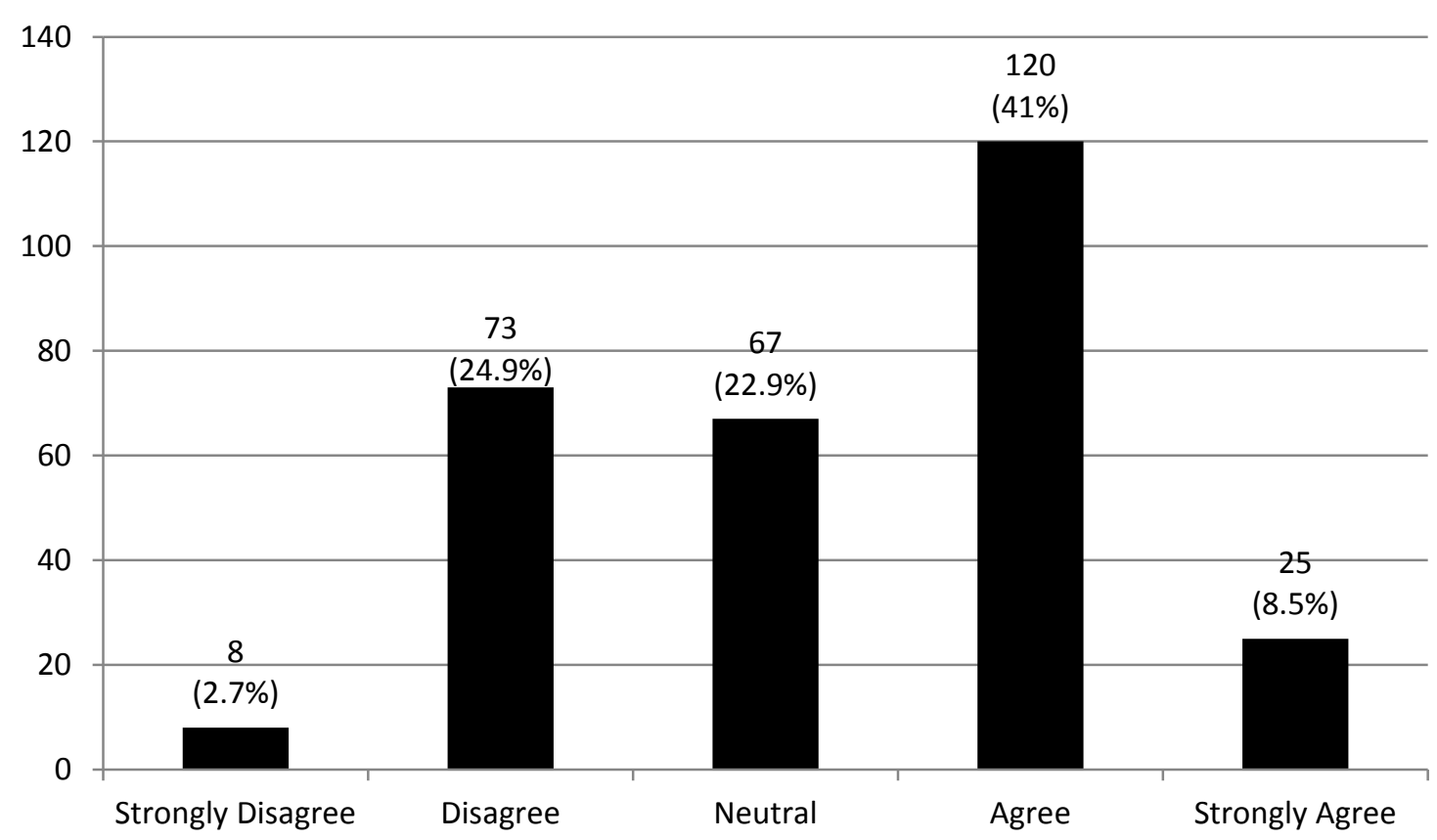

Figure 4.11. Adequacy of current professional behavior assessment $(\mathrm{n}=293)$.

Assessment intervals. Assessing professional fieldwork at the end of Level 1 and Level 2 fieldwork were the most frequently agreed with intervals for assessment. Two hundred seventy-one participants agreed or strongly agreed with assessing professional behavior at the end of Level 1 experiences and 262 participants agreed or strongly agreed with assessment at the end of Level 2 fieldwork. Most participants either disagreed (85) or strongly disagreed (188) with assessing professional behaviors only when there is a problem. See Table 4.9 for detailed results. A ranked list of agreement for assessment interval was created by adding the number of participants who indicated “Agree” or "Strongly agree” those results are presented in Table 4.10. 
Table 4.9

Frequency of Assessment (N=294)

\begin{tabular}{|c|c|c|c|c|c|}
\hline & $\begin{array}{l}\text { Strongly } \\
\text { Disagree }\end{array}$ & Disagree & Neutral & Agree & $\begin{array}{l}\text { Strongly } \\
\text { Agree }\end{array}$ \\
\hline $\begin{array}{l}\text { Every semester or term } \\
(n=293)\end{array}$ & $1(.3 \%)$ & $19(6 \%)$ & $24(8 \%)$ & $104(35 \%)$ & 145 (49\%) \\
\hline Each year $(n=292)$ & $2(.7 \%)$ & $20(7 \%)$ & $21(7 \%)$ & 99 (34\%) & 150 (51\%) \\
\hline $\begin{array}{l}\text { End of Level } 1 \\
\text { fieldwork }(n=292)\end{array}$ & $0(0 \%)$ & $7(2 \%)$ & $14(5 \%)$ & 85 (29\%) & $186(64 \%)$ \\
\hline $\begin{array}{l}\text { End of Level } 2 \\
\text { fieldwork }(n=292)\end{array}$ & $1(.3 \%)$ & $12(4 \%)$ & $17(6 \%)$ & 73 (25\%) & $189(65 \%)$ \\
\hline $\begin{array}{l}\text { Only when there is a } \\
\text { problem }(n=293)\end{array}$ & $188(64 \%)$ & 85 (29\%) & 8 (3\%) & $5(2 \%)$ & 7 (2\%) \\
\hline
\end{tabular}


Table 4.10

Assessment Intervals Ranked by Agreement

\begin{tabular}{lc}
\hline & $\begin{array}{c}\text { No. and \% of participants who indicated } \\
\text { "Strongly Agree” or “Agree” }\end{array}$ \\
\hline End of Level 1 Fieldwork & $271(92 \%)$ \\
End of Level 2 Fieldwork & $262(89 \%)$ \\
Every semester or term & $249(85 \%)$ \\
Each Year & $249(85 \%)$ \\
Only when there is a problem & $12(4 \%)$ \\
\hline
\end{tabular}

Tools of Assessment. Overall, participants identified rating forms, rubrics, and critical incident reports as "Valuable” or "Very valuable” tools in the assessment of professional behaviors. Specific items on written exams were most frequently identified as "Valueless" or “Very valueless” by faculty members. See Table 4.11 for further details. A ranked list of value of the presented assessment tools was also created by adding the number of participants who chose "Very valuable” or "Valuable” for each tool. The ranked list is presented in table 4.12. 
Table 4.11

The Value of Specific Tools for the Assessment of Professional Behavior $(\mathrm{N}=294)$

\begin{tabular}{|c|c|c|c|c|c|}
\hline & $\begin{array}{c}\text { Very } \\
\text { valueless }\end{array}$ & Valueless & $\begin{array}{c}\text { Neither } \\
\text { valueless or } \\
\text { valuable }\end{array}$ & Valuable & $\begin{array}{c}\text { Very } \\
\text { valuable }\end{array}$ \\
\hline $\begin{array}{l}\text { Rating } \\
\text { Form } \\
(n=286)\end{array}$ & $1(.3 \%)$ & $9(3 \%)$ & 37 (13\%) & $188(66 \%)$ & $51(18 \%)$ \\
\hline $\begin{array}{l}\text { Rubric } \\
(n=286)\end{array}$ & $1(.3 \%)$ & $5(2 \%)$ & $29(10 \%)$ & 150 (52\%) & $101(35 \%)$ \\
\hline $\begin{array}{l}\text { Critical } \\
\text { incident } \\
\text { reports } \\
(n=289)\end{array}$ & $0(0 \%)$ & $7(2 \%)$ & 37 (13\%) & $151(52 \%)$ & 94 (33\%) \\
\hline $\begin{array}{l}\text { Portfolio } \\
(n=288)\end{array}$ & $7(2 \%)$ & $26(9 \%)$ & 93 (32\%) & 107 (37\%) & 55 (19\%) \\
\hline $\begin{array}{l}\text { Student } \\
\text { reflection } \\
(n=289)\end{array}$ & $2(.6 \%)$ & 15 (5\%) & 38 (13\%) & 147 (51\%) & 87 (30\%) \\
\hline $\begin{array}{l}\text { Practical } \\
\text { Exam items } \\
(n=286)\end{array}$ & 12 (4\%) & $30(10 \%)$ & 93 (33\%) & 111 (39\%) & $40(14 \%)$ \\
\hline $\begin{array}{l}\text { Written } \\
\text { exam items } \\
(n=279)\end{array}$ & $18(6 \%)$ & 48 (17\%) & 124 (44\%) & 77 (28\%) & $12(4 \%)$ \\
\hline
\end{tabular}


Table 4.12

Assessment Tools Ranked by Value

\begin{tabular}{lc}
\hline & $\begin{array}{l}\text { No. and \% of participants who } \\
\text { chose "Very valuable” or } \\
\text { "Valuable” }\end{array}$ \\
\hline Rubric & $251(87 \%)$ \\
Critical incident reports & $245(84 \%)$ \\
Rating form & $239(83 \%)$ \\
Student reflection & $234(80 \%)$ \\
Portfolio & $162(56 \%)$ \\
Practical exam items & $151(52 \%)$ \\
Written exam items & $89(31 \%)$ \\
\hline
\end{tabular}

Participants were provided with a text box to indicate other tools that they felt were valuable. A total of 24 other tools were identified by participants. These included: advising sessions (5), peer feedback (3), direct observation of student behavior in clinic and classroom (2), clinical simulations (1), electronic rating form (1), Fieldwork Education Assessment Tool (FEAT) (1), fieldwork feedback (1), group debriefing after clinical experiences (1), hands-on skills (1), mentored experiences (1), Problem-Based Learning (1), percentage of course grade (1) pre-service feedback (1), role playing (1), self-assessment form (1), standardized patient videos (1), and video recording and self-reflection (1).

Observations to include in assessment. Participants were asked to indicate the value of including observations of student behavior in different situations in the assessment of professional behavior. All participants responded that observations of clinical behavior were 
“Valuable” or "Very valuable.” Performance on specific written exam items was most frequently identified as "Valueless" or "Very valueless” by participants. See Table 4.13 for detailed frequencies. A rank order of the tools presented was created by adding the number of participants who chose "Very valuable" or "Valuable" in response to the question. The rank order of value is presented in table 4.14 . 
Table 4.13

Value of Observations of Student Behavior $(\mathrm{N}=294)$

\begin{tabular}{|c|c|c|c|c|c|}
\hline & $\begin{array}{c}\text { Very } \\
\text { valueless }\end{array}$ & Valueless & $\begin{array}{c}\text { Neither valueless } \\
\text { or valuable }\end{array}$ & Valuable & $\begin{array}{c}\text { Very } \\
\text { valuable }\end{array}$ \\
\hline $\begin{array}{l}\text { Classroom Behavior } \\
(\mathrm{n}=289)\end{array}$ & $0(0 \%)$ & $2(.7 \%)$ & $9(3 \%)$ & $167(58 \%)$ & $111(38 \%)$ \\
\hline $\begin{array}{l}\text { Laboratory Behavior } \\
(\mathrm{n}=288)\end{array}$ & $0(0 \%)$ & $1(.3 \%)$ & $8(3 \%)$ & $123(43 \%)$ & $156(54 \%)$ \\
\hline $\begin{array}{l}\text { Clinical Behavior } \\
(\mathrm{n}=288)\end{array}$ & $0(0 \%)$ & $0(0 \%)$ & $0(0 \%)$ & 35 (12\%) & $253(88 \%)$ \\
\hline $\begin{array}{l}\text { Group Work } \\
(\mathrm{n}=289)\end{array}$ & $0(0 \%)$ & $0(0 \%)$ & $6(2 \%)$ & $124(43 \%)$ & $159(55 \%)$ \\
\hline Practical Exams (n=288) & $2(.7 \%)$ & $7(2 \%)$ & $41(14 \%)$ & $155(54 \%)$ & 83 (29\%) \\
\hline $\begin{array}{l}\text { Performance on written } \\
\text { exam items }(n=289)\end{array}$ & $8(3 \%)$ & $29(10 \%)$ & $121(42 \%)$ & $111(38 \%)$ & $20(7 \%)$ \\
\hline $\begin{array}{l}\text { Social Interactions with } \\
\text { peers }(n=288)\end{array}$ & $2(.7 \%)$ & $6(2 \%)$ & $44(15 \%)$ & $151(52 \%)$ & $85(30 \%)$ \\
\hline $\begin{array}{l}\text { OT related } \\
\text { extracurricular }(n=289)\end{array}$ & $2(.7 \%)$ & $6(2 \%)$ & $78(27 \%)$ & $143(49 \%)$ & $60(21 \%)$ \\
\hline $\begin{array}{l}\text { Professional Conference } \\
(n=289)\end{array}$ & $1(.3 \%)$ & $6(2 \%)$ & $71(25 \%)$ & $140(48 \%)$ & $71(25 \%)$ \\
\hline $\begin{array}{l}\text { Non-institution } \\
\text { Continuing Education } \\
(\mathrm{n}=289)\end{array}$ & $1(.3 \%)$ & $8(3 \%)$ & $78(27 \%)$ & $142(49 \%)$ & $60(21 \%)$ \\
\hline
\end{tabular}


Table 4.14

Observations of Student Behavior Ranked by Value

\begin{tabular}{lc}
\hline & $\begin{array}{c}\text { No. and \% of participants who chose "Very } \\
\text { valuable” or "Valuable” }\end{array}$ \\
\hline Clinical Behavior & $288(100 \%)$ \\
Group Work & $283(97 \%)$ \\
Classroom Behavior & $279(96 \%)$ \\
Laboratory Behavior & $279(96 \%)$ \\
Practical exams & $238(82 \%)$ \\
Social interactions with peers & $236(81 \%)$ \\
Professional conferences & $211(73 \%)$ \\
OT related extra-curricular & $203(70 \%)$ \\
Non-institutional continuing & $202(70 \%)$ \\
education & \\
Performance on written exam & $131(45 \%)$ \\
items & \\
\hline
\end{tabular}

Individuals who should participate in the assessment of professional behavior.

Participants felt that the participation of full-time faculty in the assessment of student professional behavior was “Important” (21\%) or "Very important” (78\%). There was strong agreement that it was “Important” (21\%) or "Very important” (79\%) for level 2 fieldwork instructors to also participate. Self-reflection by students was also considered “Important” (27\%), or "Very important” (69\%) by participants. Participants were most split on the importance of peer participation in the assessment process with $4 \%$ feeling that is was "Very unimportant” or "Unimportant”, 27\% feeling it was neither unimportant nor important and 69\% feeling that is was "Important” or "Very important.” Table 4.15 contains the complete results; 
Table 4.16 contains the results ranked by the number of participants who indicated that the individual was "Very important” or "Important."

Table 4.15

Participants in Professional Behavior Assessment (N=294)

\begin{tabular}{|c|c|c|c|c|c|}
\hline & $\begin{array}{l}\text { Very } \\
\text { unimportant }\end{array}$ & Unimportant & $\begin{array}{l}\text { Neither unimportant } \\
\text { or important }\end{array}$ & Important & $\begin{array}{l}\text { Very } \\
\text { Important }\end{array}$ \\
\hline $\begin{array}{l}\text { Full-time } \\
\text { faculty }(n=291)\end{array}$ & $1(.3 \%)$ & $0(0 \%)$ & $2(.7 \%)$ & $61(21 \%)$ & 227 (78\%) \\
\hline $\begin{array}{l}\text { Part-time or } \\
\text { Adjunct } \\
(n=291)\end{array}$ & $0(0 \%)$ & $2(.7 \%)$ & 17 (6\%) & $\begin{array}{c}137 \\
(47 \%)\end{array}$ & 135 (46\%) \\
\hline Student $(\mathrm{n}=291)$ & $1(.3 \%)$ & $0(0 \%)$ & $10(3 \%)$ & 79 (27\%) & 201 (69\%) \\
\hline Peers $(n=291)$ & $1(.3 \%)$ & $13(4 \%)$ & 78 (27\%) & $\begin{array}{c}145 \\
(50 \%)\end{array}$ & 54 (19\%) \\
\hline $\begin{array}{l}\text { Level } 1 \\
\text { Fieldwork } \\
\text { instructors } \\
(n=291)\end{array}$ & $0(0 \%)$ & $0(0 \%)$ & $2(.7 \%)$ & $91(31 \%)$ & 198 (68\%) \\
\hline $\begin{array}{l}\text { Level } 2 \\
\text { Fieldwork } \\
\text { instructors } \\
(\mathrm{n}=289)\end{array}$ & $0(0 \%)$ & $0(0 \%)$ & $0(0 \%)$ & 61 (21\%) & 228 (79\%) \\
\hline $\begin{array}{l}\text { Lab Instructors/ } \\
\text { TAs }(n=289)\end{array}$ & $1(.6 \%)$ & $4(1 \%)$ & $26(9 \%)$ & 17 (6\%) & 131 (45\%) \\
\hline $\begin{array}{l}\text { Program } \\
\text { Professional } \\
\text { Staff }(n=288)\end{array}$ & $2(.7 \%)$ & 15 (5\%) & $68(24 \%)$ & $\begin{array}{c}122 \\
(42 \%)\end{array}$ & $81(28 \%)$ \\
\hline
\end{tabular}


Table 4.16

Participants in Assessment Ranked Importance

\begin{tabular}{ll}
\hline Participant & $\begin{array}{l}\text { \# and \% of Participants who indicated "Very } \\
\text { important” or “Important” }\end{array}$ \\
\hline Level 2 Fieldwork instructors & $289(100 \%)$ \\
Level 1 Fieldwork instructors & $289(99 \%)$ \\
Full-Time faculty & $288(99 \%)$ \\
Student & $280(96 \%)$ \\
Part-Time or Adjunct & $272(93 \%)$ \\
Program professional staff & $203(70 \%)$ \\
Peers & $199(68 \%)$ \\
Lab instructors/ TAs & $148(51 \%)$ \\
\hline
\end{tabular}

Use of assessment results. Participants most frequently identified advising individual students, determining effectiveness of instruction, and changing the professional behavior assessment plan as “Important” or "Very important” uses of assessment results. Compiling the results to reflect group performance was most frequently identified as “Neither unimportant or important,” "Unimportant,” or “Very unimportant” by faculty members. Table 4.17 demonstrates the full detailed results and table 4.18 demonstrates the results ranked by number of participants who indicated "Very important” or "Important." 
Table 4.17

Use of Professional Behavior Assessment Results ( $N=294)$

\begin{tabular}{|c|c|c|c|c|c|}
\hline & $\begin{array}{c}\text { Very } \\
\text { unimportant }\end{array}$ & Unimportant & $\begin{array}{c}\text { Neither } \\
\text { unimportant } \\
\text { or important }\end{array}$ & Important & $\begin{array}{c}\text { Very } \\
\text { important }\end{array}$ \\
\hline $\begin{array}{l}\text { Compiled to reflect } \\
\text { group performance } \\
(\mathrm{n}=285)\end{array}$ & $12(4 \%)$ & 49 (17\%) & 87 (30\%) & $116(40 \%)$ & $21(7 \%)$ \\
\hline $\begin{array}{l}\text { Advise individual } \\
\text { students }(\mathrm{n}=286)\end{array}$ & $0(0 \%)$ & $0(0 \%)$ & $1(.3 \%)$ & 79 (28\%) & $\begin{array}{c}206 \\
(72 \%)\end{array}$ \\
\hline $\begin{array}{l}\text { Compiled and shared } \\
\text { with faculty }(n=284)\end{array}$ & $0(0 \%)$ & $10(4 \%)$ & 48 (17\%) & 153 (54\%) & 73 (26\%) \\
\hline $\begin{array}{l}\text { Determine effectiveness } \\
\text { of current instruction } \\
(\mathrm{n}=284)\end{array}$ & $0(0 \%)$ & $0(0 \%)$ & $13(5 \%)$ & $148(52 \%)$ & $\begin{array}{c}123 \\
(43 \%)\end{array}$ \\
\hline $\begin{array}{l}\text { Lead to changes in } \\
\text { curriculum }(n=286)\end{array}$ & $0(0 \%)$ & $3(1 \%)$ & 43 (15\%) & 141 (50\%) & 99 (35\%) \\
\hline $\begin{array}{l}\text { Changes in professional } \\
\text { behavior assessment } \\
\text { plan }(n=286)\end{array}$ & $0(0 \%)$ & $0(0 \%)$ & $13(5 \%)$ & $122(43 \%)$ & $\begin{array}{c}151 \\
(53 \%)\end{array}$ \\
\hline $\begin{array}{l}\text { Results included in the } \\
\text { Program assessment or } \\
\text { evaluation plan }(n=285)\end{array}$ & $1(.4 \%)$ & $5(2 \%)$ & 38 (13\%) & $131(46 \%)$ & $\begin{array}{c}110 \\
(39 \%)\end{array}$ \\
\hline $\begin{array}{l}\text { Inform faculty } \\
\text { professional } \\
\text { development }(n=281)\end{array}$ & $2(.7 \%)$ & $4(1 \%)$ & 39 (14\%) & 135 (48\%) & $\begin{array}{c}101 \\
(36 \%)\end{array}$ \\
\hline
\end{tabular}


Table 4.18

Uses of Assessment Ranked by Importance

\begin{tabular}{lc}
\hline & $\begin{array}{l}\text { No. and \% of participants who } \\
\text { answered “Very important” or } \\
\text { "Important” }\end{array}$ \\
\hline Advise individual students & 285 (99\%) \\
Determine effectiveness of current instruction & 271 (95\%) \\
Changes in professional behavior assessment plan & 273 (95\%) \\
Results included in the program assessment or & 241 (85\%) \\
evaluation plan & 240 (84\%) \\
Lead to changes in the curriculum & $236(84 \%)$ \\
Inform faculty professional development & $226(79 \%)$ \\
Compiled and shared with faculty & 137 (48\%) \\
Compiled to reflect group performance & \\
\hline
\end{tabular}

Student consequences of professional behavior issues. Participants were presented with a list of possible consequences of professional behavior issues. They were then asked to indicate at what level of professional behavior infraction they felt the consequence would be appropriate. For “Mild” infractions “No consequences” was the most frequently indicated followed by counseling with faculty advisor. Participants were strongly aligned regarding dismissal from the program with $75 \%$ feeling that it was appropriate only in cases of severe professional behavior infractions. Professional behavior development plans were indicated as appropriate most frequently for professional behavior infractions ranging from "Mild to moderate” to "Moderate to severe.” Counseling with faculty advisor was chosen most frequently for infractions ranging from “Mild” to "Moderate." A majority of participants indicated that 
program probation was only appropriate in "Moderate to severe" or "Severe” infractions. See

Table 4.19 for complete results.

Table 4.19 Student Consequences of Poor Professional Behavior (N=294)

\begin{tabular}{|c|c|c|c|c|c|c|}
\hline & Mild & $\begin{array}{l}\text { Mild to } \\
\text { moderate }\end{array}$ & Moderate & $\begin{array}{l}\text { Moderate } \\
\text { to severe }\end{array}$ & Severe & Never \\
\hline Program probation (283) & $5(2 \%)$ & $10(4 \%)$ & $35(12 \%)$ & $104(37 \%)$ & 125 (44\%) & $4(1 \%)$ \\
\hline $\begin{array}{l}\text { Counseling with faculty } \\
\text { advisor }(n=284)\end{array}$ & $\begin{array}{c}60 \\
(21 \%)\end{array}$ & 108 (38\%) & 83 (29\%) & 25 (9\%) & $8(3 \%)$ & $0(0 \%)$ \\
\hline $\begin{array}{l}\text { Professional Behavior } \\
\text { development plan } \\
(\mathrm{n}=285)\end{array}$ & $11(4 \%)$ & $63(22 \%)$ & $114(40 \%)$ & $81(28 \%)$ & $15(5 \%)$ & $1(.3 \%)$ \\
\hline $\begin{array}{l}\text { Decrease in course grade } \\
(\mathrm{n}=284)\end{array}$ & $16(6 \%)$ & $43(15 \%)$ & $88(31 \%)$ & 88 (31\%) & $36(13 \%)$ & $13(5 \%)$ \\
\hline $\begin{array}{l}\text { Delayed progression in } \\
\text { program } \\
(\mathrm{n}=282)\end{array}$ & $4(1 \%)$ & $8(3 \%)$ & 27 (10\%) & 107 (38\%) & 129 (46\%) & 7 (2\%) \\
\hline $\begin{array}{l}\text { Delayed entry into } \\
\text { fieldwork experiences } \\
(n=282)\end{array}$ & 7 (2\%) & $10(4 \%)$ & $36(13 \%)$ & 117 (41\%) & 107 (38\%) & $5(2 \%)$ \\
\hline $\begin{array}{l}\text { Termination from OT } \\
\text { program }(n=281)\end{array}$ & 8 (3\%) & $2(.7 \%)$ & $10(4 \%)$ & 38 (14\%) & 212 (75\%) & $11(4 \%)$ \\
\hline $\begin{array}{l}\text { No consequences } \\
(n=263)\end{array}$ & $\begin{array}{c}87 \\
(33 \%)\end{array}$ & $2(.7 \%)$ & $5(2 \%)$ & $0(0 \%)$ & $1(.3 \%)$ & 168 (64\%) \\
\hline
\end{tabular}

\section{General opinions regarding assessment of professional behaviors of students.}

Participants in this study agreed that OT educational programs should assess the professional behaviors of students with 68\% “Strongly agreeing” and 30\% “Agreeing.” Participants did 
express concerns that faculty are not consistent in rating the behaviors of students with 32\%

“Disagreeing”, 24\% “Neutral” and only 35\% “Agreeing” with the statement "Faculty

consistently rate the professional behaviors of the same student.” Participants indicated they did not believe that OT students valued professional behavior assessment with $61 \%$ indicating that they were "Neutral”, “Disagreed”, or "Strongly disagreed” with the statement. More detailed results are shown in Table 4.20.

Table 4.20

General Opinions of Participants Regarding Assessment of Professional Behavior. (N=294)

\begin{tabular}{lccccc}
\hline & $\begin{array}{l}\text { Strongly } \\
\text { disagree }\end{array}$ & Disagree & Neutral & Agree & $\begin{array}{l}\text { Strongly } \\
\text { agree }\end{array}$ \\
\hline $\begin{array}{l}\text { Faculty value assessment of } \\
\text { professional behaviors (n=284) }\end{array}$ & $4(1 \%)$ & $\begin{array}{c}35 \\
(12 \%)\end{array}$ & $24(8 \%)$ & $136(48 \%)$ & $85(30 \%)$ \\
$\begin{array}{l}\text { Faculty consistently rate same } \\
\text { student (n=285) }\end{array}$ & $6) 2 \%)$ & $\begin{array}{c}90 \\
(32 \%)\end{array}$ & $\begin{array}{c}69 \\
(24 \%)\end{array}$ & $101(35 \%)$ & $19(7 \%)$ \\
$\begin{array}{l}\text { OT students value professional } \\
\text { behavior assessment (n=284) }\end{array}$ & $3(1 \%)$ & $\begin{array}{c}70 \\
(25 \%)\end{array}$ & $\begin{array}{c}99 \\
(35 \%)\end{array}$ & $95(34 \%)$ & $17(6 \%)$ \\
$\begin{array}{l}\text { Students have outstanding } \\
\text { professional behaviors (n=284) }\end{array}$ & $1(.3 \%)$ & $\begin{array}{c}31 \\
(11 \%)\end{array}$ & $\begin{array}{c}51 \\
(18 \%)\end{array}$ & $161(57 \%)$ & $40(14 \%)$ \\
$\begin{array}{l}\text { OT educational programs should } \\
\text { assess professional behaviors } \\
\text { (n=285) }\end{array}$ & $1(.3 \%)$ & $1(.3 \%)$ & $5(2 \%)$ & $85(30 \%)$ & $193(68 \%)$ \\
\hline
\end{tabular}

Frequency of assessment of professional behaviors by participants. Two hundred and thirty-nine (81.3\%) participants reported that the educational program they worked in currently assessed the professional behaviors of their students while 46 (15.6\%) reported their program did not. 
Research Question 3: Is there a significant difference in the responses of faculty from different institutional (Carnegie Classification) in regards to what professional behaviors should be assessed

After the data was gathered the researcher collapsed the categories for statistical analysis into 4 groups, Doctoral/research universities, Masters Institutions, Special Institutions, and Baccalaureate/Associates institutions. These groupings were consistent with the grouping of institutional types presented by the Carnegie Classification (Carnegie, 2014) and were necessary to try to limit type one error caused by small independent variable size that would have occurred if analysis were completed at specific institutional classification level.

A Chi-Square analysis revealed no significant differences $(\mathrm{p} \leq 0.01)$ in the importance of inclusion of specific professional behaviors in professional behavior assessment among faculty from different Carnegie classification institutions. See Table 4.21 for detailed Chi-Square analysis results. 
Table 4.21

Chi-Square Analysis of Professional Behaviors by Institution Type $(\mathrm{p} \leq 0.01)$

\begin{tabular}{lccc}
\hline Behavior & $\mathrm{n}$ & Chi-Square Value & $\mathrm{P}$ \\
& & & \\
\hline Dependability & 285 & 4.76 & 0.855 \\
Timeliness & 284 & 11.114 & 0.519 \\
Awareness of emotions & 284 & 8.298 & 0.504 \\
Acceptance and Integration of Feedback & 284 & 8.639 & 0.195 \\
Initiative & 284 & 8.109 & 0.523 \\
Responsibility for own learning & 284 & 7.584 & 0.577 \\
Responsibility for own actions & 285 & 7.084 & 0.313 \\
Verbal Communication & 285 & 9.971 & 0.126 \\
Written Communication & 284 & 15.009 & 0.091 \\
Professional Appearance & 285 & 5.953 & 0.745 \\
Enthusiasm & 285 & 4.686 & 0.861 \\
Clinical Reasoning & 283 & 6.603 & 0.678 \\
\hline
\end{tabular}

Research Question 4: Is there a significant difference in responses from faculty from different institutional types (Carnegie Classification) in regards to how professional behaviors should be assessed?

To complete these analysis participants groups were collapsed into four groups as described above in research question 3.

Assessment Intervals. Participants were asked to report their level of agreement with a series of statements regarding the timing and frequency of professional behavior assessment. A Chi-Square analysis of their responses found no significant differences in the responses of 
faculty members from different Carnegie institution types $(p \leq 0.01)$. See Table 4.22 for detailed results of the Chi-Square analysis.

Table 4.22

Chi-Square Analysis of Assessment Timing by Institution Type $(\mathrm{p} \leq 0.01)$

\begin{tabular}{lccc}
\hline & $\mathrm{n}$ & Chi-Square Value & $\mathrm{p}$ \\
\hline Professional Behavior is adequately & 286 & 12.992 & 0.370 \\
assessed & & & \\
Semester assessment & 287 & 11.733 & 0.467 \\
Yearly assessment & 286 & 21.289 & 0.046 \\
End of Level 1 assessment & 286 & 10.572 & 0.306 \\
End of Level 2 & 286 & 6.997 & 0.858 \\
Only when problem exists & 287 & 7.357 & 0.833 \\
\hline
\end{tabular}

Tools of assessment. Faculty from different Carnegie institution types assigned similar value to potential tools that could be used in the assessment of student professional behaviors. A Chi-Squared analysis revealed no significant differences $(p \leq 0.01)$ in responses to the question “How valuable are the following tools in the assessment of student's professional behaviors?” Table 4.23 contains the detailed results. 
Table 4.23

Chi-Square Analysis of Assessment Tools by Institution Type $(\mathrm{p} \leq 0.01)$

\begin{tabular}{lccc}
\hline & $\mathrm{n}$ & Chi-Square & $\mathrm{p}$ \\
\hline Rating form & 280 & 5.391 & 0.944 \\
Rubric & 280 & 5.059 & 0.956 \\
Critical incident reports & 283 & 2.071 & 0.990 \\
Portfolios & 282 & 4.798 & 0.964 \\
Student reflections & 283 & 18.256 & 0.108 \\
Practical exam items & 280 & 9.117 & 0.693 \\
Written exam items & 273 & 6.966 & 0.860 \\
\hline
\end{tabular}

Observations to include in assessment. A Chi-Square analysis (table 4.24) of faculty responses to the question, “How valuable are observations of students’ professional behavior in the following situations” resulted in a significant difference between the responses of faculty members from different Carnegie Classification types in the value of observations of students at professional conferences and non-institution sponsored continuing education. This significant finding is decreased by the existence of low cell counts that resulted from a small sample of faculty from Baccalaureate institutions.

Faculty members from Baccalaureate institutions were more likely to rate the observation of behavior at professional conferences as "Valueless" (13.6\%) compared to the other Carnegie classifications, Masters (1.8\%), Special (2.4\%), or Doctorate (0\%). Faculty from Baccalaureate and Doctoral institutions were also less likely to report observations of students at professional conferences as "Valuable” (31.8\% and 39.3\% respectively), compared with $51.2 \%$ of Special 
institutional faculty and 59.3\% of Masters Faculty. In this analysis, eight cells in the contingency table (40\%) had lower than expected counts.

Similar responses were observed in the value assigned to observing students at noninstitution hosted professional education. Nine cells (45\%) of the Chi-Square analysis had lower than expected counts. Faculty from Baccalaureate institutions more frequently chose “Valueless” (13.6\%) than faculty from Masters (2.7\%), Special (4.9\%), and Doctoral (0\%) institutions. Baccalaureate faculty members were also more like to choose "Neither valueless nor valuable” (40.9\%) than Masters (23.9\%), special (26.8\%), or Doctoral (27.1\%) faculty.

Table 4.24

Observations of Professional Behavior Chi-Square Analysis by Institution Type $(\mathrm{p} \leq 0.01)$

\begin{tabular}{lccc}
\hline & $\mathrm{N}$ & Chi-Square & $\mathrm{p}$ \\
\hline Classroom behavior & 283 & 8.857 & 0.451 \\
Laboratory Behavior & 282 & 12.923 & 0.166 \\
Clinical behavior & 282 & 1.130 & 0.770 \\
Group work & 283 & 6.607 & 0.359 \\
Practical exams & 282 & 8.757 & 0.715 \\
Written exams & 283 & 13.758 & 0.316 \\
Social interactions with peers & 282 & 10.736 & 0.552 \\
OT related extra-curricular activities & 283 & 18.524 & 0.101 \\
Professional conferences & 283 & 35.626 & $0.000^{*}$ \\
Non-institution hosted Continuing education & 283 & 32.231 & $0.001^{*}$ \\
\hline
\end{tabular}

\section{Individuals who should participate in the assessment of professional behavior. A}

Chi-Square analysis of responses to the question "How important is it for the following 
individuals to participate in the assessment of students' professional behaviors” found no significant differences between faculty members from different Carnegie Classification institutions. Table 4.25 has the specific results of analysis.

Table 4.25

Chi-Square Analysis of Contributors to Assessment by Institution Type ( $\mathrm{p} \leq 0.01)$

\begin{tabular}{lccc}
\hline & $\mathrm{N}$ & Chi-Square & $\mathrm{p}$ \\
\hline Full-time faculty & 285 & 3.930 & 0.916 \\
Part-Time faculty & 285 & 4.310 & 0.890 \\
Student & 285 & 5.355 & 0.802 \\
Peers & 285 & 8.812 & 0.719 \\
Level 1 fieldwork instructors & 285 & 12.589 & 0.050 \\
Level 2 fieldwork instructors & 283 & 3.750 & 0.290 \\
Lab instructors TAs & 283 & 6.270 & 0.902 \\
Administrative/Professional Staff & 282 & 11.765 & 0.465 \\
\hline
\end{tabular}

Use of assessment results. The only statistically significant difference occurred with responses to questions about the importance of compiling assessment results to reflect performance of the group as a whole. Overall faculty from Baccalaureate institutions ranked this as less important than faculty from other institution types. A greater percentage of Baccalaureate institution participants ranked compiling results as "Very unimportant”, "Unimportant”, and a lesser percentage ranked it as "Important" or "Very important" when compared to other institution types. Figure 4.12 below demonstrates responses as expressed in percentages of Carnegie group. However the significance of this finding is decreased by the existence of 7 
cells or $35.5 \%$ of boxes with lower than expected counts. This was caused by the small sample of participants from baccalaureate institutions.

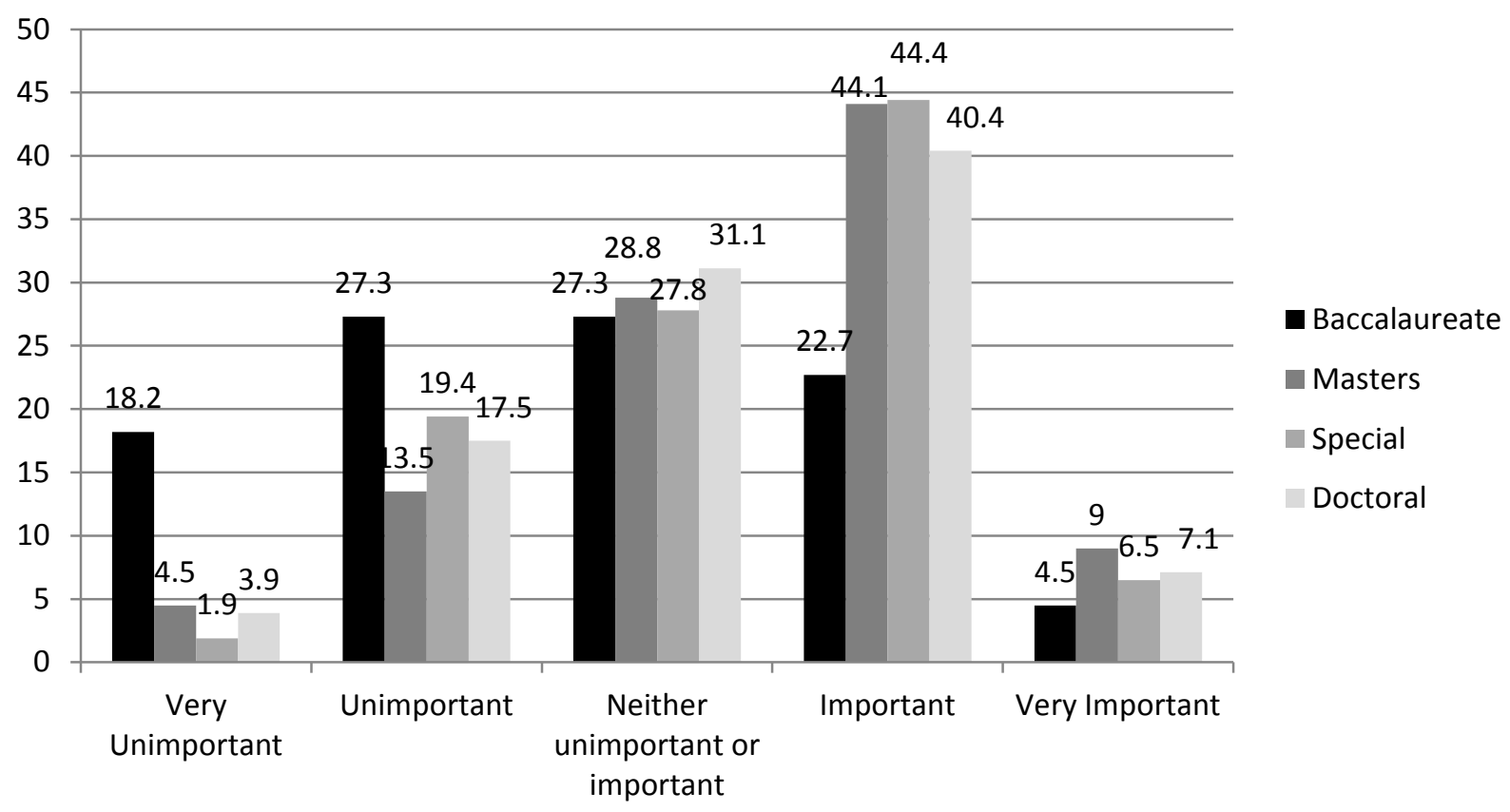

Figure 4.12. Frequency of responses expressed in percentages to using assessment result to reflect performance of the group as a whole. 
Table 4.26

How Assessment Results Should be Used Chi-Square Analysis by Institution Type $(\mathrm{p} \leq 0.01)$

\begin{tabular}{|c|c|c|c|}
\hline & $\mathrm{n}$ & $\begin{array}{l}\text { Chi-Square } \\
\text { value }\end{array}$ & $\mathrm{p}$ \\
\hline Compiled to reflect performance of the group & 280 & 26.202 & $.010^{*}$ \\
\hline Used to advise individuals students & 279 & 9.319 & .156 \\
\hline Compiled and shared with faculty & 279 & 5.745 & .765 \\
\hline $\begin{array}{l}\text { Used to determine effectiveness of current } \\
\text { instruction }\end{array}$ & 279 & 7.379 & .287 \\
\hline Lead to changes in curriculum & 281 & 13.423 & .144 \\
\hline $\begin{array}{l}\text { Lead to changes in professional behavior } \\
\text { assessment plan }\end{array}$ & 281 & 6.607 & .359 \\
\hline $\begin{array}{l}\text { Included in OT program assessment or evaluation } \\
\text { plan }\end{array}$ & 280 & 18.806 & .093 \\
\hline Inform faculty professional development & 276 & 10.440 & .577 \\
\hline
\end{tabular}

Student consequences of professional behavior issues. Faculty members were asked to indicate at what level of professional behavior infraction they felt possible consequences to students were appropriate. A Chi-Square analysis of their responses indicated no significant 
differences between the feelings of faculty members from differing Carnegie classification institutions.

Table: 4.27

Consequences of Assessment Chi-Square Analysis by Institution Type $(\mathrm{p} \leq 0.01)$

\begin{tabular}{lccc}
\hline & $\mathrm{n}$ & Chi-Square & $\mathrm{p}$ \\
\hline Required counseling with faculty advisor & 279 & 18.307 & .107 \\
Professional Behavior development plan & 280 & 20.094 & .168 \\
Decrease in course grade & 279 & 14.895 & .459 \\
Program probation & 287 & 14.978 & .453 \\
Delayed progression & 277 & 10.966 & .755 \\
Delayed entry into fieldwork & & & \\
Termination from program & 277 & 11.343 & .728 \\
No Consequences & 276 & 10.271 & .802 \\
\hline
\end{tabular}

General opinions regarding assessment. A Chi-Square analysis revealed that there are no significant differences in the level of agreement faculty members from different Carnegie institution types had with several general statements regarding the assessment of professional behaviors of occupational therapy students. The results are detailed in table 4.28. 
Table 4.28

General Opinions About Professional Behavior Assessment Chi-Square Analysis by Institution Type $(\mathrm{p} \leq 0.01)$

\begin{tabular}{lccc}
\hline & $\mathrm{n}$ & Chi-Square & $\mathrm{p}$ \\
\hline $\begin{array}{l}\text { All faculty value assessment of students' } \\
\text { professional behavior. }\end{array}$ & 279 & 11.944 & .450 \\
When assessing the same student faculty members & 280 & 4.507 & .972 \\
$\begin{array}{l}\text { consistently rate students at same level. } \\
\text { OT students value assessment of their professional }\end{array}$ & 279 & 13.65 & .323 \\
behaviors. & & & \\
Majority of students have outstanding professional & 279 & 7.692 & .809 \\
behaviors. & & & \\
OT educational programs should assess the & 280 & 8.103 \\
professional behaviors of students.
\end{tabular}

Research Question 5: Is There a Significant Difference Between Full-time and Part-time Faculty Responses Regarding What Professional Behaviors Should be Assessed in OT Educational Programs?

Faculty members were asked to rate the importance of including specific behaviors in the professional behavior assessment of students. Out of the twelve behaviors included in the survey, two, initiative and responsibility for own learning, were assigned significantly different importance by full time versus part-time faculty. The small sample size of part-time or adjunct 
participants resulted in eight (8) cells with a lower than expected cell count for initiative and responsibility for own learning. The existence of lower than expected cell counts decreases the significance of the findings.

A greater percentage of full-time faculty members (64.7\%) reported initiative as "Very important” as compared to part-time faculty (33.3\%). The majority of part-time faculty (61.1\%) rated initiative as "Important” while 33.8\% of full-time faculty rated initiative as "Important.”

A similar difference was noted in the responses to the importance of including "takes responsibility for own learning” in professional behavior assessment. Seventy-three point two percent (73.2\%) of full-time faculty rated this as "Very important” versus only $38.9 \%$ of parttime faculty. Most part-time faculty rated responsibility for own learning as "Important” (61.1\%) as compared to $25.3 \%$ of full-time faculty. See Table 4.29 for detailed Chi-Square results. 
Table 4.29

Importance of Assessing Behaviors Chi-Square Analysis by Faculty Employment Status ( $\mathrm{p} \leq$ $0.01)$

\begin{tabular}{|c|c|c|c|}
\hline & $\mathrm{n}$ & Chi-Square Value & $\mathrm{P}$ \\
\hline Dependability & 288 & .440 & .932 \\
\hline Timeliness & 287 & .546 & .969 \\
\hline Awareness of Emotions & 287 & .891 & .828 \\
\hline $\begin{array}{l}\text { Acceptance and integration of } \\
\text { feedback }\end{array}$ & 287 & .204 & .903 \\
\hline Initiative & 287 & 12.884 & $.005 *$ \\
\hline Responsibility for own learning & 287 & 10.937 & $.012 *$ \\
\hline Responsibility for own actions & 288 & .313 & .855 \\
\hline Verbal Communication & 288 & .203 & .903 \\
\hline Written communication & 287 & .381 & .944 \\
\hline Professional Appearance & 288 & 2.516 & .472 \\
\hline Enthusiasm & 288 & 9.940 & .019 \\
\hline Clinical Reasoning & 286 & 1.316 & .725 \\
\hline
\end{tabular}


Research Question 6: Is There a Significant Difference Between Full-time and Part-time faculty Responses how Professional Behaviors Should be Assessed in OT Educational Programs?

Adequacy of professional behavior assessment by OT educational programs. A ChiSquare analysis revealed that there was not a significant difference between full-time and parttime faculty opinions about the adequacy of the assessment of students' professional behaviors. See Table 4.30 for detailed test results.

Table 4.30

Opinions Regarding Adequacy of Assessment Chi-Square Analysis by Faculty Employment Type $(\mathrm{p} \leq 0.01)$

\begin{tabular}{lccc}
\hline & $\mathrm{n}$ & Chi-Square & $\mathrm{P}$ \\
\hline $\begin{array}{l}\text { Professional behavior is adequately } \\
\text { assessed by OT educational programs }\end{array}$ & 289 & 7.832 & .098 \\
\hline
\end{tabular}

Assessment intervals. There was not a significant difference in how frequently full-time and part-time faculty felt professional behavior assessment should be completed. See Table 4.31 for the Chi-Square analysis results. 
Table 4.31

Assessment Intervals Chi-Square analysis by Faculty Employment Type $(\mathrm{p} \leq 0.01)$

\begin{tabular}{lccc}
\hline & $\mathrm{n}$ & Chi-Square & $\mathrm{p}$ \\
\hline Assessment every semester or term & 290 & 5.672 & .225 \\
Assessment every year & 289 & 3.657 & .454 \\
Assessment at end of Level 1 & 289 & 1.999 & .573 \\
Assessment at end of Level 2 & 289 & 2.620 & .623 \\
Assessment only when there is a problem & 290 & 1.382 & .847 \\
\hline
\end{tabular}

Tools of assessment. A Chi-Square analysis for independence revealed no significant difference in the importance assigned to the use of various assessment tools by full-time or parttime faculty. See Table 4.32 for specific Chi-Square results.

Table 4.32

Chi-Square Analysis of Assessment Tools by Faculty Employment Status $(\mathrm{p} \leq 0.01)$

\begin{tabular}{lccc}
\hline & $\mathrm{n}$ & Chi-Square & $\mathrm{p}$ \\
\hline Rating Form & 283 & 5.282 & .260 \\
Rubrics & 283 & 1.432 & .839 \\
Critical incident reports & 286 & 2.505 & .474 \\
Portfolios & 285 & .711 & .950 \\
Student Reflections & 286 & 2.009 & .734 \\
Specific items on Practical exams & 283 & 2.444 & .655 \\
Specific items on written exams & 276 & 2.788 & .594 \\
\hline
\end{tabular}


Observations to include in assessment. Chi-Square analysis identified two areas where there were significant differences in responses between full-time and part-time faculty when asked how valuable it was to include observations of student behavior from different situations. The significance of these findings is limited by a smaller than expected count in some boxes. Those incidences are reported along with results below. Full-time faculty participants were more likely to think that observations of laboratory behavior was "Neither valueless nor valuable” in professional behavior assessment with $3 \%$ selecting this versus $0 \%$ of part-time faculty. Three cells, or 37.5\%, had lower than expected cell counts in this analysis. In the area of group, work full-time faculty assigned greater value to group work observations than part-time faculty. Fiftysix point seven percent (56.7\%) of full time faculty identified group work as "Very valuable" while only 22\% of part-time faculty chose “Very valuable.” Part-time faculty identified observations of group work as "Valuable" (77.8\%) while $41 \%$ of full-time faculty identified group work as "Valuable.” Only 1 cell in this analysis had a lower than expected count. See Table 4.33 for the complete Chi-Square analysis. 
Table 4.33

Chi-Square analysis of Value of Observations of Student Behavior by Faculty Employment Status $(\mathrm{p} \leq 0.01)$

\begin{tabular}{lccc}
\hline & $\mathrm{n}$ & Chi-Square & $\mathrm{p}$ \\
\hline Classroom Behavior & 286 & 9.021 & 0.029 \\
Laboratory behavior & 286 & 16.928 & $0.001^{*}$ \\
Clinical Behavior & 285 & .807 & 0.369 \\
Group work & 286 & 9.332 & $0.009^{*}$ \\
Practical exams & 285 & 3.835 & 0.429 \\
Specific items on written exams & 286 & 1.153 & 0.886 \\
Social interactions & 285 & 1.362 & 0.851 \\
OT on campus extracurricular & 286 & 4.367 & 0.359 \\
Professional Conferences & 286 & 11.599 & 0.021 \\
Non-institution sponsored continuing & 286 & 6.951 & 0.138 \\
education & & & \\
\hline
\end{tabular}

Individuals who should participate in the assessment of professional behavior. A Chi-Square analysis resulted in no significant difference between the feelings of full-time and part-time faculty regarding the importance of including specific individuals in the assessment of students’ professional behavior. Table 4.34 below has the specific Chi-Square results. 
Table 4.34

Chi-Square analysis of Participants in Assessment by Faculty Employment Status $(\mathrm{p} \leq 0.01)$

\begin{tabular}{lccc}
\hline & $\mathrm{n}$ & Chi-Square & $\mathrm{p}$ \\
\hline Full-time faculty & 288 & .210 & 0.976 \\
Part-Time faculty & 288 & 1.663 & 0.645 \\
Student & 288 & 2.066 & 0.559 \\
Peers & 288 & 2.343 & 0.673 \\
Level 1 fieldwork instructors & 288 & 7.275 & 0.026 \\
Level 2 fieldwork instructors & 286 & .476 & 0.490 \\
Lab Instructors & 287 & .761 & 0.944 \\
Professional/Administrative staff & 285 & 4.839 & 0.304 \\
\hline
\end{tabular}

Use of assessment results. When asked the importance of using assessment results in specific ways, full-time and part-time faculty demonstrated a statistically significant difference in only two of eight possible uses: including the results in the program assessment or evaluation plan and informing faculty professional development in professional behavior assessment. A greater percentage of part time faculty reported that including results in the OT program assessment or evaluation plan was “Very unimportant.” However, this greater percentage represented only a single participant. A greater percentage of full time faculty (14\%) selected “Neither important or unimportant” for this item than part-time faculty (0\%). A greater percentage of part-time faculty (55.6\%) selected “Important” as compared to full-time faculty where $45.1 \%$ selected “Important.” The significance of this finding is decreased by the five cells (50\%) with lower than expected counts that resulted from the small sample of part-time participants. The Chi-Square analysis is reported in Table 4.35 below and the responses reported as percentages to this item are reported in Figure 4.14. 


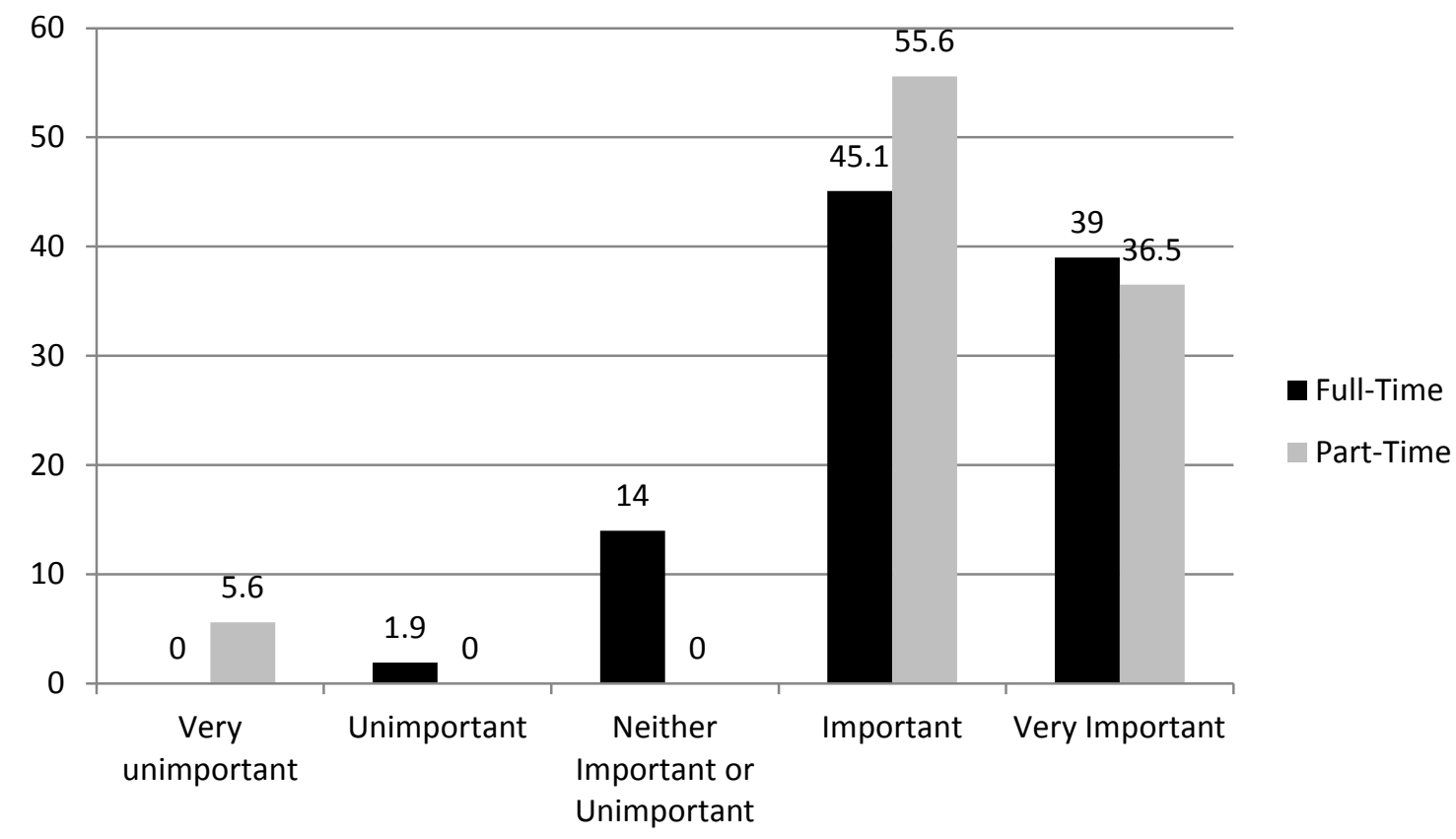

Figure 4.14. Responses to Use of Results in OT program Assessment or Evaluation Plan by employment type.

Full-time faculty felt that is was more important to use assessment results to inform professional development about professional behavior assessment than part-time faculty. A greater percentage of full-time faculty members chose “Neutral,” "Important,” or "Very important” for this item when compared to part-time faculty. However, the significance of this finding is limited by the five cells (50\%) with lower than expected counts. Figure 4.15 shows the responses for this question separated by employment status. 


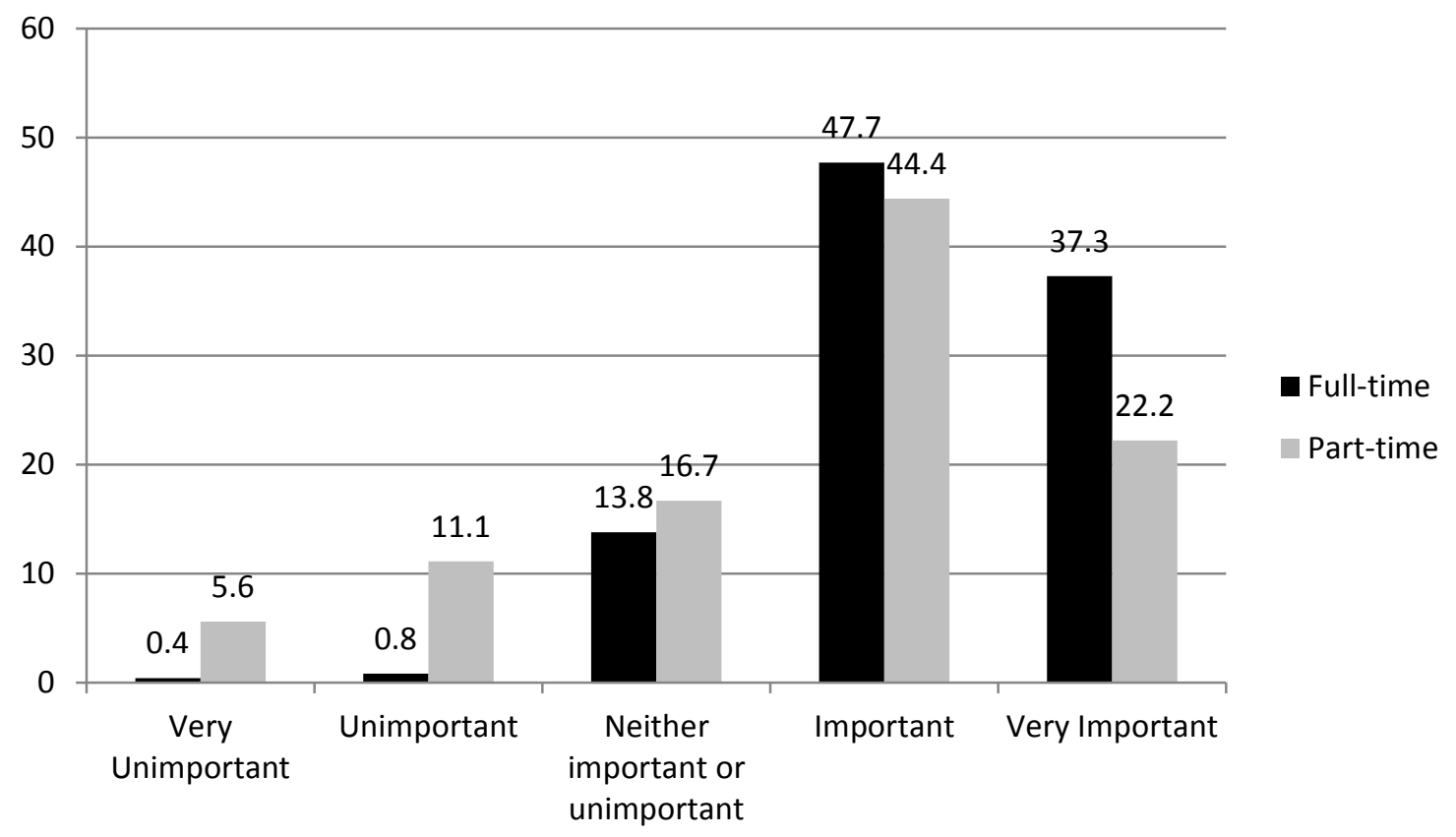

Figure 4.15. Responses to use of results in to inform professional development expressed in percentages. 
Table 4.35

Chi-Square Analysis of Uses of Assessment Results by Faculty Employment Status $(\mathrm{p} \leq 0.01)$

\begin{tabular}{lccc}
\hline & $\mathrm{n}$ & Chi-Square & $\mathrm{p}$ \\
\hline Compiled to reflect performance of the group. & 282 & 301 & 0.990 \\
Advise individual students. & 283 & .339 & 0.844 \\
Compiled and shared with faculty. & 281 & 3.845 & 0.279 \\
Used to determine effectiveness of current & 281 & .064 & 0.968 \\
instruction. & & & 0.650 \\
Lead to changes in curriculum. & 283 & 1.642 & 0.462 \\
Lead to changes in professional behavior & 283 & & \\
assessment plan. & & 1.545 & $0.001^{*}$ \\
Included in the OT program assessment or & 282 & & $0.001^{*}$ \\
evaluation plan. & & 19.958 & \\
Inform faculty professional development. & 278 & & \\
\hline
\end{tabular}

Student consequences of professional behavior issues. The Chi-Square analysis results detailed in Table 4.36 demonstrates no significant difference in how full-time or part-time faculty think about the potential consequences to students as a result of professional behavior assessment. 
Table 4.36

Chi-Square Analysis of Student Consequences by Faculty Employment Type $(\mathrm{p} \leq 0.01)$

\begin{tabular}{lccc}
\hline & $\mathrm{N}$ & Chi-Square & $\mathrm{p}$ \\
\hline Required counseling & 281 & 4.595 & 0.331 \\
Professional behavior development plan & 282 & 5.746 & 0.332 \\
Decrease in course grade & 281 & 2.582 & 0.764 \\
Program probation & 280 & 8.857 & 0.115 \\
Delayed progression in program & 279 & 6.314 & 0.277 \\
Delayed entry into fieldwork experiences & 279 & 4.970 & 0.420 \\
Termination from educational program & 278 & 3.280 & 0.657 \\
No Consequences & 260 & .606 & 0.962 \\
\hline
\end{tabular}

General opinions regarding assessment of professional behaviors of students. Fulltime and Part-time faculty reported similar opinions regarding the assessment of professional behaviors in occupational therapy students. See Table 4.37 for the Chi-Square analysis. 
Table 4.37

Chi-Square Analysis of General Thoughts by Faculty Employment Status $(\mathrm{p} \leq 0.01)$

\begin{tabular}{lccc}
\hline & $\mathrm{N}$ & Chi-Square & $\mathrm{p}$ \\
\hline $\begin{array}{l}\text { All faculty value assessment of professional } \\
\text { behaviors }\end{array}$ & 281 & 3.194 & 0.526 \\
$\begin{array}{l}\text { Faculty members consistently rate students’ } \\
\text { professional behaviors the same }\end{array}$ & 282 & 4.804 & 0.308 \\
$\begin{array}{l}\text { OT students value professional behavior } \\
\text { assessment }\end{array}$ & 281 & 2.166 & 0.705 \\
$\begin{array}{l}\text { Students have outstanding professional } \\
\text { behaviors }\end{array}$ & 281 & 2.756 & 0.599 \\
$\begin{array}{l}\text { OT educational programs should assess the } \\
\text { professional behaviors of students }\end{array}$ & 282 & 8.335 & 0.080 \\
\hline
\end{tabular}

\section{Final Thoughts From Participants, Open Comments}

At the conclusion of the survey, participants were given the opportunity to provide any final thoughts on the assessment of students' professional behaviors. These comments were then reviewed and categorized by the primary investigator. The comments were grouped into ten categories: current assessment practices of professional behavior; survey feedback; professional behavior and fieldwork success; need for resources; role modeling; difficulties and dissatisfaction; fairness; age and development; professional versus academic success; and, general comments.

Assessment practices. There were thirty-eight comments related to current assessment practices. The most common practices mentioned were the use of a rating form or rubric (15 comments) and the most frequent interval mentioned was every semester (11 comments). 
Participants also frequently mentioned the use of student self-reflection as an integral part of the assessment practice (11 Comments).

Dissatisfaction with current practices. Sixteen participants mentioned dissatisfaction with their current or recent past assessment practices. A common concern was the amount of time and work involved when only a few students presented with problems. As one participant stated, “....and certainly don’t like having to do paperwork for ALL students when it is just 2 or 3 that need feedback.” Workload concerns were expressed by four participants, with one noting, "Although it is vitally important, it is unfortunately sometimes an afterthought, as the curriculum is so full as it is. It is challenging to individualize assessment and intervention for professional behavior with a large class cohort.” Another participant stated, “There is unanimous agreement that this is a critical area to address with our students, but teaching load, institutional constraints, and departmental issues have made it difficult for our program to be truly consistent with this area of student assessment.” Participants also expressed dissatisfaction with dealing with negative behaviors. One participant reported, “...it is the advisor who has the responsibility of informing the students of behaviors that are not acceptable, even if that faculty has not observed the behavior in questions. This often makes it uncomfortable to counsel a student since information is second hand.”

Fairness and consistency. Fairness and consistency in assessment of professional behaviors was the subject of eleven comments. One participant expressed concern with assessing students on concepts that were not well developed or researched stating, "I am not sure that there is enough agreement on what constitutes professional behavior (i.e. dress standards) for accurate assessment, nor am I convinced that classroom behavior is a reasonable measure/indicator of professional behavior.” Other participants expressed concerns with faculty buy in with seven 
participants mentioning consistent faculty assessment and participation as concerns for maintaining a fair process. One participant also addressed the cultural issues associated with fair assessment of professional behaviors, noting, "Professional behaviors often include marked cultural difference between student and academic/clinic in expectations of behaviors.”

Professional behavior and fieldwork performance. Six comments were made on the relationship between professional behavior and fieldwork. Five shared that problems with professional behavior led to performance problems in fieldwork and one participant mentioned professional behaviors affected the willingness of clinical supervisor to accept students.

Need for resources and tools. Five comments related to a need for more resources to implement good assessment practices. Three participants felt that there was a need for more instruments or tools to use in professional behavior assessment as summed up by this statement, "Wish we had more options....needs to get better." The remaining two comments addressed issues with valid and reliable assessments based on widely accepted understandings of professionalism. One participant stated, "It is difficult to determine which characteristics of students should be assessed since there is no universally accepted definition of what professional behavior/professionalism is in our profession or in any other. We first need to define it and then measure it.” Another participant stated, “There is definitely a dearth of valid, reliable assessment tools for occupational therapy educators to use to assess professional behaviors.”

Academic versus professional behavior performance. Four participants mentioned the difference between academic and professional behavior performance. One participant stated, "It is a challenge as some students are able to advance academically but may still have professional behavior issues." One participant shared that his/her program had moved professional behavior 
assessment to be part of each course grade to overcome a student's statement, "So what if I'm consistently late to class, I'm still making all A's”. One participant stated that professional behavior was kept separate from academic performance and that student grades or progression could not be hindered by professional behavior.

Age and development of students. Three comments addressed the effects of age on professional behavior assessment. One participant stated that since his/her program worked with older non-traditional students, so professional behaviors were of minimal concern. The third participant felt that it was important that programs consider the characteristics of Generation Y when setting and teaching professional behaviors.

Role modeling. Similar to the construct of fairness, was a feeling that professional behavior raters had to role model the desired behavior. Two comments addressed this subject. One participant stated, “All raters should first be able to demonstrate consistently high professional behavior standards.” Another participant stated that modeling was more likely to shape behavior versus assessment.

General comments. Eleven comments provided by participants were classified into a general category. Two of the comments addressed the importance of the topic. Three of the comments addressed the importance of having a complete process in place. The remaining comments addressed various issues associated with the instruction and assessment of professional behavior not addressed above.

Survey instrument. Nine participants provided feedback regarding the survey instrument. One person reported the survey as a whole was confusing; four participants reported that they found the consequences question confusing or difficult to answer. One participant 
indicated that their program was not a Master’s level entry program any longer. One participant indicated that it was a "great” survey. 


\section{Chapter 5: Discussion}

This was a descriptive study that examined the thoughts and opinions held by Occupational Therapy (OT) faculty members in Master’s level educational programs regarding the assessment of students' professional behaviors. In the discussion section, I will review the major findings of the research, faculty members' opinions about the professional behaviors that should be assessed, assessment practices, and general believes about the assessment of professional behavior. Potential implications of the findings for practice and research, and limitations of the study will also be reviewed.

Palomba and Banta (1999) state, “successful assessment requires carefully laid groundwork” (p 19). Agreement in terms definitions and performance expectations are essential to complete reliable and accurate assessment that fosters student growth. The results of this research study emphasizes the need for the profession of Occupational Therapy in the United States to follow the lead of other health care professions and occupational therapy professionals in other countries to lay the groundwork and develop common understandings of professionalism and professional behaviors.

As health professions seek increased independence in a new model of health care, ensuring the professionalism of students entering the profession is essential. Professionalism is, "the application of the values of the profession and the demonstration of essential professional behaviours and attitudes” (Aguilar, Stupas, Scutter \& King, 2013, p. 207). Swick (2000) states that medical professionalism is a balance between applying specialized knowledge and meeting a societal need. Professional behaviors are the observable application of the values of the profession and guide how professionals apply their specialized knowledge to meet the needs of those they serve. Each health care profession has its own values and code of ethics; so, 
professionalism and professional behaviors may be different in various health professions. This requires the individual professions to identify the key professional behaviors that express the values and ethics of their profession. Within the field of Occupational Therapy in the United States, the values and the ethics of the profession have been clearly stated in the Occupational Therapy Values and Code of Ethics statement published by the American Occupational Therapy Association (2010). However, the profession has not developed an official definition of professionalism or identified expected professional behaviors (Robinson, Tanchuk, \& Sullivan, 2012). Most of the research within Occupational Therapy that explores professional behavior has focused on individual educational program efforts. This study is one of the first studies to attempt to examine professional behavior assessment at a national/profession level.

\section{Research Question 1: What professional behaviors do faculty express should be assessed in Occupational Therapy educational programs in the United States?}

Faculty rating of importance of professional behaviors. In this study, participants were presented with a list of professional behaviors that were included in other research regarding professional behaviors or behaviors that were used in widely recognized professional behavior tools (Kasar \& Clark, 2000; Ledet, Esparza \& Peloquin, 2005; Randolph, 2003) and asked to rate the importance of including the behaviors in the assessment of professional behavior. The results of this section of the survey revealed that Occupational Therapy (OT) faculty assigned high importance to most behaviors, included a clinical competency as professional behavior, conceptualized professional behavior differently, lacked common definitions of professional behaviors, and lacked a common understanding of what professional behaviors are essential for clinical practice. 


\section{Relationship between the Occupational Therapy Code of Ethics and professional}

behavior. Participants in this study assigned high importance to most of the behaviors presented. Of the thirteen behaviors presented, ten of them were rated as "Very Important" or “Important” by at least 283 of the 289 participants. Aguilar et al. (2013) state that professional behaviors are a reflection of ethics and it is to be expected that practitioners and faculty members think that professional behaviors are equally important.

Most of the behaviors included in the survey are clearly tied to the OT Code of Ethics Document (AOTA, 2010). For example, 288 of the participants (99\%) rated "Responsibility for own Actions” as “Very important” or “Important.” Responsibility for own actions is a reflection of several of the ethical principles in the OT Code of Ethics (AOTA). Under the principle of beneficence, the code requires that the practitioner "Take responsibility for promoting and practicing occupational therapy on the basis of current knowledge and research and for further developing the profession's body of knowledge” (p. 4). Under the principle of non-maleficence, the code requires practitioners and students to "Recognize and take appropriate action to remedy personal problems and limitations that might cause harm to recipients of service, colleagues, students, research participants, or others” (p. 4). In the principle of veracity practitioners and students are expected to “Accept responsibility for any action that reduces the public’s trust in occupational therapy services” (p 9).

Acceptance and integration of feedback was another behavior that was rated as "Very important” or “Important” by 287 participants. This behavior also reflects the values and ethics of occupational therapy. References to this skill can be found in the ethical principles of beneficence and procedural justice. As cited in the principle of beneficence "occupational therapy personnel shall take responsible steps (e.g., continuing education, research, supervision, 
training) and use careful judgment to ensure their own competence and weigh potential for client harm when generally recognized standards do not exist in emerging technology or areas of practice” (p 3).

Although the difference was minimal behaviors that were not as closely tied to the values and ethics of the profession of OT were ranked as less important. Enthusiasm was ranked as “Very important” or "Important” by the fewest number of participants (278,95\%). Within the survey enthusiasm was defined as "Projects a positive attitude, appears to enjoy work, and appears confident in a variety of circumstances.” Within the AOTA Code of ethics no part of the definition of enthusiasm appears. The closest guidance that could be associated with enthusiasm is use of words like "actively participate” and "make every effort." However, these words are used to promote ethical principles procedural and social justice.

Clinical reasoning as a professional behavior. Clinical reasoning was rated as a "Very important” or “Important” professional behavior by most of the participants (283,97\%). This result is consistent with previous research that cited clinical reasoning as important in professional development assessment and as an indicator for fieldwork success (Davis, 2009; Gutman, 1998; James and Musselman, 2005). However, this is an example of an important construct of professional development that may be grouped inappropriately as a professional behavior when, in fact, it is a clinical skill that is in the cognitive versus affective domain of learning.

The original Bloom's taxonomy of learning identified three domains in which learning can occur: cognitive; affective; and, psycho-motor (Suskie, 2009). A student's knowledge, reasoning, analysis, and evaluation skills are considered to be part of the cognitive domain of 
learning. The affective domain targets the individual's feelings, attitudes, and values. The psycho-motor domain deals with the person's ability to physical manipulate items in the environment in a skilled manner. Professional behavior is thought to reflect the student's acceptance of the values of the profession; instruction and learning in this area is considered affective. Clinical reasoning is a skill that is learned through academic education and clinical experience (Rogers, 1983) and is part of the cognitive domain.

In their book on clinical reasoning, Mattingly and Fleming (1994) state that clinical reasoning involves several forms of thinking and is a way of perceiving. Given these characteristics, clinical reasoning might not be considered an observable behavior but instead a discipline of thoughts and perceptions. Neistadt (1997) defines clinical reasoning as “...the thought process practitioners use during evaluation and intervention” (p 227). Multiple authors have identified clinical reasoning as a process that integrates multiple other types of reasoning including procedural, narrative, interactive, pragmatic, conditional, and ethical (Mattingly and Fleming 1994; Rogers 1983; Schell \& Cuevero, 1993). If clinical reasoning, as research suggests, is a complex cognitive process that is influenced by ethics as well as knowledge base and experience, it would appear that this is a skill that might be best assessed as a clinical competency versus a professional behavior.

Respondents to this survey might have assigned clinical reasoning high importance for three possible reasons. First and foremost is the acceptance that clinical reasoning is essential for success as a clinician. The educational program's ultimate goal is to educate competent therapists with sound clinical reasoning. In the literature, professional behavior has been cited as a primary reason for failure in fieldwork as has poor clinical reasoning (Gutman et al., 1998; James \& Musselman, 2005). This might have led to the two concepts being tied together. 
It is also possible that the inclusion of clinical reasoning in some published professional behavior assessments, such as Kasar and Clark (2000), have led to acceptance of clinical reasoning as a professional behavior. This was reinforced by the inclusion of clinical reasoning in the survey instrument.

Another possible reason for the inclusion of clinical reasoning as an important professional behavior might be the interchangeability and lack of clarity between the concepts of professionalism, professional development, and professional behaviors (Aguilar et. al, 2013). In the review of the literature concepts of professional development, professionalism, and professional behavior were often mixed and used interchangeably (Swick, 2000). Because these concepts are unique to professions and national affiliations they can be easy to confuse when no official terminology exists (Martimianakis, Maniate \& Hodges, 2009).

OT faculty conceptualize professional behaviors differently. In this research, participants were presented with a set of professional behaviors that were defined in the literature as related to the practice of occupational therapy. In general, these behaviors were the basic behaviors of professionalism. As discussed in the literature review, several researchers have shared their professional behavior assessment tools and each one used a unique organization or conceptualization of professional behavior (Fidler, 1996; Kasar \& Clark, 2000; Ledet et al. 2005; Randolph, 2003). The organization and conceptualization of other researchers is shown in Table 2.1. As part of the survey instrument development the researcher looked for common behaviors in the research and developed the list of 12 behaviors presented to the participants. In addition to assigning high importance to the behaviors presented, participants in this study also identified many additional important behaviors to be assessed in an open response section. 
The most frequently mentioned behaviors were teamwork, ethical behavior, cultural competence, leadership, and therapeutic use of self. These behaviors represent composite behaviors that are made up of many behaviors used in concert. Assessing composite professional behaviors is consistent with the approaches of Fidler (1996) and Kasar and Clark (2000). For example, therapeutic use of self requires the skills of awareness of emotions, and communication. Teamwork requires responsibility for self, awareness of emotions, and communication. Assessing both the basic behaviors and the larger composite behaviors leads to the same behavior being assessed multiple times. Verbal communication, for example, would be included in the assessment of teamwork, leadership, and therapeutic use of self. When a student struggled with verbal communication they would be assessed lower in all of these skills. This can lead to student confusion and frustration with professional behavior assessment.

One of the basic assumptions of this research was that professional behaviors are a reflection of the ethics of the profession. One of the most frequently written in behaviors was ethical behavior; this indicates that some OT faculty feel that professional behaviors are not based in ethics. Without ethics as the foundation of professional behaviors, other contextual influences such as reimbursement, practice setting, and corporate demands can influence what professional behaviors are considered desirable. This further increases student confusion about which behaviors are necessary and how context affects desired behaviors (Robinson et al., 2012).

Lack of common definitions. Other behaviors included in the open response section point to a lack of agreement in the definition of professional behaviors. Some of the behaviors mentioned by participants could have been included in or were very similar to the defined behaviors provided by the researcher. See Table 5.1 for examples. 
As an example of this, the survey defined responsibility for own learning as "Selfdirected in learning experiences, seeks additional learning from multiple sources.” Participants in this survey also wrote in similar behaviors such as commitment to learning and intellectual curiosity. Clinical reasoning is another example of lack of common acceptance of meaning. In the survey, clinical reasoning was defined as "Utilizes knowledge, experience, observations, and client input to make appropriate treatment decisions.” Participants in the survey listed skills that could be considered part of clinical reasoning including problem solving, critical reasoning, and synthesis and application of knowledge. This lack of consistency in definitions of professional behavior results from the limited research, publication, and professional discourse regarding professional behaviors in occupational therapy.

Table 5.1

Comparison Between Researchers Provided Behaviors and Participant Identified Behaviors

\begin{tabular}{ll}
\hline Researcher provided term and definition & Participant identified behavior \\
\hline Responsibility for own learning & Commitment to learning, intellectual curiosity \\
Professional Appearance & Cover tattoos \\
Enthusiasm & Engagement \\
Awareness of emotions & Self-awareness \\
Verbal communication & Client centered communication \\
\hline
\end{tabular}

Essential behaviors for professional success. Current researchers in occupational therapy have identified a lack of common understanding of professionalism and essential behavior necessary for clinical practice (Aguilar et al., 2013; Robinson et al., 2012). The lack of 
common understanding within the profession regarding necessary professional behaviors for practice is best demonstrated by the addition of 52 behaviors participants identified to be included in professional behavior assessment. The profession has identified seven values, seven ethical principles (AOTA, 2010), and has included seven professional behaviors in the Fieldwork Performance Evaluation (AOTA, 2002). If professional behaviors are a reflection of the values of a profession, the number of essential professional behaviors should be significantly less than the number identified by participants. This was not an unexpected result, as occupational therapy professional behavior assessment tools discussed in the literature have included as many as 43 behaviors (Hubbard, Beck, Stutz-Tennenbaum, \& Battaglia, 2007), and as few as 17 (Ledet et al., 2005). Aguilar et al.'s (2013) study to identify essential professional behaviors for OTs in Australia started with a list of 32 behaviors that, through a Delphi process, was eventually shortened to seven.

One of the key reasons for the differences in expectations may arise from the diversity of the occupational therapy profession. Occupational Therapists' practice can include clients who range from pre-mature infants to the very old. The clients OTs work with include individuals with physical, cognitive, and emotional impairments and disabilities. Occupational Therapists work in variety of settings including hospitals, nursing homes, outpatient clinics, community mental health centers, homes, schools, and/or prisons. OTs may practice both in and outside of the medical model. This diversity of practice leads to different expectations based on population, disability, and setting. Individual faculty members may perceive behaviors expectations through their own experiences. A larger discussion that aims for consensus of truly essential behaviors that apply in many settings will be necessary to develop common understanding and consistent expectations. 


\section{Research Question 2: How should professional behaviors be assessed in OT educational programs in the United States as expressed by faculty?}

The second research question examined what assessment techniques and tools faculty felt were valuable and important to use in the assessment of the professional behavior of OT students. The publications regarding assessment of professional behavior presented multiple tools, timelines, participants, and uses of assessment results. Most of the OT literature highlighted the professional behavior assessment of single educational programs (Balboa \& Peloquin; 1999; Fidler, 1996; Ledet et al. 2005).

\section{The role of clinical experiences in the assessment of professional behavior.}

Throughout the second section of the survey, which dealt with assessment methods, faculty expressed strong preferences for including clinical experiences into the assessment of professional behavior. Faculty held the highest agreement with assessing professional behavior at the end of Level 1 and 2 clinical experiences, with having Level 1 and 2 clinical educators contribute to professional behavior assessment, and including observations of the students in clinical situations in professional behavior assessment. Due to the consistency of faculty opinions, and the unique nature of clinical experience in the education of occupational therapists, this section of the discussion will address this area separately and then address the findings in the specific areas of assessment included in the survey instrument.

Level 1 and Level 2 fieldwork experiences are required in all OT educational programs by the Accreditation Council for Occupational Therapy Education (ACOTE, 2010). Level 1 experiences are intended to be short term and observational in nature and are typically placed at intervals throughout the didactic instruction portions of the educational curriculum. Each educational program has freedom to determine the length, format, and placement within the 
curriculum of the Level 1 fieldwork experiences. One of the only validated OT professional behavior assessments reported in the literature was developed for use at the end of Level 1 experiences by the Philadelphia Regional Fieldwork Consortium (Koenig, Johnson, Morano, \& Ducette, 2003). This tool focuses on students’ professional behavior in the Level 1 clinical environment. This assessment has been adopted by some OT educational programs outside of the consortium for use at the end of Level 1 experiences.

Level 2 fieldwork experiences are three-month full time clinical experiences also required by ACOTE. The goal for these two experiences is for the student to perform as an entry-level therapist by the conclusion of each fieldwork (ACOTE, 2002). Because the student is expected to perform as a clinician, Level 2 fieldwork experiences are typically placed at the end of the academic preparation phase of educational programs. Assessment of professional behavior is already included in the standardized “Fieldwork Performance Evaluation” (FWPE) (AOTA, 2002) that is completed for all students in the U.S. at the conclusion of each of their three-month full-time clinical experiences. An additional scale intended to assess just professional behaviors during Level 2 fieldwork was developed by Hubbard et al. (2007). This tool is voluntary and is intended to be used in addition to the FWPE.

In this study, when asked about when professional behavior should be assessed, the two most agreed-upon times to assess professional behavior was at the conclusion of Level 1 and Level 2 fieldwork experiences (92\% and 89\% “Strongly agreeing” or “Agreeing”, respectively). When asked what observations of student behavior should be included in assessment, all of the participants reported clinical behavior as "Valuable” or "Very valuable.” When asked to identify the importance of various participants in assessment, 99\% of respondents indicated that Level 1 fieldwork instructors and 100\% of respondents indicated that Level 2 fieldwork 
instructors were "Important” or "Very important." These responses when considered as a whole indicate a strong preference for including students' clinical experiences in the assessment of professional behavior within the educational program.

The purpose of assessing professional behavior in the educational program is to ensure that students possess and demonstrate appropriate professional behaviors when they enter the clinical environment. The most likely reason for the consistent opinions regarding the value of clinical experience in assessment is the authenticity and assumed validity of student performance in these settings. There also is a lack of research that clearly ties behavior observed in the academic environments to behavior exhibited in the clinic. The study completed by Papadakis et al. (2005) is the only published research to demonstrate a link between professional behavior problems in medical school and complaints to medical licensure boards.

Interval for assessment. Development of skills requires regular feedback. Occupational Therapy faculty in this study agreed that regular assessment of professional behavior was important with 93\% of participants “Disagreeing” or "Strongly disagreeing” with only assessing professional behavior when there was a problem.

Most Occupational Therapy education programs require between 28 to 36 months of education before graduation. When faculty were asked to indicate their level of agreement with suggested assessment intervals as discussed above, assessment at the conclusion of fieldwork experiences had the highest level of agreement.

After the conclusion of clinical experiences, faculty expressed the highest level of agreement with assessing professional behavior each year (85\% strongly agree or Agree) followed by each semester (84\% Strongly agree or Agree). These are common intervals that are 
discussed in the literature regarding professional behavior assessment in occupational therapy (Balboa \& Peloquin, 1999; Fidler, 1996).

Assessment tools for professional behavior. Assessment is strengthened by utilizing multiple methods (Banta, Jones, \& Black, 2009). In this study, participants from all institution types expressed that rubrics, critical incident reports, rating forms, and student reflections were the most valuable tools in professional behavior assessment. The use of portfolios, practical exams, and written exams were assigned the least value. This result is consistent with the frequency of the report of the use of these tools in the literature (Balboa \& Peloquin, 1999; Fidler, 1996; Koenig et al., 2003) and with the comments made by participants at the end of the survey. These results also indicate that faculty members prefer direct measures (Suskie, 2002) of student performance. In the case of professional behavior assessment, student reflection is considered a direct measure since the ability to reflect and accept responsibility for one’s performance is a professional behavior. Participants in this survey also expressed a desire for more reliable and valid tools to use in the comments section.

Observations to include in assessment. Comprehensive assessment is best performed when multiple observations of the desired behavior are included (Suskie, 2002). To this end, participants in this study were presented with a list of possible observations of behavior and asked to rate their value in the assessment of professional behavior. The results revealed a clear division between two groups of behavioral observations. As shown in Table 4.13, most participants agreed that observations of behavior in the clinic, laboratory, classroom, and in group work were valuable or very valuable. 
There was a notable decrease in the value assigned to other suggested observations, including performance on practical exams, social interactions with peers, professional conferences, OT related extracurricular activities, non-institution continuing education, and performance on written exam items. Most of the literature regarding occupational therapy professional behavior assessment only reported the use of observations of classroom and laboratory behavior (Balboa \& Peloquin, 1999; Fidler, 1996; Ledet et al., 2005).

Participants contributing to assessment. The literature review of assessment practices primarily presented faculty members as the main contributors in professional behavior assessment of students (Balboa \& Peloquin, 1999; Gutman et al. 1998; Ledet, Esperza \& Peloquin, 2005; Randoph, 2003). Other contributors identified in research include the student, peers, and clinical instructors (Fidler, 1996; Kasar \& Clark, 2000; Ledet, Esperza \& Peloquin, 2005; Randolph, 2003; Schonrock-Adema et al., 2007).

Participants in this study expressed that Level 1 and Level 2 fieldwork supervisors were the most important contributors, with 289 (100\%) participants selecting "Important” or "Very Important.” The next most important contributors were full-time faculty (288, 99\%), the student (280, 96\%), and part-time faculty (272, 93\%). After these contributors there was an observable drop in importance of the participation of program professional staff (203, 70\%), peers (199, 69\%), and lab instructors/teaching assistants (TAs) (148, 51\%).

These results highlight that faculty believe that behaviors should be assessed by “knowledgeable observers.” Most faculty members in OT programs are occupational therapists by training and educators by trade. They have specialty knowledge of, and insight into, the profession and what is required to succeed. The inclusion of students themselves as contributors 
to their own professional behavior assessment is consistent with the goal of professional behavior assessment, having the student demonstrate responsibility and self-awareness.

Program professional staff members are most likely non-occupational therapists with inconsistent knowledge of the profession and the health care arena. Lab instructors are often grad assistants or non-OT educators so faculty might question their understanding of what is needed in the clinic.

The assignment of lower importance to peer contribution is not unexpected but is interesting when considered in the context of the importance participants assigned to using observed social interactions with peers in professional behavior assessment. Only one study in the literature looked at the effect of peer assessment in professional behavior and found that it improved overall performance (Schronrock et al., 2007). Other researchers have indicated that students are concerned with the impact and anonymity of their ratings of their peers (Arnold, et al., 2005). Suskie (2009) states that peer evaluations in assessment need to be used cautiously because of the potential for biases to influence ratings (p. 106). Faculty express that student concerns with impact of their ratings often lead students to rate each other highly without consideration of actual performance. It is interesting that 236 (82\%) of the participants in this survey did express that it was important to include observation of social peer interactions in the assessment of professional behavior. Again, this supports that faculty think that observation of professional behavior is more valid when completed by skilled observers.

Use of assessment results. Palumbo and Banta (1999) identify multiple uses for assessment results at both the programmatic and individual level. Programmatic use of results includes altering the assessment process or tools, making changes to curriculum, and/or making 
changes to instruction. Currently published research on professional behavior assessment in health professions education programs has not addressed the use of results at this level. Much of the research has addressed the use of results at the individual or student level.

In this study 99\% of faculty felt that it was "Very important” or "Important” to use assessment results to advise individual students. Nearly all (95\%) of faculty expressed that is was "Very important” or "Important” to use assessment results to determine effectiveness of instruction, and to inform changes in the assessment plan. These are all considered appropriate and good uses of assessment results in the literature (Suskie, 2009).

Faculty participants felt it "Very important” or “Important” that assessment results be included in the program assessment plan (84\%), that results are used to inform faculty professional development (83\%), and that results lead to changes in the curriculum (84\%). This speaks to a belief of OT faculty that assessment of student performance is a valuable tool in educational planning.

Interestingly, only $49 \%$ of participants felt that individual assessment results should be compiled to reflect the performance of the group as a whole. This most likely arises from the belief that most students have good professional behaviors and only a few students perform poorly. This is supported by the $70 \%$ of participants who felt that students had outstanding professional behaviors and many comments made by participants on the survey. However, it is interesting to note that to use assessment results in the ways that OT faculty expressed were important it would be necessary to compile results to reflect the performance of a group of students. 
Student consequences for poor professional behavior. In this section of the survey, participants were asked to indicate at which level of severity of professional behavior problems certain consequences would be appropriate. Counseling with a faculty advisor was most often chosen for mild to moderate professional behavior problems. Program probation, delayed entry into fieldwork, and termination from program were indicated by participants for "Moderate to severe” and "Severe” problems in professional behavior. Professional behavior plans, decrease in course grades, and delayed progression in the OT program were most often chosen for "Mild to moderate”, “Moderate”, and Moderate to severe” professional behavior problems. Although various sources in the literature have suggested or reported the use of these consequences in response to professional behavior problems, no research exists reporting the frequency of these consequences or the level of severity in which they are used.

\section{Research Question 3: Is there a significant difference in the responses of faculty from} different institutional (Carnegie Classification) in regards to what professional behaviors should be assessed among different institutional (Carnegie Classification) types?

Research Question 4: Is there a significant difference in responses from faculty from different institutional types (Carnegie Classification) in regards to how professional behaviors should be assessed among different institutional (Carnegie Classification) types?

These two research questions examined if faculty from different types of institutions would have different opinions and thoughts regarding professional behaviors and how to assess them. The Carnegie classification system is intended to describe institutional characteristics in universal terms. The classifications also provide a way to represent and control for institutional differences in research on institutions (Carnegie, 2014). The Carnegie classification groups institutions using six categories including: undergraduate instructional program; graduate 
instructional program; enrollment profile; undergraduate profile; size and setting and, basic classifications. In this study the basic classification was used to group participants for comparison study.

The basic classification divides institutions based on the degrees awarded and amount of research activity. For this study participants were divided into four groups: Associates and Baccalaureate institutions; Master’s Colleges; Special Focus institutions; and, Doctoral Granting Universities.

The use of the Carnegie classification system in research about higher education assumes that institutions of similar classification will share similar characteristics in their missions, institutional culture, reward structures, and workload. These similar features are assumed to affect the thoughts and opinions of faculty working at institutions of the same type. Researchers have identified Carnegie classification as more important than academic discipline when determining scholarly productivity and in departmental culture (Gutman, 1997; Lee, 2007). However multiple research studies have shown that institutional type may not the biggest factor in faculty rewards, and workload (Fairweather, 1993; Porter \& Umbach, 2001). In this study faculty from all institution types did not vary significantly on the importance of assessing the specific professional behaviors presented in the survey instrument. In the area of assessment practices, however, there were a three specific items were statistically significant differences appeared.

Two of the statistically significant differences appeared in how valuable it was to include observations of students' behavior at conferences and non-institutional hosted professional education in the assessment of professional behavior. Overall, the results indicate that faculty 
from baccalaureate institutions assigned less value to these observations when compared to faculty from other institution types. Because research has not previously looked at how institutional type affects assessment opinions in allied health professionals, it is difficult to know what influenced these results. It is possible that faculty from institutions with less research focus would find professional conferences and educational events less important to student development than faculty from institutions with a higher research and knowledge generation emphasis. It is also possible that, since Baccalaureate institutions are smaller, opportunities and resources to attend conferences and non-institutional continuing education events are less frequent.

The final statistically significant difference was how to use assessment results at a programmatic level. Faculty from Baccalaureate institutions assigned less importance to compiling the results of assessment to reflect the performance of the group as a whole than faculty from other institutions. Again, no published research explains this variation in responses. Faculty from baccalaureate institutions may have a higher focus on individual students and find performance of the group less important than performance of the individual.

With the few exceptions noted above, OT faculty hold similar opinions regarding the importance of professional behavior assessment, the importance of specific behaviors, and the importance and value of assessment techniques despite the type of institution they worked in. The results of this research study suggest that when considering the assessment of student professional behavior, discipline, or profession specific concerns hold a greater influence than institutional classification or missions on faculty opinions. It is worth noting that most respondents to this survey (95\%) held professional OT degrees. Several factors support the maintenance of a strong identity as an occupational therapist, the accreditation standards set forth 
by ACOTE (2011) require OT faculty to demonstrate expertise in education and experience in their areas of teaching (Standard A.2.8) and that they maintain licensure as an occupational therapist in the state that the institution is located in (A.2.11). Licensure as an occupational therapist requires yearly attendance at clinically relevant continuing education; this ensures that the occupational therapy faculty member will interact with clinical occupational therapists on a regular basis. Also, in occupational therapy, only one major professional conference is held each year. The conference encourages interactions between practitioners and OT faculty helping to bolster the faculty members’ identification as occupational therapists.

\section{Research Question 5: Is there a significant difference between full-time and part-time faculty responses regarding what professional behaviors should be assessed in OT educational programs?}

\section{Research Questions 6: Is there a significant difference between full-time and part-time faculty responses regarding how professional behaviors should be assessed in OT educational programs?}

The utilization of part-time faculty is common in Occupational Therapy educational programs. According to the ACOTE educational program annual data report for 2013-2014, 42\% of full-time equivalents (FTEs) were held by part-time or adjunct faculty (ACOTE, 2014). This is less than the $50 \%$ of part-time instructional faculty employed in higher education, as reported by the National Center for Education Statistics (NCES) in their report for Fall 2013 (Ginder, Kelly-Reid, \& Mann, 2014). Part-time and adjunct faculty members are often local clinicians who work part or full-time in the clinic, in addition to their academic responsibilities. Research on part-time or adjunct faculty has found that they might have less loyalty to the institution and have less understanding of good educational and assessment practices (Levin \& Hernandez, 
2014). Due to the under-representation of part-time and adjunct faculty in this research study, it is difficult to draw any conclusions regarding differences in the thoughts and opinions of parttime OT faculty.

When examining the results of the importance of including specific behaviors in professional behavior assessment, two behaviors demonstrated statistically significant differences between full-time and part-time faculty: responsibility for own learning, and initiative. Although these differences were statistically significant, it is most likely that they are not practically significant. Most of the differences in responses were that full-time faculty were most likely to report these three behaviors as "Very important”, while part-time faculty were more likely to report these behaviors as "Important." Since the interval between "Very important" and "Important” is neither fixed nor measurable the practical significance of the findings are unknown. It is possible when the two behaviors are considered as a group that parttime faculty think that behaviors that involve the student taking a more active role are less important that full-time faculty. This may be caused by a push at the academic level to educate occupational therapists who are advocates for their clients and the profession. Full-time faculty has a clearer understanding of the accreditation standards that encourage this focus than parttime faculty.

In the area of assessment opinions, several statistically significant differences were noted. It is important to note that it is difficult to draw conclusions from these results due to the small sample size of part-time faculty in this study.

Two differences were noted when looking at the value of including specific observations in professional behavior assessment. Part-time faculty expressed that observations of student 
behavior in laboratory sessions was more important than full-time faculty. Given that many parttime faculty are assigned to instruct laboratory sessions this is not a surprising result. Part-time faculty also assigned less importance to the observation of group work in professional behavior assessment. This may be attributed to the nature of work for part-time faculty. Part-time faculty members often come to campus to teach and then quickly leave again when they are done. This provides the part-time faculty member with less time to observe the students involved in group work. Full-time faculty members spend more time at the institution and have more opportunity to observe group work. This might increase the perceived importance of these observations.

The other area in which statistically significant differences between full-time and parttime faculty appeared was in the use of assessment results at a programmatic level. This result, although statistically significant, has little practical significance due to the high empty cell count and the primary difference existing in percentage of participants who chose "Very important" versus “Important.”

The use of assessment results to inform professional development was the second statistically significant difference. Part-time faculty were more likely to rate this use as "Very “unimportant” and "Unimportant” than full-time faculty. Part-time faculty members are hired to teach and are provided with few if any opportunities to attend professional development opportunities that address their skills and knowledge in academic concerns such as assessment.

Despite the differences discussed above, overall, both part-time and full-time faculty members held similar opinions regarding professional behaviors and assessment practices. This highlights the strong identity with the profession that both full-time and part-time occupational therapy faculty experience. 


\section{Final Thoughts and Opinions Regarding Assessment}

Generally, the results of this research support that faculty believe professional behavior needs to be assessed in OT education, 97\% of participants "Strongly agreed” or “Agreed” that OT educational programs should assess the professional behaviors of students. Eighty-one percent of participants reported that their academic program currently assesses professional behavior.

However, concerns regarding professional behavior assessment were also expressed by participants. One hundred and forty-five participants (49\%) indicated that they "Strongly agreed” or “Agreed” that current assessment of student professional behavior was adequate while 148 (51\%) responded that they were neutral, disagreed, or strongly disagreed with this statement. Only 39\% of participants “Strongly agreed” or “Agreed” that OT students valued professional behavior assessment, while $77 \%$ of participants "Strongly agreed” or “Agreed” that faculty valued professional behavior assessment. Research regarding student perception of professional behavior assessment supports this result. Students have reported that professional behavior assessment is difficult because of the personal nature of the feedback (Scheerer, 2003; Rees and Shepard, 2005). Students have also reported that understanding what professional behavior is required appears to be largely contextual (Robinson, Tanchuck, \& Sullivan, 2012).

Faculty also expressed concerns with the reliability of professional behavior assessment with only $42 \%$ of faculty "Strongly agreeing” or “Agreeing” that faculty consistently rated student behavior. This was also a concern expressed in the open comments section at the end of the instrument regarding the fairness of current assessment. Despite these concerns, $71 \%$ of participants “Strongly agreed” or "Agreed” that current student professional behaviors were outstanding. 


\section{Recommendations for Practice}

The results of this study support that faculty believe that observation of professional behavior in clinical settings is important and valuable. The findings can provide guidance for curriculum development. For the development and assessment of professional behavior, students should have Level 1 fieldwork experiences spread throughout the curriculum. Level 1 fieldwork experiences are short-term clinical experiences that are intended for the student to observe and attempt some clinical skills under close supervision. Level 2 clinical experiences are intended for the OT student to function as a full time therapist for three months. The ACOTE accreditation standards state that students should have completed all of their academic preparation before completing Level 2 experiences. Level 2 fieldwork experiences are typically completed at the end of the educational program. For this reason, Level 1 fieldwork experiences lend themselves better to periodic assessment of professional behavior within the didactic portion of the occupational therapy curriculum.

\section{Recommendations for Future Research}

This study presented information regarding assessment of the professional behaviors of students from one stakeholder group, faculty. The topic requires more study with other significant stakeholders such as clinicians, students and clients to fully understand the complexities associated with the topic. The results of this study indicate the need for more research in two areas: professional behaviors; and, professional behavior assessment involving faculty, students, clinicians and clients. It is very clear that the profession of occupational therapy in the United States needs to develop a common understanding of what constitutes professionalism for occupational therapists and what professional behaviors are essential for the practice of OT. The best way to do this is a multiple step research sequence. 
First, the concept of professionalism in OT needs to be clearly defined. Researchers in Australia recently used a Delphi technique to define professionalism and identify essential professional behaviors. This technique would be the most appropriate within the United States also. Currently there are a large number of potential professional behaviors identified by this research. Aguilar et al. (2012) were able to take a list of 32 behaviors and utilizing a two-step Delphi technique develop a final list of seven essential professional behaviors. A study in the U.S. should include both faculty and clinicians and possibly clients as participants. Utilization of the Delphi technique with multiple stakeholders will also allow the profession to develop a common conceptualization of professional behaviors.

Once the essential professional behaviors have been identified, another Delphi study might be required to clearly define and describe each behavior. This study should also include both faculty members and clinical professionals.

A third study would utilize behaviors and definitions developed through the Delphi studies to present faculty and clinical professionals with a survey. Participants to the survey would be asked to rank the professional behaviors from most to least important for clinical practice. This would be similar to research carried out in Physical therapy by Davis (2009). At the conclusion of this series of studies, Occupational Therapy should have reached common professional understanding regarding essential professional behaviors.

Completing this research sequence will also benefit future occupational therapy students. Currently, the professional behavior expectations appear to vary from educational program to educational program. This leads to confusion for students and also leads students to question the validity of professional behavior assessment carried out by faculty. By having a profession-wide 
document that outlines essential behaviors, students can be assured that expectations are universal.

Assessment research. Results from this study indicate $89 \%$ of participants worked in programs where professional behavior was assessed in some manner. However, there is no current research that quantifies how many programs have a formal assessment process in place. The first step in the research on professional behavior assessment would be to determine how many programs are assessing professional behavior, what behaviors they are assessing, and how they are assessing them. This should be completed by a survey similar to the one used in this study sent to the Academic Fieldwork Coordinator (AFC) of each educational program. The AFC is the best subject for this research because each OT educational program must have an identified AFC to be accredited and the AFC is typically aware of all professional behavior assessment being completed in the program.

Once the breadth of professional behavior assessment in occupational therapy programs is understood the next step would be to research specific pieces of the assessment process in use to help determine best practice. Of particular interest would be reliability and validity studies of the tools being used in assessment. Conversation with other professionals in academic education programs and the research has indicated that many academic programs have developed their own specific tool and process for assessing professional behaviors. Participants in this study also expressed concern with the fairness of professional behavior assessment and the inter-rater reliability of the process. Research to identify and develop standardized tools with good interrater and test-retest reliability would address some of the fairness concerns of both faculty and students. Only one currently used tool, The Philadelphia Consortium Fieldwork Assessment Tool has undergone reliability and validity studies (Koenig, Johnson, Morano, \& Ducette, 2003). 
It is also important to consider the viewpoints of students in the assessment of student professional behavior. A survey similar to this one could be completed with students. This would be most effective after the essential professional behaviors have been identified and defined. The primary goal of assessment is to ensure student learning. It is critical to understand how student perceive the helpfulness of various professional behavior assessment techniques is facilitating their learning.

\section{Validity of professional behavior assessment in the academic setting as a predictor}

for clinical success. Another important area for research is to establish a link between behavior exhibited in the academic setting and behaviors exhibited in the clinical environment.

Assessment of student professional behaviors is an activity that is difficult and time intensive for students and faculty. It is essential to clearly demonstrate the link between behaviors observed in the academic setting to behaviors exhibited in the clinic. Research completed in medicine has suggested that troublesome behaviors do persist into clinical practice but no such evidence exists in occupational therapy. This would require a longitudinal multi-site research design. Students would have to be tracked from admission into the program, through their fieldwork education and then possibly into the first few years of clinical practice. Because the reported incidence of professional behavior problems remains relatively low, a large pool of participants will be needed to reach appropriate power to draw conclusions.

Students and professional behaviors assessment. Two studies in particular would be helpful to identify how to best develop assessment practices that would be accepted by and helpful to students and to identify the best instructional methods for students. 
A recent research study in Canada utilized focus groups to discuss concepts of professionalism and professional behavior with students (Robinson, Tanchuck, \& Sullivan, 2012). Information from that study revealed that students experience a lack of surety regarding what is expected from them in the arena of professional behavior. Students also expressed a desire for specific concrete expectations. This study could be repeated with students enrolled in American occupational therapy education programs to gain an understanding of how students of this generation perceive professionalism and professional behaviors. Students could also be asked to identify techniques they find particularly helpful in understanding and learning the professional expectations of the profession.

One published research report focused on occupational therapy student reaction to professional behavior assessment (Scheerer, 2003). This study was limited to a specific educational program and was completed many years ago. In an effort to recommend assessment designs that would be accepted by students, a multi-site study should be completed to understand students' perceptions of helpful and non-helpful feedback and assessment practices. Because this kind of research has not been completed before in occupational therapy, a preliminary qualitative study utilizing focus groups might be completed first to develop questions to follow up with students through a large-scale survey instrument.

\section{Limitations}

The greatest limitation of this research was the response rate of 22\% which limits external validity. The response rate is not unusual in OT educational research. Gupta and Bilics (2014) surveyed the population of OT faculty and achieved a response rate of 23\%, while Fazarano \& Zipp (2012) achieved a 13\% response rate of a population of OT faculty. The rate of responses might have been negatively affected by the method used to identify potential 
participants. The researcher noted that the websites for many programs may not have been current. Some potential participants appeared as faculty at more than one OT educational program. Also not all OT programs listed their part-time faculty on their websites which most likely explains the small sample size of part-time faculty. It is also possible that only faculty who held strong opinions regarding the assessment of students' professional behaviors chose to complete the survey. It should be considered, that since so many of the participants worked in OT programs that currently assess professional behavior that social desirability may have altered participant responses. Participants may have indicated higher levels of agreement and importance because they felt that they should be concerned with the assessment of professional behavior.

Another limitation was the survey instrument. Although the survey was able to be completed quickly online, it was a long survey and persistence of participants to the end of the survey was negatively impacted. In particular, the extent of demographic information sought seemed to be a barrier to completion of the survey, with $15 \%$ of initial participants not persisting past the demographic section of the survey. Moving the demographic questions to the end of the survey might have helped to alleviate part of this issue.

The risk of identification posed by the first question might have also limited participation. The first question asked the participant for the name of their institution. Although the participant was assured that the information would only be used to assign Carnegie Classification and regional accreditation it is reasonable that some faculty felt the risk of identification posed by providing their institution name as well as the personal demographics asked for raised the risk of identification too high. This perception of risk could be lowered by asking the participant to identify their institution Carnegie Classification and regional accreditor in future studies. 
It appeared that some participants were confused by the question regarding consequences of poor professional behavior assessment. Although the pilot study participants reported understanding the question, the response rate to the question was lower, and four participants indicated in the comments section that they found the question confusing.

The analysis of data of this survey might have been significantly affected by a ceiling effect. A ceiling effect occurs when a scale of measure does not have sufficient range to allow for variability at the high end of the scale (Keeley, English, Irons, \& Henslee, 2013). This effect is most likely observed in the results of the importance of behavior in assessment where all behaviors were rated as “Important” or “Very Important” by most participants. More variability in the responses of participants would have been achieved by the use of a Likert type scale with more range, a 1 to 9 or 1 to 7 seven scale, or by use of a visual analog scale to indicate agreement with the inclusion of behaviors.

\section{Conclusion}

This was a descriptive study of the thoughts and opinions of OT faculty regarding the assessment of the professional behavior of students in the educational environment. Previous research had looked at the picture of assessment of professional behavior through the lens of individual programs, practices, and individual tools. This study attempted to take a picture of the issue at a profession-wide faculty level. This picture shows what the literature had suggested up to this point. The literature and some of the results of this study indicates that professionalism and essential professional behaviors are not well defined in occupational therapy in the United States, however, OT faculty think that professional behaviors and the assessment of them in students is important. The profession of Occupational Therapy and OT students will benefit from embarking on a course already initiated in Britain, Australia, and Canada to define what 
professionalism means for the profession and to identify essential professional behaviors. This will require profession wide research and discourse. The review of the literature reveals that this activity has occurred before in the periods 1996-1998 and 2000-2007, but sustained activity and progress has not been maintained. Part of this might be due to a lack of emphasis in the OT profession on educational research. However, in 2013 AOTA instituted special educational issues of their research journal and has begun to host educational summits on alternating years. Perhaps with the environment changing to encourage educational research, studies to examine how the profession teaches and assesses professionalism and professional behaviors can be initiated and published.

This study also showed a picture of faculty who felt it was important to utilize good assessment methodology to inform educational practice and assessment. Faculty felt that assessment should occur at regular intervals, involve multiple observations of desired behavior, and use knowledgeable observers. The results also demonstrated that faculty may believe that professional behaviors are best assessed in a context of meaning, i.e., the clinic.

The need for further action is clear and the complex path forward will require cooperation and leadership from the professional organization representing occupational therapy, OT faculty, and OT practitioners, as well as OT students. 


\section{References}

Accreditation Council for Occupational Therapy Education. (2008). Accreditation standards for a Master's-degree-level educational program for the occupational therapist. Retrieved from http://www.aota.org/Educate/Accredit/StandardsReview/guide/Masters.aspx

Accreditation Council for Occupational Therapy Education. (2013). Academic Programs Annual Data Report. Retrieved from http://www.aota.org//media/Corporate/Files/EducationCareers/Accredit/2013-2014-Annual-Data-Report.pdf

Aguilar, A. Stupans, I., Scutter, S., \& King, S. (2013). Towards a definition of professionalism in Australian occupational therapy: Using the Delphi technique to obtain consensus on essential values and behaviours. Australian Occupational Therapy Journal, 60, 206-216. doi:10.111/14440-1630.12017

American Board of Internal Medicine. (2008). Medical professionalism in the new millennium: A Physician Charter. Retrieved from http://www.abimfoundation.org/Professionalism/ /media/Files/Physician\%20Charter.ash $\underline{x}$

American Occupational Therapy Association. (2002). Fieldwork performance evaluation for the Occupational Therapy student. Bethesda, MD: AOTA Publications.

American Occupational Therapy Association. (2010). Occupational Therapy Code of Ethics and Ethics Standards. Retrieved from http://www.aota.org/Practitioners/Official/Ethics/40611.aspx?FT=.pdf

American Occupational Therapy Association. (2008) Occupational Therapy - Referral requirements. Retrieved from http://www.aota.org/Practitioners/Licensure/StateRegs/Referral/36361.aspx?FT=.pdf 
American Occupational Therapy Association. (2010). Carnegie classifications of Occupational Therapy programs. Retrieved from http://www.aota.org//media/Corporate/Files/EducationCareers/Educators/OTEdData/Carnegie\%20Classificati ons\%200T\%202010.pdf

American Occupational Therapy Association. (2010). Faculty workforce survey. Retrieved from http://www.aota.org/$\underline{\text { /media/Corporate/Files/EducationCareers/Educators/OTEdData/2010\%20Faculty\%20Sur }}$ vey\%20Report.pdf

American Occupational Therapy Association. (2014). Occupational Therapy practice framework:Domain and process. Bethesda, MD: AOTA Publications.

American Physical Therapy Association. (2010). Professionalism in Physical Therapy: Core values. Retrieved from http://www.apta.org/uploadedFiles/APTAorg/About_Us/Policies/BOD/Judicial/Professio nalisminPT.pdf\#search=\%22Professionalism in Physical Core Values\%22

Archer, R., Elder, W., Hustedde, C., Milam, A., \& Joyce, J. (2008). The theory of planned behavior in medical education: A model for integrating professionalism training. Medical Education, 42, 771-777. doi:10.1111/j.1365-2923.2008.03130.x

Arnold, L. (2002). Assessing professional behavior: Yesterday, today, and tomorrow. Academic Medicine, 77, 502-515. doi:10.1097/00001888-200206000-00006

Arnold, L., Shue, C.K., Kritt, B., Ginsburg, S. \& Stern, D.T. (2005). Medical students’ view on peer assessment of professionalism. Journal General Internal Medicine, 20, 819-824. doi: 10.1111/j.1525-1497.2005.0162.x

Arnold, L. \& Stern, D.T. (2006). What is Medical Professionalism? In Stern, D.T. (Ed), 
Measuring medical professionalism. Retrieved from

http://site.ebrary.com/lib/nwvu/Doc?id=10375307

Babola, K. A., \& Peloquin, S. M. (1999). Making a clinical climate in the classroom: An assessment. American Journal of Occupational Therapy, 53, 373-380. doi: 10.5014/ajot.53.4.373

Banta, T.W., Jones, E.A., Black, K.E. (2009). Designing effective assessment: Principles and profiles of good practice. San Francisco: Jossey-Bass.

Best, C.E. (1994). A prediction model of performance in level II fieldwork in physical disabilities. American Journal of Occupational Therapy, 48, 926-931. doi:10.5014/ajot.48.10.926

Blue, A.V., Crandall, A., Nowacek, G., Luecht, R., Chauvin, S., \& Swick, H. (2009). Assessment of matriculating medical students' knowledge and attitudes towards professionalism. Medical Teacher, 31, 928-932. doi:10.3109/01421590802574565

Bossers, A., Kernaghan, J., Hodgins, L., Merla, L, O’Connor, C., \& VanKessel, M. (1999). Defining and developing professionalism. Canadian Journal of Occupational Therapy, 66(3) 116-121. doi:10.1177/000841749906600303

Brawner, C.E., Feldner, R.M., Allen, R., \& Brent, R. (2003). 2002 SUCCEED Faculty survey of teaching practices and perceptions of institutional attitudes toward teaching. Grantee Submission. Available from ERIC.

Bureau of Labor Statistics. (May, 2015). Occupational outlook handbook: Occupational Therapists. Retrieved from: http://www.bls.gov/ooh/Healthcare/Occupationaltherapists.htm

Carnegie Foundation for the Advancement of Teaching. (March, 2015). The Carnegie 
Classification of Institutions of Higher Education - About Carnegie Classification. Retrieved from http://carnegieclassifications.iu.edu/

Chaffey, L., Unsworth, C.A., \& Fossey, E. (2012). Relationship between intuition and emotional intelligence in occupational therapists in mental health practice. American Journal of Occupational Therapy, 66, 88-96. doi:10.5014/ajot2012.001.001693

Cullen, J. (1978). The structure of Professionalism. New York: Petrocelli Books.

Davis, D.S. (2006). Learning and developing professional behaviors as part of an entry-level physical therapy education: A survey of students and practicing clinicians. (Doctoral Dissertation) Available from ProQuest Dissertations and Theses database. (UMI No. 304974089).

Davis, D.S. (2009). Teaching professionalism: A survey of Physical Therapy educators. Journal of Allied Health. 38(2), 74-80.

Fairweather, J.S. (1993). Faculty reward structures: Toward institutional and professional homogenization. Research in Higher Education, 34(5), 603-623. doi:10.1007/BF00991922

Falzarano, M., Zipp, G. P. (2012). Perceptions of mentoring of full-time occupational therapy faculty in the United States. Occupational Therapy International, 19, 117-126. doi: 10.1002/oti.1326

Fidler, G.S. (1996). Developing a repertoire of professional behaviors. American Journal of Occupational Therapy, 50, 583-587. doi:10.5014/ajot.50.7.583

Fleming, M.H. (1991). Clinical reasoning in Medicine compared with clinical reasoning in Occupational Therapy. American Journal of Occupational Therapy, 45, 988-996. doi:10.5014/ajot.45.11.988 
Foord-May, L., \& May, W. (2007). Facilitating professionalism in physical therapy: Theoretical foundations of the facilitation process. Journal of Physical Therapy Education, 21(3), 612.

Fryer-Edwards, K., Pinsky, L.E., \& Robins, L. (2006). The use of portfolios to assess professionalism. In Stern, D.T. (Ed.), Measuring medical professionalism (pp.164-174). Retrieved from http://site.ebrary.com/lib/nwvu/Doc?id=10375307

Gay, L.R., \& Airasian, P. (2003). Educational research: Competencies for analysis and applications, $7^{\text {th }}$ ed. Upper Saddle River, NJ: Merrill Prentice Hall.

Ginder, S.A., Kelly-Reid, J.E., \& Mann, F.B. (2013). Enrollment in postsecondary institutions, Fall 2013; Financial statistics, Fiscal year 2013; and employees in postsecondary institutions, Fall 2013: First look (provisional data) (NCES 2015-012). U.S. Department of Education. Washington, D.C. Retrieved from http://nces.ed.gov/pubsearch.

Gupta, J. \& Bilics, A. (2014). Brief Report - Scholarship and research in occupational therapy education. American Journal of Occupational Therapy, 68, S87-S92. doi: 10.5014/ajot.2014.012880

Gutman, M. (1997). Faculty scholarly productivity a multilevel analysis. (Doctoral Dissertation) Available from Pro-Quest Dissertations and Theses database. (UMI No 9812843).

Gutman, S. A., McCreedy, P., \& Heisler, P. (1998). Student level II failure: Strategies for intervention. American Journal of Occupational Therapy, 52, 143-149. doi:0.5014/ajot.52.2.143

Hoonakker, P., \& Carayon, P. (2009). Questionnaire survey nonresponse: A comparison of postal mail and internet Surveys. Journal of Human-Computer Interaction, 2, 348-373. doi:10.1080/10447310902864951 
Hubbard, S., Beck, A., Stutz-Tanenbaum, P., \& Battaglia, C. (2007). Reliability and validity of the Occupational Therapy Attribute Scale. Journal of Allied Health, 36(4), 193-200.

Hudd, S.S., Apgar, C., Bonson, E.F., Less, R.G. (2009). Creating a campus culture of integrity: Comparing the perspectives of full- and part-time faculty. The Journal of Higher Education, 80(2), 146-177. http://www.jstor.org/stable/25511100

James, K. L., \& Musselman, L. (2005). Commonalities in level II fieldwork failure. Occupational Therapy in Health Care, 19(4), 67-81. doi:10.1300/J003v19n04_05

June, A.W. (2015) What it means to reach for Carnegie’s top tier. The Chronicle of Higher

Education. Retreived April 30, 2015 from: http://chronicle.com/article/What-It-Meansto-Reach-for/229651/?cid=at\&utm_source=at\&utm_medium=en

Kasar, J. E., \& Clark, N. (Eds.). (2000). Developing professional behaviors. Thorofare, NJ: Slack Inc.

Keeley, J.W., English, T., Irons, J., \& Henslee, A.M. (2013). Investigating halo and ceiling effects in student evaluations of instruction. Educational and Psychological Measurement, 73(3), 440-457. doi: 10.1177/0013164412475300

Koenig, K., Johnson, C., Morano, C., \& Ducette, J.P. (2003). Development and validation of a professional behavior assessment. Journal of Allied Health, 32(2), 86-91.

Kovach, R.A., Resch, D.S., \& Verhulst, S.J. (2009). Peer assessment of professionalism: A fiveyear experience in medical clerkship. Journal General Internal Medicine, 24, 742-746. doi:10.1007/s11606-009-0961-5

Kozeracki, C.A. (2002). Faculty attitudes about students. New Directions for Community Colleges, 118. 47- 55. doi: 10.1002/cc.63

Larkey, J. (2000). Professional presentation. In Kasar, J. \& Clark, N. (Eds.), Developing 
professional behaviors (pp.45-53). Thorofare, NJ: Slack Inc.

Lee, J.J. (2007). The shaping of the departmental culture: Measuring the relative influences of the institution and discipline. Journal of Higher Education Policy and Management, 29(1), 41-55. doi:10.1080/13600800601175771

Ledet, L., Esparza, C. K., \& Peloquin, S. M. (2005). The conceptualization, formative evaluation, and design of a process for student professional development. American Journal of Occupational Therapy, 59, 457-466. doi:10.5014/ajot.59.4.457

Levin, J.D., \& Hernandez, V.M. (2014). Divided identity: Part-time faculty in public colleges and universities. The Review of Higher Education, 37(4), 531-557. doi:10.1353/rhe.2014.0033

Little, T.L. (2008). Defining and imparting professional behavior in physical therapist educational programs: Perspectives of selected senior faculty. (Doctoral dissertation) Available from ProQuest Dissertations and Theses database. (UMI No. 3044924)

Liu, X., Zhang, L. (2007). What determines employment of part-time faculty in higher education institutions? Cornell University Higher Education Research Institute, Working Paper \#105. June 18, 2007. Retrieved May 1, 2015 from www.elr.cornell.edu/CHERI.

Lusher, A. (2010). Assessment practices in undergraduate accounting programs. Journal of Case Studies in Accreditation and Assessment, 1.

Lyons, M. (1997). Understanding professional behavior: Experiences of occupational therapy students in mental health settings. American Journal of Occupational Therapy, 51, 686692. doi:10.5014/ajot.51.8.686

Mann, W.C., \& Banasiak, N. (1985). Fieldwork performance and academic grades. American Journal of Occupational Therapy, 39(2), 92-95. 
Martimianakis, M.A., Maniate, J.M., \& Hodges B.D. (2009). Sociological interpretations of professionalism. Medical Education, 43, 829-837. doi:10.1111/j.1365-2923.2009.03408.x

Mattingly, C. (1991). What is clinical reasoning? American Journal of Occupational Therapy, 45, 979- 986. doi:10.5014/ajot.45.11.979

Mattingly, C., \& Fleming, M.H. (1994). Clinical reasoning: Forms of Inquiry in a Therapeutic Practice. Philadelphia: F.A. Davis Company.

McCormick, A.C., \& Zhao, C. (2005). Rethinking and reframing the Carnegie Classification. Change, September/October, 52-57. doi: 10.3200/CHNG.37.5.51-57

Meeus, W., VanPetegem, P., \& Engels, N. (2009). Validity and reliability of portfolio assessment in pre-service teacher education. Assessment \& Evaluation in Higher Education, 34, 401-413. doi:10.1080/02602930802062659

Meruelo, N.C. (2008). Mediation and malpractice: The need to understand why patients sue and a proposal for a specific model of mediation. The Journal of Legal Medicine, 29, 285-306. doi:10.1080/01947640802297533

Milem, J.F., Berger, J.B., \& Dey, E. L. (2000). Faculty time allocation: A study of change of twenty years. The Journal of Higher Education, 71(4), 454-475.

Morris, A. H., \& Faulk, D. (2007). Perspective transformation: Enhancing the development of professionalism in RN to BSN students. Journal of Nursing Education, 46, 445-451.

Muscari, M.E. (2000). Written communication. In Kasar, J., \& Clark, N. (Eds.), Developing professional behaviors (pp 45-53). Thorofare, NJ: Slack Inc.

Norcini, J. (2006). Faculty observations of student professional behavior. In Stern, D.T. (Ed.), Measuring medical professionalism (pp.164-174). Retrieved from http://site.ebrary.com/lib/nwvu/Doc?id=10375307 
Palomba, C.A., \& Banta, T.W. (1999). Assessment Essentials. San Francisco, Jossey-Bass.

Papadakis, M.A., Therani, A., Banach, M.A., Knettler, T.R., Rattner, S. L., Stern D.T., \& Hodgson, C.S. (2005). Disciplinary action by medical boards and prior behavior in medical school. The New England Journal of Medicine, 353, 2673-2682.

doi:10.1056/NEJMsa05296

Paul, S., Liu, Y., Ottenbacher, K.J. (2002). Brief report: Research productivity among occupational therapy faculty members in the United States. The American Journal of Occupational Therapy, 56(3), 331-334. doi: 10.5014/ajot.56.3.331

Paul, S., Stein, F., Ottenbacher, K.J., \& Liu, Y. (2002). The role of mentoring on research productivity among occupational therapy faculty. Occupational Therapy International, 9(1), 24-40. doi: 10.1002/oti.154

Peloquin, S. (1993). The depersonalization of patients: A profile gleaned from narratives. American Journal of Occupational Therapy, 47(9), 830-837. doi:10.5014/ajot.47.9.830

Peloquin, S. (2002). Confluence: Moving forward with affective strength. American Journal of Occupational Therapy, 56(1), 69-77. doi:10.5014/ajot.56.1.69

Peterson, P. (2000). Dependability, in Kasar, L., \& Clark, E.N. (Eds.), Developing professional behaviors (pp. 29-42). Thorofare, NJ: Slack Inc.

Pollart, S.M., Dandar, A. Brubaker, L., Chaudron, L., Morrison, L.A., Fox, S., Mylona, E. \& Bunton, S. (2015). Characteristics, satisfaction, and engagement of part-time faculty at U.S. Medical schools. Academic Medicine, 90(3), 355-364. doi: 10.1097/ACM.0000000000000470

Porter, S. R., \& Umbach, P.D. (2001). Analyzing faculty workload data using multilevel modeling. Research in Higher Education, 42(2), 171-196. 
Portney, L.G., \& Watkins, M.P. (2000). Foundations of clinical research: Applications to practice. $2^{\text {nd }}$ ed. Upper Saddle River, NJ: Prentice Hall Health.

Punwar, A. (2000). The art and science of practice. In Punwar, A., \& Peloquin, S. (Eds), Occupational Therapy: Principles and practice, $3^{\text {rd }}$ edition (pp 93-108). Baltimore: Lippincott Williams \& Williams.

Quiroga, V.A.M. (1995). Occupational therapy: The first 30 years, 1900-1930. Bethesda, MD: The American Occupational Therapy Association.

Randolph, D. S. (2003). Evaluating the professional behaviors of entry-level occupational therapy students. Journal of Allied Health, 32(2) 116-121.

Rees, C., \& Shepherd, M. (2005). Students' and assessors' attitudes towards students' selfassessment of their personal and professional behaviours. Medical Education, 39, 30-39. doi:10.1111/j.1365-2929.2004.02030.x

Roberts, C., \& Stark, P. (2008). Readiness for self-directed change in professional behaviors: Factorial validation of the Self-reflection and Insight Scale. Medical education, 42, 1054-1063. doi:10.1111/j.1365-2923.2008.03156.x

Robinson, A.J., Tanchuk, C.J., \& Sullivan, T.M. (2012). Professionalism and occupational therapy: An exploration of faculty and students' perspectives. Canadian Journal of Occupational Therapy, 79(5) 275-284. doi:10.2182/cjot.2012.79.5.3

Rogers, J.C. (1983). Eleanor Clarke Slagle Lectureship- 1983; Clinical reasoning: The ethics, science and art. American Journal of Occupational Therapy, 37(9), 601- 616. doi:10.5014/ajot.37.9.601

Sapsford, R. (2007). Survey Research, $2^{\text {nd }}$ ed. Thousand Oaks, CA: Sage.

Sands, M. (1995). Readying occupational therapy assistant students for level II fieldwork: 
Beyond academics to personal behaviors and attitudes. American Journal of Occupational Therapy, 49, 150-152. doi:10.5014/ajot.49.2.150

Santasier, A.M., \& Plack, M.M. (2007). Assessing professional behaviors using qualitative data analysis. Journal of Physical therapy Education, 21(3), 29-39.

Scheerer, C. R. (2003). Perceptions of effective professional behavior feedback: Occupational therapy student voices. American journal of Occupational Therapy, 57, 205-214. doi:10.5014/ajot.57.2.205

Schell, B.A., \& Cervero, R.M. (1993). Clinical reasoning in Occupational Therapy: An integrative review. The American Journal of Occupational Therapy, 47, 605-610. doi:10.5014/ajot.47.7.605

Schonrock-Adema, J., Heijne-Penninga, M., VanDuijn, M.A., Geertsma, J., \& Cohen-Schotanus, J. (2007). Assessment of professional behavior in undergraduate medical education: Peer assessment enhances performance. Medical Education, 41, 836-842. doi:10.1111/j.13652223.2007.02817.x

Shah, N., Anderson, J., \& Humphrey, H.J. (2008). Teaching professionalism a tale of three schools. Perspectives in Biology and Medicine, 51, 535-546. doi:10.1353/phbm.0.0041

Suskie, L. (2009). Assessing student learning: A common sense guide. San Francisco: JosseyBass.

Swick, H.M. (2000). Toward a normative definition of medical professionalism. Academic Medicine, 75, 612-616. doi:10.1097/00001888-200006000-00010

Teherani, A., Hodgson, C.S., Canach, M., \& Papadakis, M.A. (2005). Domains of unprofessional behavior during medical school associated with future disciplinary action by a state medical board. Academic Medicine, 80(10), S17-S20. 
Tryssenaar, J.,\& Perkins, J. (2001). From student to therapist: Exploring the first year of practice. American Journal of Occupational Therapy, 55, 19-27. doi:10.5014/ajot.55.1.19

Tickle-Degnen, L. (1998). Working well with others: The prediction of students' clinical performance. American Journal of Occupational Therapy, 52, 133-142. doi:10.5014/ajot.52.2.133

vanMook, W., vanLuijk, S.J., O’Sullivan, H., Wass, V., Schuwirth, L.W., \& van der Vleuten, C.P.M. (2009). General considerations regarding assessment of professional behaviour. European Journal of Internal Medicine, 20(4), e90-e95. doi:10.1016/j.ejim.2008.11.011

Wolff-Burke, M. (2005). Clinical instructors’ descriptions of physical therapist student professional behaviors. Journal of Physical Therapy Education, 19(1), 67-75.

Wolff-Burke, A., Ingram, D., Lewis, K., Odom, C., \& Shoaf, L.D. (2007) Generic inabilities and the use of decision-making rubric for addressing deficits in professional behavior. Journal of Physical Therapy Education, 21(3), 13- 22.

Zubrow, J. (2012). Case study: Engaging adjunct faculty in program assessment. Journal of Assessment and Institutional Effectiveness, 2(1), 77-102. Retrieved May 12015 from: http://muse.jhu.edu/journals/aie/summary/v002/2.1.zubrow.html 


\section{Appendix A: Survey Instrument \\ Assessment of the Professional Behaviors of}

\section{Students in Entry Level Master’s OT Programs}

Welcome! This survey is being conducted to assess the perceptions and beliefs of OT faculty members regarding the assessment of students' professional behaviors. This survey will take between 10 to 15 minutes to complete.

This research is being conducted by Diana Davis, MA, OTR/L in partial fulfillment of the requirements of a dissertation for a Ph.D. in Interdisciplinary Educational Studies. Your involvement in this project will be kept confidential and all data will be reported in the aggregate. Your participation is completely voluntary and you can skip any question in the survey. By clicking on the next button below you agree to participate in this research study. Acknowledgement of this study is on file with West Virginia University's Institutional Review Board.

Your participation in this study is greatly appreciated. Professionalism of OT students is a growing concern in Occupational Therapy education and this survey is the first step to understanding how the professional behaviors of students can be addressed and improved.

Thank you for your time.

If you have any questions about research project please contact Diana Davis, at (304) 293-0584 or by e-mail at dmdavis@hsc.wvu.edu.

\section{A. Program Demographics}

\section{Please share information about your institution and OT program.}

1) What is the name of your institution?

(This information will only be used for establishing Carnegie Classifications, regional groupings, and prevalence numbers. Data will only be reported in the aggregate, no institution names will be used in data analysis or reporting.)

2) In what year was your OT program established?

3) In what year did your OT program institute the Master's Degree education program? 
4) How many students (total) are currently enrolled in your entry-level OT Master's Degree educational program? (All years)

5) How many full-time faculty members does your entry-level OT Master's Degree program have? (include program chair and academic fieldwork coordinator)

6) How many part-time or adjunct faculty does your program hire in an academic year in the entry-level Master’s degree OT program?

\section{B) Faculty Instructional Work Load Characteristics}

Please answer the following questions as they apply to you and your work in the OT program.

7) What is your current status at the University/College?
a. Full-time faculty
b. Part-time faculty

8) What is your faculty rank?
a. Full professor
b. Associate Professor
c. Assistant Professor
d. Instructor 
e. Other

9) Do you have tenure?
a. Yes
b. No
c. Tenure is not available
d. N/A (Clinical or Teaching track)

10) How many years have you been teaching in Occupational Therapy?
a. $0-5$ years
b. 6-10 years
c. 11-15 years
d. 16-20 years
e. 21-25 years
f. 26-30 years
g. $31+$ years

11) What is your current age?
a. 20 - 29 years
b. $30-39$ years
c. $40-49$ years
d. 50 - 59 years
e. $60-69$ years 

f. $70-79$ years
g. $80+$ years

12) What is your gender identity?
a. Male
b. Female
c. Transgender

13) What is your professional (OT) degree level?
a. Bachelors
b. Masters
c. Doctorate

14) What is your terminal degree?
a. MA
b. MS
c. MOT
d. Ed.D
e. OTD
f. Sc.D.
g. Ph.D.
h. Other 
Please answer the following questions about your typical workload. Please include your teaching in all programs at your institution.

15) How many credit hours of lecture-based teaching do you complete per term?

16) How many contact hours do you spend in lecture instruction a typical week?

17) How many credit hours of lab-based instruction do you complete per term?

18) How many contact hours do you spend in lab instruction in a typical week?

19) How many contact hours do you spend in online instruction in a typical week?

20) How many students are enrolled in your typical lecture-based course section per term?

21) How many students are enrolled in your typical lab-based course section per term?

22) How many students do you supervise in clinical experiences per term? 


\section{C) Professional Behavior Assessment}

Please answer the following questions as they apply to students enrolled in an entry-level Master's degree OT program.

23) What is your level of agreement with the following statements?

\begin{tabular}{|c|c|c|c|c|c|}
\hline & $\begin{array}{l}\text { Strongly } \\
\text { disagree }\end{array}$ & Disagree & Neutral & Agree & $\begin{array}{l}\text { Strongly } \\
\text { agree }\end{array}$ \\
\hline $\begin{array}{l}\text { Professional behavior is adequately } \\
\text { assessed by OT educational } \\
\text { programs. }\end{array}$ & & & & & \\
\hline $\begin{array}{l}\text { Assessment of students' professional } \\
\text { behaviors should be completed every } \\
\text { semester. }\end{array}$ & & & & & \\
\hline $\begin{array}{l}\text { Assessment of students' professional } \\
\text { behaviors should be completed each } \\
\text { year. }\end{array}$ & & & & & \\
\hline $\begin{array}{l}\text { Assessment of the professional } \\
\text { behaviors of students should be } \\
\text { completed at the end of level } 1 \\
\text { fieldwork experiences. }\end{array}$ & & & & & \\
\hline $\begin{array}{l}\text { Assessment of the professional } \\
\text { behaviors of students should be } \\
\text { completed at the end of level } 2\end{array}$ & & & & & \\
\hline
\end{tabular}




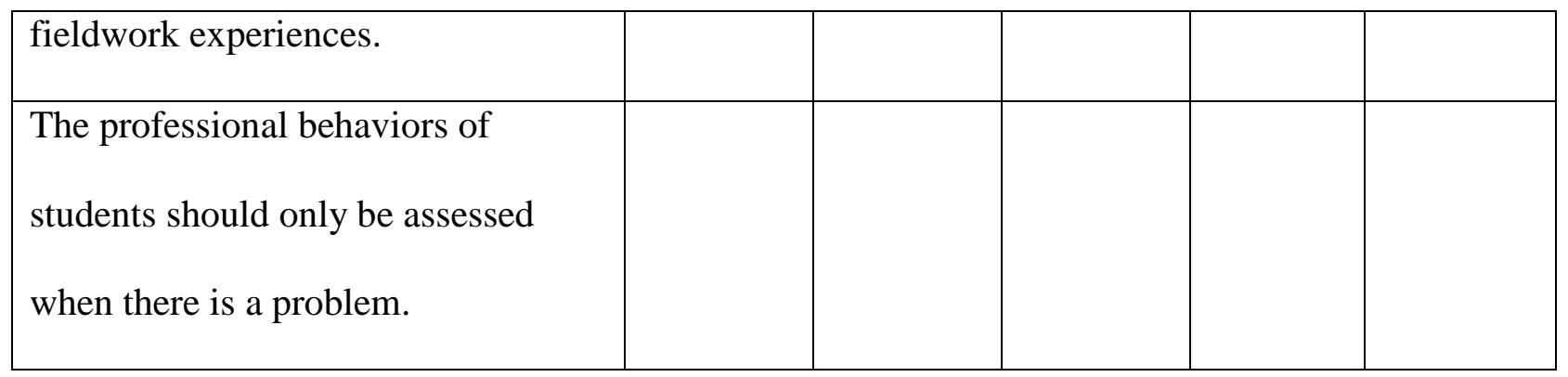

24) How important is it to assess the following student professional behaviors?

\begin{tabular}{|c|c|c|c|c|c|}
\hline & $\begin{array}{l}\text { Very } \\
\text { unimportant }\end{array}$ & Unimportant & $\begin{array}{l}\text { Neither } \\
\text { unimportant } \\
\text { or } \\
\text { important }\end{array}$ & Important & $\begin{array}{l}\text { Very } \\
\text { important }\end{array}$ \\
\hline $\begin{array}{l}\text { Dependability } \\
\text { Is reliable, performance is } \\
\text { consistent even under stress } \\
\text { Can be trusted. }\end{array}$ & & & & & \\
\hline $\begin{array}{l}\text { Timeliness (Time } \\
\text { management) } \\
\text { On time to class, turns in } \\
\text { assignments and completes } \\
\text { work on time. }\end{array}$ & & & & & \\
\hline $\begin{array}{l}\text { Awareness of emotions } \\
\text { Being aware of emotions of } \\
\text { self and others, ability to }\end{array}$ & & & & & \\
\hline
\end{tabular}




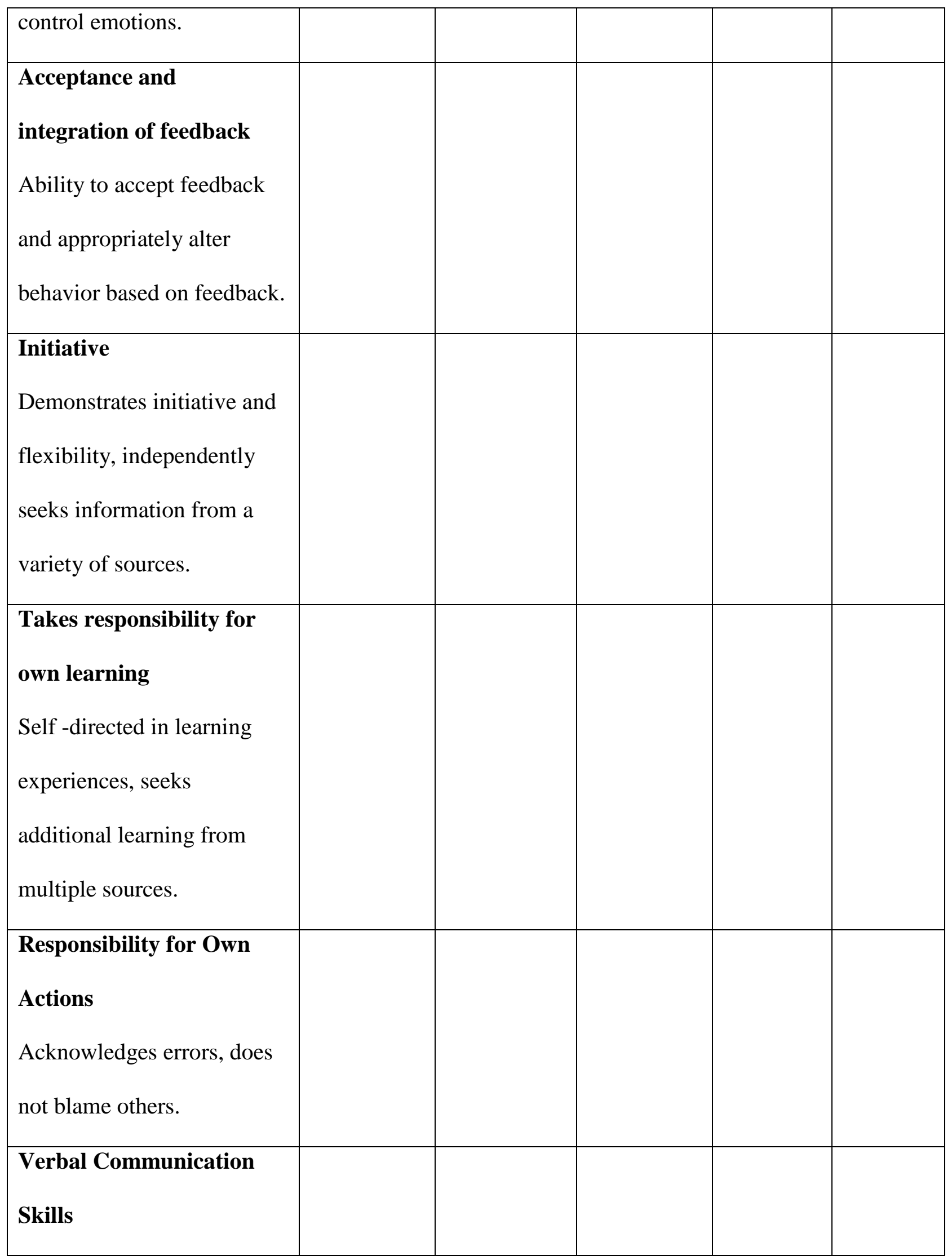




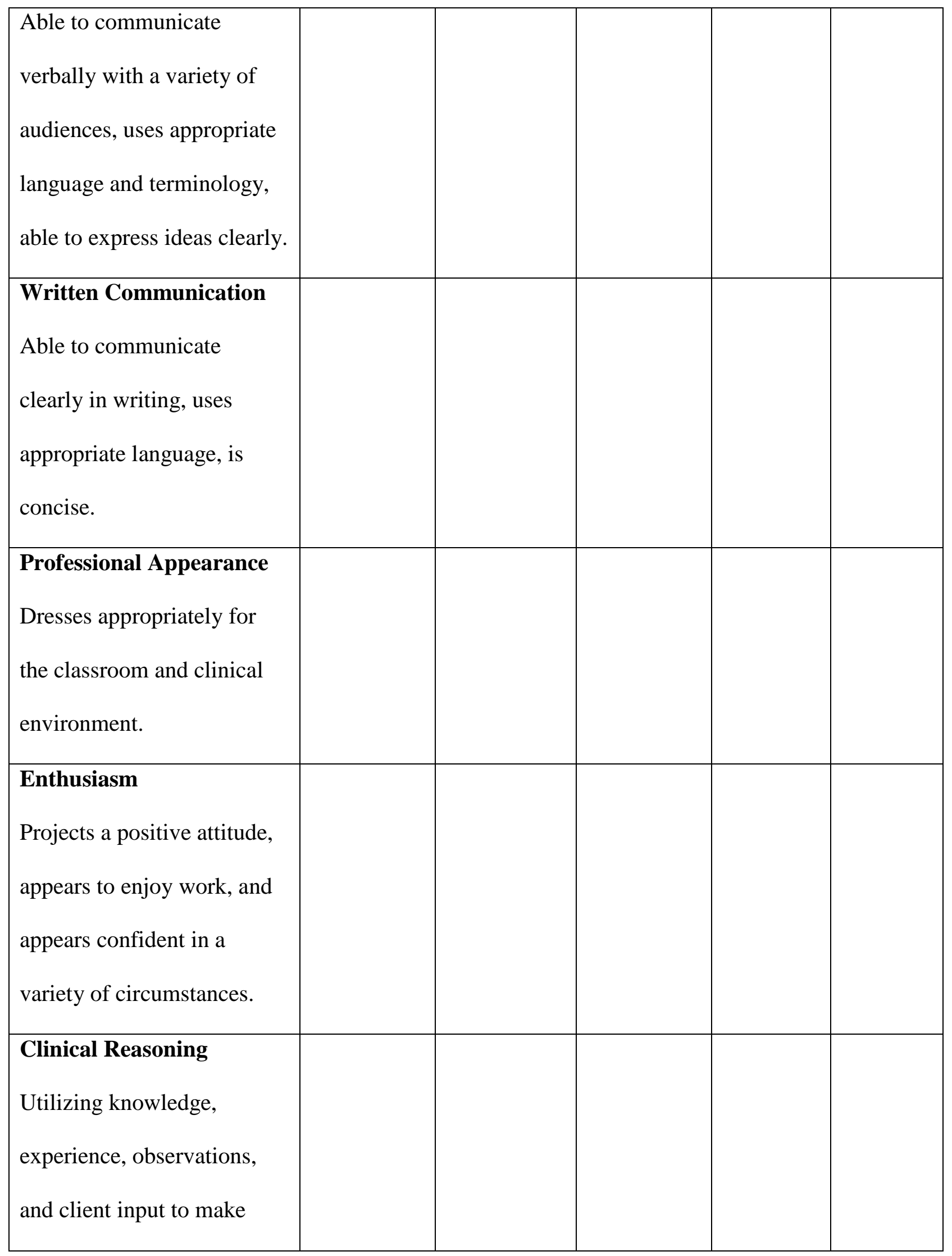




\begin{tabular}{|l|l|l|l|l|l|}
\hline appropriate treatment & & & & & \\
decisions. & & & & & \\
\hline Other (Please Indicate) & & & & & \\
\hline Other (Please Indicate) & & & & & \\
\hline Other (Please Indicate) & & & & & \\
\hline
\end{tabular}

25) How valuable are the following tools in the assessment of students' professional behaviors?

\begin{tabular}{|l|l|l|l|l|l|}
\hline & Very & Valueless & Neither & Valuable & Very \\
& valueless & & valueless & & valuable \\
& & & or valuable & & \\
\hline
\end{tabular}




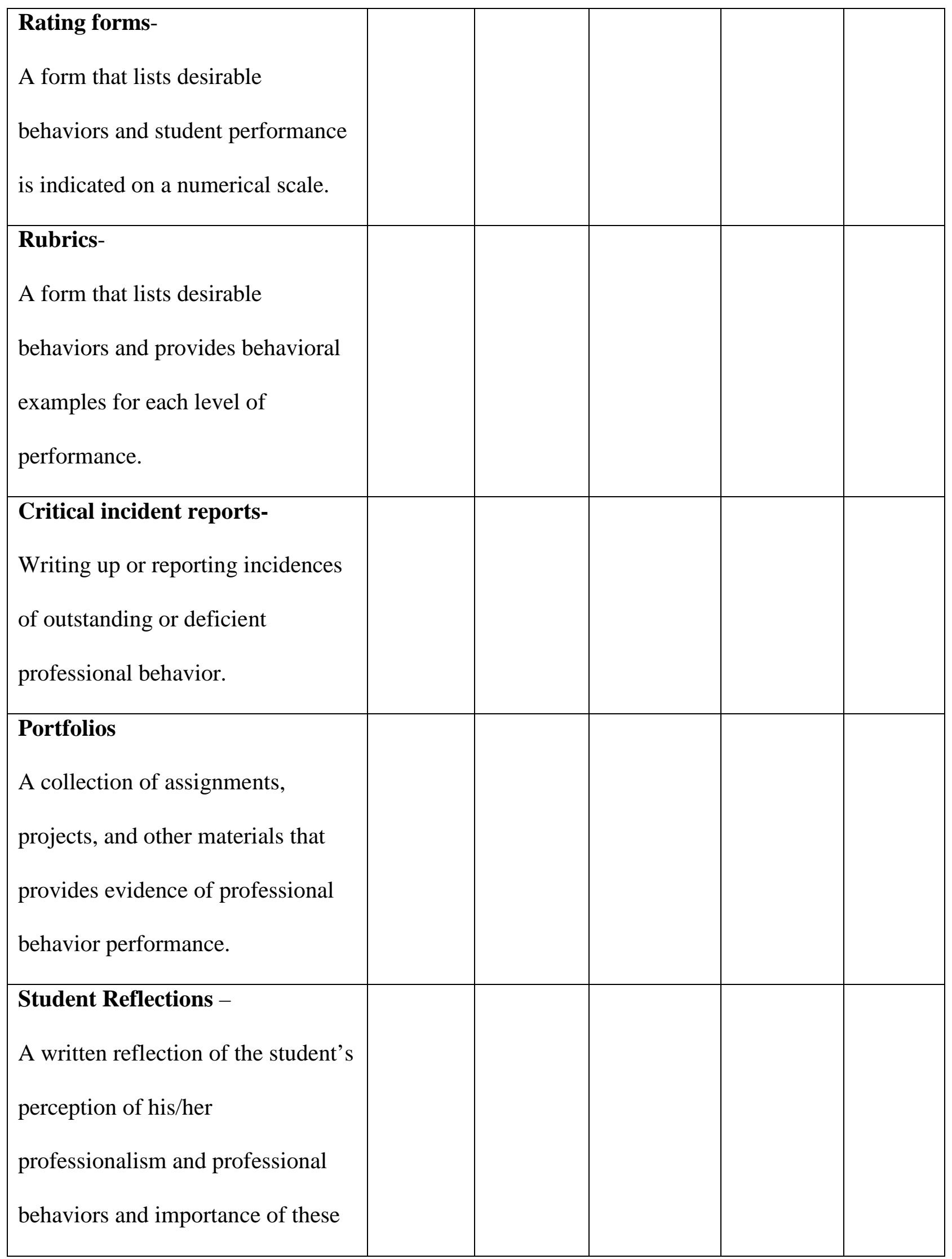




\begin{tabular}{|l|l|l|l|l|l|}
\hline issues in his/her career. & & & & & \\
\hline Specific items on practical exams & & & & & \\
\hline Specific items on written quizzes & & & & & \\
\hline Other (please indicate): & & & & & \\
\end{tabular}

26) How valuable are observations of students' professional behavior in the following situations?

\begin{tabular}{|c|c|c|c|c|c|}
\hline & $\begin{array}{l}\text { Very } \\
\text { valueless }\end{array}$ & Valueless & $\begin{array}{l}\text { Neither } \\
\text { valueless } \\
\text { or valuable }\end{array}$ & Valuable & $\begin{array}{l}\text { Very } \\
\text { Valuable }\end{array}$ \\
\hline Classroom behavior & & & & & \\
\hline Laboratory behavior & & & & & \\
\hline Clinical behavior & & & & & \\
\hline $\begin{array}{l}\text { Performance in group work an } \\
\text { activities }\end{array}$ & & & & & \\
\hline Performance on practical exan & & & & & \\
\hline $\begin{array}{l}\text { Performance on specific items } \\
\text { written quizzes or exams }\end{array}$ & & & & & \\
\hline Social interactions with peers & & & & & \\
\hline
\end{tabular}




\begin{tabular}{|l|l|l|l|l|l|}
\hline OT related on-campus extra- & & & & & \\
curricular activities & & & & & \\
\hline Attendance at professional & & & & & \\
\hline Attendance at professional & & & & & \\
institution & & & & & \\
\hline
\end{tabular}

27) How important is it for the following individuals to participate in the assessment of students’ professional behaviors?

\begin{tabular}{|c|c|c|c|c|c|}
\hline & $\begin{array}{l}\text { Very } \\
\text { unimportant }\end{array}$ & Unimportant & $\begin{array}{l}\text { Neither } \\
\text { important } \\
\text { or } \\
\text { unimportant }\end{array}$ & Important & $\begin{array}{l}\text { Very } \\
\text { Important }\end{array}$ \\
\hline Full-time Faculty & & & & & \\
\hline Part-time or Adjunct Fac & & & & & \\
\hline Student (self-assessment & & & & & \\
\hline Peers & & & & & \\
\hline Level 1 fieldwork instru & & & & & \\
\hline Level 2 fieldwork instruc & & & & & \\
\hline Lab instructors/ TAs & & & & & \\
\hline Program professional or & & & & & \\
\hline
\end{tabular}




\begin{tabular}{|l|l|l|l|l|l|}
\hline administrative staff & & & & & \\
\hline Other, (please indicate) & & & & & \\
& & & & & \\
\hline
\end{tabular}




\section{D) Impact of Professional Behavior Assessment on Student and OT Program}

The results from professional behavior assessments can be utilized by educational programs in a variety of ways. The following questions address some of these possible uses.

28) How important is it that the results of assessment be used in the following ways?

Professional behavior assessment results for students should...

\begin{tabular}{|l|l|l|l|l|l|}
\hline & Very & Unimportant & Neither & Important & Very \\
umportant or & & important \\
performance of & & & & & \\
students as a group. & & & & & \\
\hline $\begin{array}{l}\text { be used to advise } \\
\text { individual students } \\
\text { about how to improve } \\
\text { their behaviors. }\end{array}$ & & & & & \\
\hline be shared with faculty. & & & & & \\
\hline $\begin{array}{l}\text { be used to determine } \\
\text { effectiveness of } \\
\text { current professional } \\
\text { behavior instructional } \\
\text { techniques. }\end{array}$ & & & & & \\
\hline
\end{tabular}




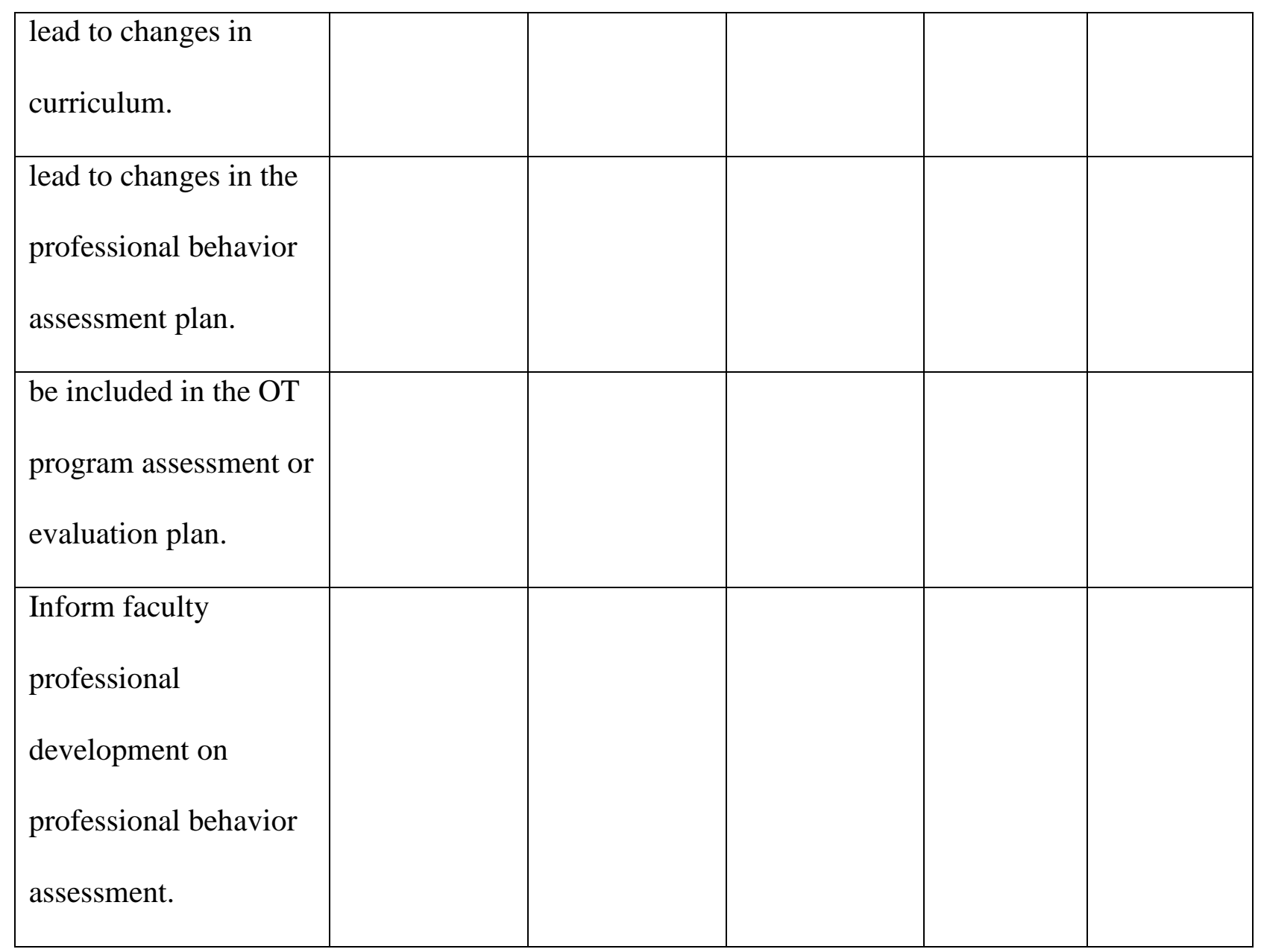

29) At what level of severity of professional behavior infraction do you feel the following consequences are appropriate?

\begin{tabular}{|l|l|l|l|l|l|}
\hline & Mild & Mild to & Moderate & Severe & Never \\
\hline Required counseling with faculty & & & Moderate & & \\
advisor or other faculty member & & & & & \\
\hline Creation of professional \\
behavior development plan
\end{tabular}




\begin{tabular}{|l|l|l|l|l|l|}
\hline (remediation) & & & & & \\
\hline Decrease in course grade & & & & & \\
\hline Student placed on program & & & & & \\
\hline pelayed progression in program & & & & & \\
\hline Delayed entry into fieldwork & & & & & \\
\hline Termination from educational & & & & & \\
\hline program & & & & & \\
\hline No consequences & & & & & \\
\hline
\end{tabular}

30) What is your level of agreement with the following general statements regarding assessment of the professional behavior of students?

\begin{tabular}{|c|c|c|c|c|c|}
\hline & $\begin{array}{l}\text { Strongly } \\
\text { disagree }\end{array}$ & Disagree & Neutral & Agree & $\begin{array}{l}\text { Strongly } \\
\text { agree }\end{array}$ \\
\hline $\begin{array}{l}\text { All faculty value the assessment of } \\
\text { professional behaviors for the OT } \\
\text { program students. }\end{array}$ & & & & & \\
\hline $\begin{array}{l}\text { When assessing the same student, } \\
\text { faculty members consistently rate } \\
\text { students at the same level in terms }\end{array}$ & & & & & \\
\hline
\end{tabular}




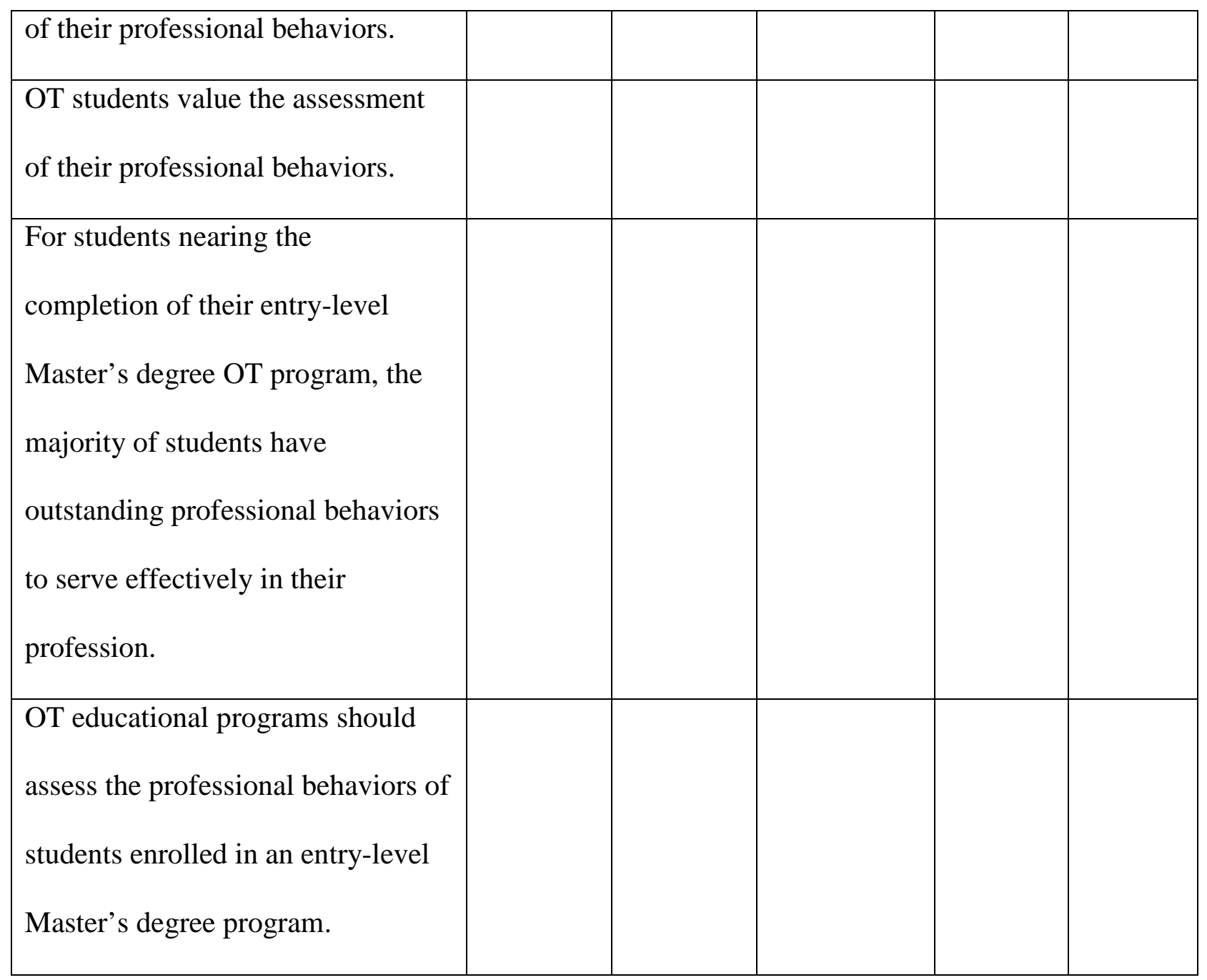

31) Does your Master's entry-level OT educational program have a formal process in place to assess the professional behaviors of students?

Yes

No

32) Please share any additional comments you have regarding the assessment of the professional behaviors of students. 
Thank you for completing this survey! If you wise to receive results of the study please e-mail Diana Davis at dmdavis@hsc.wvu.edu 


\section{Appendix B: Institutions With Master's Degree Level Occupational Therapy Educational Programs}

Table B.1 Occurrence of Institution Type and by Regional Accreditation

\begin{tabular}{|c|c|c|c|c|c|}
\hline Carnegie Type & $\begin{array}{c}\mathrm{N} \\
(\mathbf{1 5 0 )})\end{array}$ & $\%$ & $\begin{array}{l}\text { Regional } \\
\text { Accrediting } \\
\text { Association }\end{array}$ & $\begin{array}{c}\mathrm{N} \\
(\mathbf{1 5 0 )}\end{array}$ & $\%$ \\
\hline Research Very High & 24 & 16 & Middle States & 36 & 24 \\
\hline Research High & 19 & 12.7 & New England & 13 & 8.7 \\
\hline Doctoral & 9 & 6.0 & North Central & 48 & 32 \\
\hline Masters Large & 54 & 36 & Northwest & 7 & 4.7 \\
\hline Masters Medium & 9 & 6.0 & Southern & 40 & 26.7 \\
\hline Masters Small & 4 & 2.7 & Western & 6 & 4 \\
\hline $\begin{array}{l}\text { Baccalaureate } \\
\text { Diverse }\end{array}$ & 5 & 3.3 & & & \\
\hline Baccalaureate A\&S & 3 & 2.0 & & & \\
\hline Assoc. Public & 1 & .7 & & & \\
\hline $\begin{array}{l}\text { Specialty - } \\
\text { Medicine }\end{array}$ & 16 & 10.7 & & & \\
\hline Specialty - Health & 5 & 3.3 & & & \\
\hline Unclassified & 1 & .7 & & & \\
\hline
\end{tabular}


Table B.2 Institutions with Masters Level OT programs with Carnegie Designation and Regional Accrediting Association.

\begin{tabular}{|c|c|c|}
\hline Institution Name & \begin{tabular}{|l|} 
Carnegie \\
Designation \\
\end{tabular} & $\begin{array}{l}\text { Regional Accrediting } \\
\text { Association }\end{array}$ \\
\hline $\begin{array}{l}\text { University of Minnesota- } \\
\text { Rochester Campus }\end{array}$ & Associate - Pub 4 & North Central \\
\hline Bay Path College & Baccalaureate - A\&S & New England \\
\hline Shawnee State University & Baccalaureate - A\&S & North Central \\
\hline University of Puget Sound & Baccalaureate - A\&S & Northwest \\
\hline Lenoir-Rhyne University & $\begin{array}{l}\text { Baccalaureate - } \\
\text { Diverse }\end{array}$ & Southern \\
\hline Milligan College & $\begin{array}{l}\text { Baccalaureate - } \\
\text { Diverse }\end{array}$ & Southern \\
\hline Tuskegee University & $\begin{array}{l}\text { Baccalaureate - } \\
\text { Diverse }\end{array}$ & Southern \\
\hline York College- CUNY & $\begin{array}{l}\text { Baccalaureate - } \\
\text { Diverse }\end{array}$ & Middle States \\
\hline Elizabethtown College & $\begin{array}{l}\text { Baccalaureate - } \\
\text { Diverse }\end{array}$ & Middle States \\
\hline Barry University & Doctoral University & Southern \\
\hline East Carolina University & Doctoral University & Southern \\
\hline Florida A\&M & Doctoral University & Southern \\
\hline Maryville University & Doctoral University & North Central \\
\hline Seton Hall University & Doctoral University & Middle States \\
\hline Spalding University & Doctoral University & Southern \\
\hline Tennessee State University & Doctoral University & Southern \\
\hline Texas Woman's University & Doctoral University & Southern \\
\hline $\begin{array}{l}\text { Texas Woman's University } \\
\text { Dallas }\end{array}$ & Doctoral University & Southern \\
\hline Alabama State University & Masters - Large & Southern \\
\hline $\begin{array}{l}\text { American International } \\
\text { College }\end{array}$ & Masters - Large & New England \\
\hline Baker College Center & Masters - Large & North Central \\
\hline Belmont University & Masters - Large & Southern \\
\hline Brenau University & Masters - Large & Southern \\
\hline Brenau University- Atlanta & Masters - Large & Southern \\
\hline $\begin{array}{l}\text { California State- } \\
\text { Dominguez Hills }\end{array}$ & Masters - Large & Western \\
\hline Chatham University & Masters - Large & Middle States \\
\hline Chicago State University & Masters - Large & North Central \\
\hline
\end{tabular}




\begin{tabular}{|c|c|c|}
\hline $\begin{array}{l}\text { Concordia University- } \\
\text { Wisconsin }\end{array}$ & Masters - Large & North Central \\
\hline D'Youville College & Masters - Large & Middle States \\
\hline $\begin{array}{l}\text { Eastern Kentucky } \\
\text { University }\end{array}$ & Masters - Large & Southern \\
\hline $\begin{array}{l}\text { Eastern Michigan } \\
\text { University }\end{array}$ & Masters - Large & North Central \\
\hline $\begin{array}{l}\text { Eastern Washington } \\
\text { University }\end{array}$ & Masters - Large & Northwest \\
\hline $\begin{array}{l}\text { Florida Gulf Coast } \\
\text { University }\end{array}$ & Masters - Large & Southern \\
\hline Gannon University & Masters - Large & Middle States \\
\hline Governors State University & Masters - Large & North Central \\
\hline $\begin{array}{l}\text { Grand Valley State } \\
\text { University }\end{array}$ & Masters - Large & North Central \\
\hline Ithaca College & Masters - Large & Middle States \\
\hline James Madison University & Masters - Large & Southern \\
\hline Kean University & Masters - Large & Middle States \\
\hline $\begin{array}{l}\text { Long Island University } \\
\text { Brooklyn Campus }\end{array}$ & Masters - Large & Middle States \\
\hline Mercy College & Masters - Large & Middle States \\
\hline $\begin{array}{l}\text { New York Institute of } \\
\text { Technology }\end{array}$ & Masters - Large & Middle States \\
\hline Pacific University & Masters - Large & Northwest \\
\hline Philadelphia University & Masters - Large & Middle States \\
\hline Quinnipiac University & Masters - Large & New England \\
\hline Radford University & Masters - Large & Southern \\
\hline Rockhurst University & Masters - Large & North Central \\
\hline Sacred Heart University & Masters - Large & New England \\
\hline Sage College & Masters - Large & Middle States \\
\hline $\begin{array}{l}\text { Saginaw Valley State } \\
\text { University }\end{array}$ & Masters - Large & North Central \\
\hline Saint Francis University & Masters - Large & Middle States \\
\hline Salem State University & Masters - Large & New England \\
\hline San Jose State University & Masters - Large & Western \\
\hline Shenandoah University & Masters - Large & Southern \\
\hline Springfield College & Masters - Large & New England \\
\hline St. Ambrose University & Masters - Large & North Central \\
\hline St. Catherine University & Masters - Large & North Central \\
\hline $\begin{array}{l}\text { The University of Texas } \\
\text { PanAmerican }\end{array}$ & Masters - Large & Southern \\
\hline Touro College & Masters - Large & Middle States \\
\hline
\end{tabular}




\begin{tabular}{|c|c|c|}
\hline Touro College - Manhattan & Masters - Large & Middle States \\
\hline Touro University Nevada & Masters - Large & Northwest \\
\hline Towson University & Masters - Large & Middle States \\
\hline $\begin{array}{l}\text { University of Central } \\
\text { Arkansas }\end{array}$ & Masters - Large & North Central \\
\hline University of Findlay & Masters - Large & North Central \\
\hline University of Indianapolis & Masters - Large & North Central \\
\hline University of Mary & Masters - Large & North Central \\
\hline $\begin{array}{l}\text { University of New } \\
\text { England }\end{array}$ & Masters - Large & New England \\
\hline University of Scranton & Masters - Large & Middle States \\
\hline $\begin{array}{l}\text { University of Southern } \\
\text { Indiana }\end{array}$ & Masters - Large & North Central \\
\hline $\begin{array}{l}\text { University of Southern } \\
\text { Maine }\end{array}$ & Masters - Large & New England \\
\hline $\begin{array}{l}\text { University of Wisconsin } \\
\text { LaCrosse }\end{array}$ & Masters - Large & North Central \\
\hline Xavier University & Masters - Large & North Central \\
\hline Alvernia University & Masters - Medium & Middle States \\
\hline $\begin{array}{l}\text { College of Saint } \\
\text { Scholastica }\end{array}$ & Masters - Medium & North Central \\
\hline Husson University & Masters - Medium & New England \\
\hline Misericordia University & Masters - Medium & Middle States \\
\hline $\begin{array}{l}\text { Richard Stockton College } \\
\text { of New Jersey }\end{array}$ & Masters - Medium & Middle States \\
\hline Utica College & Masters - Medium & Middle States \\
\hline $\begin{array}{l}\text { Western New Mexico } \\
\text { University }\end{array}$ & Masters - Medium & North Central \\
\hline $\begin{array}{l}\text { Winston-Salem State } \\
\text { University }\end{array}$ & Masters - Medium & Southern \\
\hline Worcester State University & Masters - Medium & New England \\
\hline College of Saint Mary & Masters - Small & North Central \\
\hline Dominican College & Masters - Small & Middle States \\
\hline Keuka College & Masters - Small & Middle States \\
\hline Mount Mary College & Masters - Small & North Central \\
\hline Cleveland State University & Research - High & North Central \\
\hline Duquesne University & Research - High & Middle States \\
\hline $\begin{array}{l}\text { Florida International } \\
\text { University }\end{array}$ & Research - High & Southern \\
\hline Howard University & Research - High & Middle States \\
\hline Idaho State University & Research - High & Northwest \\
\hline Indiana University & Research - High & North Central \\
\hline
\end{tabular}




\begin{tabular}{|c|c|c|}
\hline $\begin{array}{l}\text { Nova Southeastern } \\
\text { University }\end{array}$ & Research - High & Southern \\
\hline Saint Louis University & Research - High & North Central \\
\hline Temple University & Research - High & Middle States \\
\hline University of Missouri & Research - High & North Central \\
\hline $\begin{array}{l}\text { University of New } \\
\text { Hampshire }\end{array}$ & Research - High & New England \\
\hline $\begin{array}{l}\text { University of North } \\
\text { Dakota }\end{array}$ & Research - High & North Central \\
\hline $\begin{array}{l}\text { University of North } \\
\text { Dakota at Casper College }\end{array}$ & Research - High & North Central \\
\hline $\begin{array}{l}\text { University of South } \\
\text { Alabama }\end{array}$ & Research - High & Southern \\
\hline $\begin{array}{l}\text { University of South } \\
\text { Dakota }\end{array}$ & Research - High & North Central \\
\hline $\begin{array}{l}\text { University of Texas El } \\
\text { Paso }\end{array}$ & Research - High & Southern \\
\hline $\begin{array}{l}\text { University of Wisconsin } \\
\text { Milwaukee }\end{array}$ & Research - High & North Central \\
\hline West Virginia University & Research - High & North Central \\
\hline $\begin{array}{l}\text { Western Michigan } \\
\text { University }\end{array}$ & Research - High & North Central \\
\hline Boston University & $\begin{array}{l}\text { Research - Very } \\
\text { High }\end{array}$ & New England \\
\hline Colorado State University & $\begin{array}{l}\text { Research - Very } \\
\text { High }\end{array}$ & North Central \\
\hline Columbia University & $\begin{array}{l}\text { Research - Very } \\
\text { High }\end{array}$ & Middle States \\
\hline New York University & $\begin{array}{l}\text { Research - Very } \\
\text { High }\end{array}$ & Middle States \\
\hline Ohio State University & $\begin{array}{l}\text { Research - Very } \\
\text { High }\end{array}$ & North Central \\
\hline Stony Brook University & $\begin{array}{l}\text { Research - Very } \\
\text { High }\end{array}$ & Middle States \\
\hline The University of Utah & $\begin{array}{l}\text { Research - Very } \\
\text { High }\end{array}$ & Northwest \\
\hline Tufts University & $\begin{array}{l}\text { Research - Very } \\
\text { High }\end{array}$ & New England \\
\hline $\begin{array}{l}\text { University of Alabama at } \\
\text { Birmingham }\end{array}$ & $\begin{array}{l}\text { Research - Very } \\
\text { High }\end{array}$ & Southern \\
\hline University of Buffalo & $\begin{array}{l}\text { Research - Very } \\
\text { High }\end{array}$ & Middle States \\
\hline University of Florida & $\begin{array}{l}\text { Research - Very } \\
\text { High }\end{array}$ & Southern \\
\hline
\end{tabular}




\begin{tabular}{|c|c|c|}
\hline $\begin{array}{l}\text { University of Illinois at } \\
\text { Chicago }\end{array}$ & $\begin{array}{l}\text { Research - Very } \\
\text { High } \\
\end{array}$ & North Central \\
\hline University of Kansas & $\begin{array}{l}\text { Research - Very } \\
\text { High } \\
\end{array}$ & North Central \\
\hline University of Minnesota & $\begin{array}{l}\text { Research - Very } \\
\text { High } \\
\end{array}$ & North Central \\
\hline University of New Mexico & $\begin{array}{l}\text { Research - Very } \\
\text { High }\end{array}$ & North Central \\
\hline $\begin{array}{l}\text { University of North } \\
\text { Carolina at CH }\end{array}$ & $\begin{array}{l}\text { Research - Very } \\
\text { High }\end{array}$ & Southern \\
\hline University of Pittsburgh & $\begin{array}{l}\text { Research - Very } \\
\text { High }\end{array}$ & Middle States \\
\hline $\begin{array}{l}\text { University of Southern } \\
\text { California }\end{array}$ & $\begin{array}{l}\text { Research - Very } \\
\text { High }\end{array}$ & Western \\
\hline $\begin{array}{l}\text { University of Tennessee } \\
\text { HSC }\end{array}$ & $\begin{array}{l}\text { Research - Very } \\
\text { High }\end{array}$ & Southern \\
\hline University of Washington & $\begin{array}{l}\text { Research - Very } \\
\text { High } \\
\end{array}$ & Northwest \\
\hline $\begin{array}{l}\text { University of Wisconsin } \\
\text { Madison }\end{array}$ & $\begin{array}{l}\text { Research - Very } \\
\text { high }\end{array}$ & North Central \\
\hline $\begin{array}{l}\text { Virginia Commonwealth } \\
\text { University }\end{array}$ & $\begin{array}{l}\text { Research - Very } \\
\text { High }\end{array}$ & Southern \\
\hline Washington University & $\begin{array}{l}\text { Research - Very } \\
\text { High }\end{array}$ & North Central \\
\hline Wayne State University & $\begin{array}{l}\text { Research - Very } \\
\text { High }\end{array}$ & North Central \\
\hline $\begin{array}{l}\text { Jefferson College of } \\
\text { Health Sciences }\end{array}$ & Spec - Health & Southern \\
\hline Samuel Merritt University & Spec - Health & Western \\
\hline $\begin{array}{l}\text { University of St Augustine } \\
\text { for Health Sciences }\end{array}$ & Spec - Health & Southern \\
\hline $\begin{array}{l}\text { University of St. Augustine } \\
\text { for Health Sciences, S.D. }\end{array}$ & Spec - Health & Western \\
\hline University of the Sciences & Spec - Health & Middle States \\
\hline $\begin{array}{l}\text { Arizona School of Health } \\
\text { Sciences AT Still }\end{array}$ & Spec - Med & North Central \\
\hline Loma Linda University & Spec - Med & Western \\
\hline $\begin{array}{l}\text { Louisiana State University } \\
\text { HSC }\end{array}$ & Spec - Med & Southern \\
\hline $\begin{array}{l}\text { Louisiana State University, } \\
\text { HSC, Shreveport }\end{array}$ & Spec - Med & Southern \\
\hline $\begin{array}{l}\text { Medical University of } \\
\text { South Carolina }\end{array}$ & Spec - Med & Southern \\
\hline
\end{tabular}




\begin{tabular}{|l|l|l|}
\hline Midwestern University & Spec - Med & North Central \\
\hline $\begin{array}{l}\text { Midwestern University- } \\
\text { Glendale }\end{array}$ & Spec - Med & North Central \\
\hline Rush University & Spec - Med & North Central \\
\hline State University of NY & Spec - Med & Middle States \\
\hline $\begin{array}{l}\text { Texas Tech University } \\
\text { HSC }\end{array}$ & Spec - Med & Southern \\
\hline $\begin{array}{l}\text { The University of } \\
\text { Mississippi Medical Center }\end{array}$ & Spec - Med & Southern \\
\hline $\begin{array}{l}\text { Thomas Jefferson } \\
\text { University }\end{array}$ & Spec - Med & Middle States \\
\hline $\begin{array}{l}\text { University of Oklahoma } \\
\text { HSC }\end{array}$ & Spec - Med & North Central \\
\hline University of Puerto Rico & Spec - Med & Middle States \\
\hline $\begin{array}{l}\text { University of Texas HSC } \\
\text { at S.A. }\end{array}$ & Spec - Med & Southern \\
\hline $\begin{array}{l}\text { University of Texas } \\
\text { Medical Branch }\end{array}$ & Spec - Med & Southern \\
\hline $\begin{array}{l}\text { Georgia Health Sciences } \\
\text { University }\end{array}$ & & Southern \\
\hline
\end{tabular}




\section{Appendix C: Letter for Pilot Study Participants}

Dear Participant,

This letter is a request for you to take part in a research project to look at how OT educational programs are assessing the professional behaviors of students. You are being asked to participate in the pilot study to establish the validity of the survey instrument. This project is being conducted by Diana Davis, MA, OTR/L in the College of Human Resources and Education at West Virginia University with the supervision of Duane Scott Davis, Ed.D., Professor in Physical Therapy (no relation) and Samuel Stack, Ph.D. Professor in Curriculum and Instruction Literacy . Ms. Davis is completing the research as partial fulfillment of the requirements for dissertation for a Ph.D. in Interdisciplinary Educational Studies. Your participation in this project is greatly appreciated and will take approximately 15 minutes to fill out an online survey. Then I would like to ask for your evaluation of the survey by talking with you on the phone for about 10 minutes. I will use your feedback to make improvements to the survey.

Your involvement in this project will be kept confidential. All data will be reported in the aggregate. You must be 18 years of age or older to participate. I will not ask any information that should lead back to your identity as a participant. Your participation is completely voluntary. You may skip any question that you do not wish to answer and you may discontinue the survey or phone interview at any time. West Virginia University's Institutional Review Board acknowledgement of this project is on file.

I hope that you will participate in this research project as it could be beneficial in understanding attitudes and feelings about professional behavior assessment of Occupational Therapy students. Professionalism of students is a growing concern in education and this study is the first step to understanding how professional behaviors can be assessed and improved. Thank you very much for your time. Should you have any questions about this letter or the research project, please feel free to contact Diana Davis at (304) 293-0584 or by e-mail at dmdavis@hsc.wvu.edu .

Please click on the link below to go to the survey. Once you are completed with the survey you will be contacted by Ms. Davis to complete the brief phone interview. Please complete the survey by $\{$ deadline .

Thank you for your time and help with this project.

Sincerely,

Diana Davis, MA, OTR/L

Student, Interdisciplinary Ph.D. in Education

West Virginia University 


\section{Appendix D: Pilot Study Phone Interview Questions}

1) Did the cover letter clearly state the purpose of the study?

2) Were the instructions for completing the survey clear?

3) Does the letter encourage you to participate in the study?

4) Does the format of the questions, make the survey easy to complete?

5) Are the questions clear and easy to understand?

6) Were there any questions you did not understand?

7) Where there enough/the correct behaviors included in the survey?

8) How long did it take you to complete the survey? 
9) Are there any questions or possible replies that should be added?

10) Are there any changes that could be made that would make the survey easier/quicker to complete?

11) Any other comments? 


\section{Appendix E: Cover Letter for Participants}

\section{Dear Participant,}

This letter is a request for you to take part in a research project to examine the perceptions and beliefs of OT faculty members regarding the assessment of students' professional behaviors. You are being asked to complete a brief online survey. This project is being conducted by Diana Davis, MA, OTR/L in the College of Education and Human Services at West Virginia University with the supervision of Duane Scott Davis, Ed.D, Professor in Physical Therapy (no relation), and Samuel Stack, Ph.D. Professor in Curriculum and Instruction Literacy. Ms. Davis is completing the research as partial fulfillment of the requirements of a dissertation for a Ph.D. in Interdisciplinary Educational Studies. Your participation in this project is greatly appreciated and will take approximately 10 to 15 minutes to fill out an online survey. You must be a full or part-time faculty member in an accredited Occupational Therapy program to participate.

Your involvement in this project will be kept confidential. All data will be reported in the aggregate. I will not ask any information that should lead back to your identity as a participant. Your participation is completely voluntary. You may skip any question that you do not wish to answer and you may discontinue the survey at any time. West Virginia University's Institutional Review Board acknowledgement of this project is on file.

I hope that you will participate in this research project as it could be beneficial in understanding how faculty feel about assessing the professional behaviors of students. Professionalism of students is a growing concern in education and this study is the first step to understanding how professional behaviors of students can be assessed and improved. Thank you very much for your time. Should you have any questions about this letter or the research project, please feel free to contact Diana Davis at (304) 293-0584 or by e-mail at dmdavis@hsc.wvu.edu

Please click on the link below to go to the survey. Please complete the survey by May 30, 2014

Thank you for your time and help with this project.

Sincerely,

Diana Davis, MA, OTR/L

Student, Interdisciplinary Ph.D. in Education

West Virginia University 


\section{Appendix F: 1st Reminder}

Dear OT Faculty Member- Two weeks ago I sent you an invitation to participate in my Ph.D. research study: “Assessment of the Professional Behaviors of Students in Entry Level Master's OT Programs” and asked you to complete a brief online survey.

If you have taken the time to complete this survey, thank you very much. If you haven’t completed the survey or, if you have started it but haven't finished it, may I ask that you take a few minutes and complete the survey? I am trying to obtain the opinions of as many OT faculty members as possible on this important topic. The survey takes 10 to 15 minutes to complete and your assistance in my research is greatly appreciated especially at this busy time of year.

Remember, you do not have to answer all of the questions but any answers you can provide will be helpful.

Follow the link below to go to the survey.

Sincerely,

Diana Davis, MA, OTR/L 


\section{Appendix G: Reminder \#2}

Dear OT Faculty Member- As May draws to a close I am preparing to conclude data collection in my study, “Assessment of the Professional Behaviors of Students in Entry Level Masters OT Programs.” I asked you to participate in this study last month via e-mail and I am trying to ensure that I get the most complete data possible.

If you have taken the time to complete this survey, thank you very much. If you have not, may I ask that you take a few minutes and complete the survey? If you started the survey and have not completed it, please consider completing the survey; remember you can skip any questions for which you do not know the answer. The survey has taken other participants less than 15 minutes to complete and your assistance in my research is greatly appreciated. The professional behavior of students is a growing area of concern in our profession and I value your opinion. The survey will close on May 30, 2014.

Sincerely,

Diana Davis, MA, OTR/L 